\title{
The Berger Bluff Site (41GD30A): Excavations in the Upper Deposits, 1979.
}

David O. Brown

Follow this and additional works at: https://scholarworks.sfasu.edu/ita

Part of the American Material Culture Commons, Archaeological Anthropology Commons, Environmental Studies Commons, Other American Studies Commons, Other Arts and Humanities Commons, Other History of Art, Architecture, and Archaeology Commons, and the United States History Commons

Tell us how this article helped you.

This Article is brought to you for free and open access by the Center for Regional Heritage Research at SFA ScholarWorks. It has been accepted for inclusion in Index of Texas Archaeology: Open Access Gray Literature from the Lone Star State by an authorized editor of SFA ScholarWorks. For more information, please contact cdsscholarworks@sfasu.edu. 


\section{The Berger Bluff Site (41GD30A): Excavations in the Upper Deposits, 1979. \\ Creative Commons License \\ (c) $($ ) (8)}

This work is licensed under a Creative Commons Attribution-NonCommercial 4.0 International License 


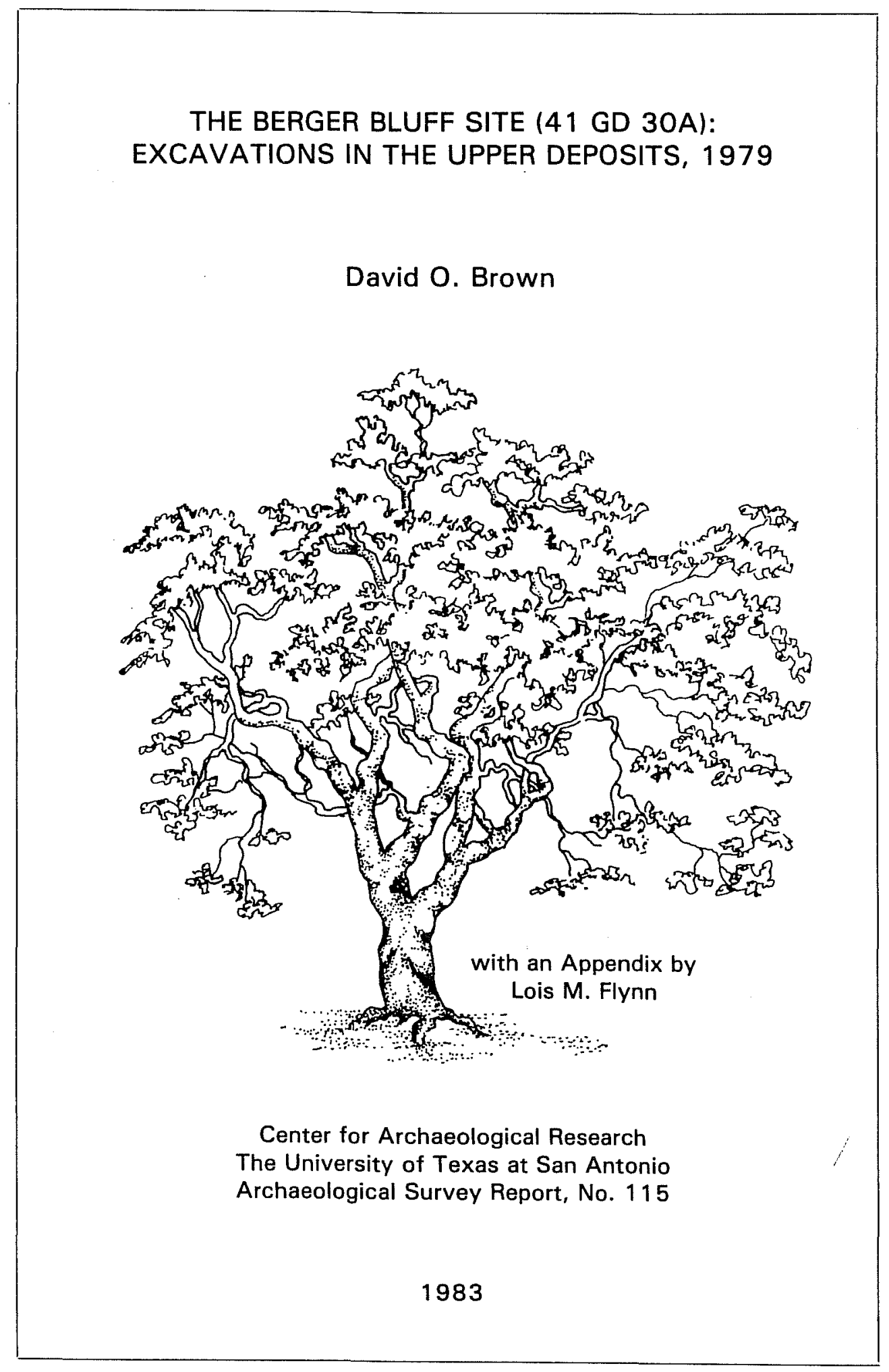




THE BERGER BLUFF SITE (4T GD 30A):

EXCAVATIONS IN THE UPPER DEPOSITS, 1979

David 0. Brown

With an Appendix by Lois M. Flynn 
The following information is provided in accordance with General Rules of Practice and Procedure 355.01.017(3), Texas Antiquities Committee:

1. Type of investigation: Archaeological mitigation at the Berger Bluff site (41 GD 30A);

2. Project name: Berger Bluff site (4l GD 30A);

3. County: Goliad County, Texas;

4. Principal Investigators: Thomas R. Hester, Principal Investigator; Jack D. Eaton, Co-Principal Investigator;

5. Name and location of sponsoring agency: Guadalupe-Blanco River Authority, Seguin, Texas;

6. Texas Antiquities Committee Permit No. 80;

7. Published by the Center for Archaeological Research, The University of Texas at San Antonio, San Antonio, Texas 78285; 1983. 


\section{ABSTRACT}

During summer 1979, the Center for Archaeological Research conducted excavations at the Berger Bluff site (41 GD 30A) in Goliad County, Texas. The site, located on a high bluff above Coleto Creek, had been shown to be a valuable archaeological resource in previous test excavations and was potentially endangered by wave erosion from the waters of the soon to be completed Coleto Creek Reservoir. The excavations were considered necessary as a partial mitigation, under the provisions of the Texas Antiquities Code.

A single three by four meter excavation unit was opened at the site. Depth of this excavation unit varied from one to two and one-half meters. A large quantity of artifacts, shel1, and animal bone was removed from this unit. Although some mixing of deposits was noted, the general cultural stratigraphy appeared much better preserved than at any other sites in the region.

Although no radiocarbon dates were available from the upper zone at the site, a comparison of diagnostic materials from the site with those from nearby areas suggested that the site was occupied a number of times between the Middle Archaic and the Late Prehistoric. The most intense periods of occupation were during the early Late Prehistoric Austin phase and a probable Late Archaic occupation, which could not be tied to a known phase or complex. In addition to the Archaic and Late Prehistoric materials from the upper zone, a radiocarbon date of $11,500 \pm 800$ B.P., or 9600 B.C., from a hearth (Feature 5) at the base of the biuff suggested a Paleo-Indian occupation at the site. Several general hypotheses concerning the inland coastal cultures of this area are presented as concluding remarks.

In addition to the work at 41 GD 30A, a brief examination of the Burris site (41 VT 66) was undertaken at the same time. Data concerning the condition of the site and a list of material collected from the surface are presented in Appendix I. 


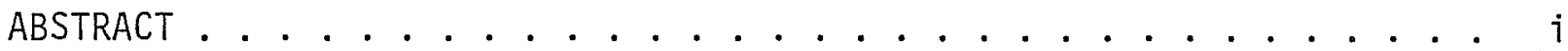
LIST OF FIGURES . . . . . . . . . . . . . . . . LIST OF TABLES ...................... . . iv ACKNOWLEDGMENTS .................... . . v

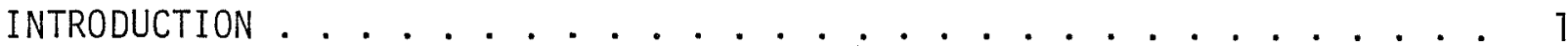
ENVIRONMENTAL SETTING . . . . . . . . . . . . . . . . . 1 PREVIOUS ARCHAEOLOGICAL INVESTIGATIONS ............. 6 COASTAL PLAIN PREHISTORY . . . . . . . . . . . . . 8 SITE HISTORY OF 41 GD $30 \ldots \ldots$. . . . . . . . . . . . . . 11 RESEARCH DESIGN ............................ 12 EXCAVATION METHODS ........................ 16 THE EXCAVATIONS ........................... 17 THE FEATURES ....................... . . 21 LITHIC ARTIFACTS . . . . . . . . . . . . . . . 26 Cores.................... . . 30

Flakes ..................... . . 33

Bifaces . . . . . . . . . . . . . . . . 42

Ground and Pecked Stone . . . . . . . . . . . . . 66 NONLITHIC ARTIFACTS ....................... 67

Ceramics . . . . . . . . . . . . . . . . 67

She11..................... . . 69

Bone .. . . . . . . . . . . . . . . . . . 69

Brass Cartridge Case . . . . . . . . . . . . . . 72

Miscellaneous Metal . . . . . . . . . . . . . 72 NONARTIFACTUAL REMAINS ................... . . 72 FAUNAL AND FLORAL REMAINS ................ 72

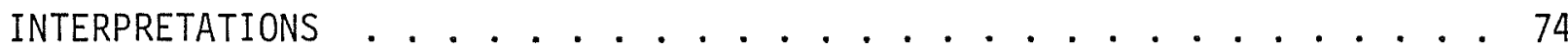

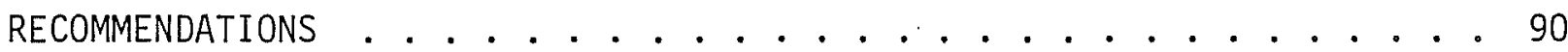
REFERENCES CITED .................... 91 APPENDIX I: THE BURRIS SITE $(41$ VT 66) . . . . . . . . . . . 98 APPENDIX II: FAUNAL ANALYSIS: 41 GD 30A (Lois M. Flynn) . . . . 104 


\section{LIST OF FIGURES}

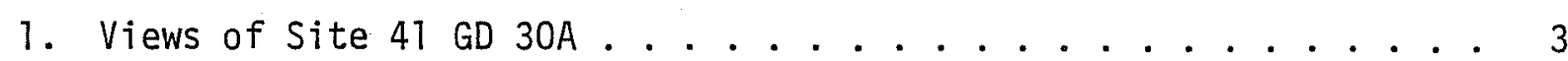

2. Coleto Creek Reservoir Area ................ 4

3. The Berger Bluff Site--41 GD $30 \ldots . . . . . . . .55$

4. Plan Map of 41 GD 30 ..................... 13

5. South Wall Profile, 41 GD 30A ............. 19

6. West Wall Profile, $41 \mathrm{GD} 30 \mathrm{~A}$. . . . . . . . . . 20

7. Views of Excavation Unit, 41 GD 30A . . . . . . . . . 22

8. Plan Map of Austin Phase Midden, Feature 1 . . . . . . . 23

9. Views of Subsurface Features 2 and $3 \ldots . . . . . .25$

10. Views of Subsurface Feature 4 and Occupation Floor II . . . . . . 27

11. Profile of Berger Bluff . . . . . . . . . . . . . . 28

12. Trimmed Flakes . . . . . . . . . . . . . 43

13. Bifaces: Stage II through Stage IV . . . . . . . . . . . 49

14. Stage $V$ Preforms . . . . . . . . . . . . . . 53

15. Stage VI Finished Tools . . . . . . . . . . . . . . 57

16. Stemmed Projectile Points . . . . . . . . . . . . . 61

17. Bone, She11, and Burris Site Artifacts . . . . . . . . . 71

18. Diagnostic Artifact Sequence . . . . . . . . . . . . . 75

19. Plan Map of Burris Site Area . . . . . . . . . . . . . . . 99

20. Idealized Cross Section of the Burris Site . . . . . . . . . 100 


\section{LIST OF TABLES}

1. Materials Recovered from 1977 Shovel Tests . . . . . . . . 14

2. Cores by Level . . . . . . . . . . . . . . . . . 31

3. Core Group Percentages by Leve1 . . . . . . . . . . . 32

4. Utilized Flakes by Type of Removal . . . . . . . . . . 36

5. Utilized Flakes by Technological Category . . . . . . . . 37

6. 1979 Utilized Flakes by Group and Level . . . . . . . . . . . . 38

7. 1979 Utilized Flake Percentages .............. . 39

8. Trimmed Flakes by Level . . . . . . . . . . . . . 40

9. Trimmed Flake Percentages by Level ............ . 41

10. Thick Bifaces by Level ................ . . . 45

11. Thick Biface Percentages by Leve1 . . . . . . . . . . . . 46

12. Unfinished Thin Bifaces by Leve1 . . . . . . . . . . . . 51

13. Finished Stage VI Thin Bifaces by Level . . . . . . . . . . 55

14. Ground and Pecked Stone by Leve1 ............. . . 66

15. Nontithic Modified Materials by Level ............. 68

16. Flake versus Blade Utilization Percentages . . . . . . . . 76

17. Single versus Multiple Edge Flake (and Blade) Utilization . . . . 77

18. Relative Percentages for a11 Lithic and Nonlithic Artifacts . . . . 79

19. Artifact Inventories by Level . . . . . . . . . . . . 86

20. Distribution of Faunal Material by Weight . . . . . . . 105

21. Faunal Inventory: $41 \mathrm{GD} 30 \mathrm{~A} \ldots . . \ldots 106$

22. Provenience of Identified Faunal Remains . . . . . . . . 108

23. Distribution and Description of Bone: $41 \mathrm{GD} 30 \mathrm{~A}$. . . . . . 112 


\section{ACKNOWLEDGMENTS}

The excavations were greatly aided by the cooperation of David Welsch and Bryan Serold of the Guadalupe-Blanco River Authority (GBRA). Dr. Thomas R. Hester, Center Director, and Jack D. Eaton, Associate Director of the Center for Archaeological Research, were responsible for project planning and offered support throughout the field work and report preparation. Glen Evans visited the site and made notes on the geomorphology, especially in the interpretation of the lower zone.

A great deal of the excavation's success depended upon the assistance of a number of Victoria area avocational archaeologists. William W. Birmingham, E. H. (Smitty) Schmied7in, C. T. (Sonny) Timme, Ed Vogt, and Don Will all donated their time and considerable talents to the excavation. Kate Vaught, a San Antonio amateur archaeologist, helped with sorting and cataloguing.

Thanks also goes to the regular field crew who spent many long hot days at the site: Ken Brown, Waynne Cox, James T. Escobedo, Jr., Thomas C. Kel1y, Herbert G. Uecker, and Don White.

In the laboratory Sylvia Bento, Elaine Brown, Judy Gillis, Laura Keene, and Robin Wood sorted and catalogued materials from the site.

Field photography was a collaboration among Thomas. C. Kelly, Ken Brown, Herbert G. Uecker, and the author. The main site map is redrawn from the original made by the author during the 1977 excavation, and the location maps are his responsibility. Profiles and feature maps were drafted by the author from the originals by Herbert G.. Uecker, James T. Escobedo, Jr., and C. T. Timme. Thanks to Augustine J. Frkuska, Jr., for some redrafting of maps and tables.

Lastly, thanks to the UTSA laboratory personnel who generously tolerated a mountain of Coleto Creek boxes and a never-ending flood of questions. 



\section{INTRODUCTION}

In April 1979, the Guadalupe-Blanco River Authority (GBRA) contacted the Center for Archaeological Research (CAR), The University of Texas at San Antonio (UTSA), regarding test excavations in portions of 41 GD 30 that would be inundated upon completion of the Coleto Creek Reservoir. A proposal out1 ining these excavations was subsequently approved by the Texas Historical Commission (THC). The plan called for limited test excavations within the portions to be inundated in order to establish a correlation with the undisturbed remainder of the site, as well as an assessment of the management alternatives should construction of the planned Discharge Flume \#3 endanger the site at some future date.

A field crew from the CAR, under the direction of David Brown, spent three weeks conducting excavations at the site in June 1979. Project planning and coordination were accomplished by Dr. Thomas R. Hester, Director of the CAR and Principal Investigator for the project, assisted by Jack D. Eaton, Associate Director, and by the author. This report presents the results of the most recent excavations, along with a description of the artifactual materials collected. All of these materials are now catalogued and permanently stored in the laboratory of the Center for Archaeological Research.

Based on testing activities of Fox, Black, and James (1979:36), site 41 GD 30 was divided into two major areas: $41 \mathrm{GD} 30 \mathrm{~A}$ along the bluff area and $41 \mathrm{GD} 30 \mathrm{~B}$ along an arroyo to the south-southwest. This report will document archaeological investigations carried out at $41 \mathrm{GD} 30 \mathrm{~A}$. Investigations of the "lower bench" area at 41 GD 30A began in December 1979, and the analys is is stil1 in progress (Brown n.d.).

\section{ENVIRONMENTAL SETTING}

\section{Soils and Topography}

The environmental setting of the Coleto Creek region has been described in detail in the initial environmental assessment report prepared for the GBRA (Environmental Consultants Inc., 1975) and is summarized with some additions in the report on the archaeological testing phase in the reservoir (Fox, Black, and James 1979). The general summary below relies heavily on these two reports, and the reader is advised to refer to them for more detailed information.

The Coleto Creek Reservoir lies within the coastal prairie region of Texas. The geologic basal formations in the area are Quaternary and Tertiary deposits of deltaic and fluvial origin which outcrop in belts generally paralleling the coastline, with the older sediments farthest inland. Along the larger creeks and river valleys are alluvial terrace deposits dating to the Quaternary. Soils throughout the area are generally sandy loams with a montmorillonitic clay subsoil. The topography is gently rolling terrain with a generally dendritic drainage pattern. Aside from Coleto Creek itself, a perennial stream, water is supplied by the Gulf Coast. Aquifer, which provides varying amounts of fresh to moderately saline water. 
The reservoir area is in a transitional zone between Blair's (1950) Texan and Tamaulipan Biotic Provinces. Four general vegetation zones can be identified from nearby areas: gulf prairies and marshes, post oak savannah, blackland prairies, and south Texas plains. Despite distinct differences in plant types between these zones, they can be very generally characterized as grasslands or savannahs with occasional patches of shrubs and small trees. Although invader species such as mesquite and acacia have formed a fairly dense brushy growth in many areas, researchers feel that the prehistoric countryside would have been more open (Fox, Black, and James 1979:4). Recent environmental data from the Choke Canyon Reservoir area indicate that, at least near the drainages, some of the invader species such as mesquite and acacia were definitely present in prehistoric times (Hall, Black, and Graves 1982).

\section{The Berger Bluff Site (41 GD 30A)}

This site is located on a high bluff (Fig. 1,a) on the west bank of Coleto Creek more than $4.8 \mathrm{~km}$ upstream from its confluence with Turkey Creek (Fig. 2). The bluff is part of a fluvial terrace deposit laid down by the creek throughout the Holocene and the late Pleistocene. Basal gravel deposits are not visible near the site, but the surface of the terrace at the highest point of the bluff is approximately $9 \mathrm{~m}$ above the present water surface. Underlying this terrace are deposits of the Goliad Formation of Pliocene age. Contained in this formation are clay, sand, sandstone, marl, caliche, limestone, and conglomerate (Bureau of Economic Geology 1975). In an arroyo southwest of the site, bedrock is exposed for some distance, showing interbedded sandstones, clay, and caliche. Shovel tests at the site and observation of the bedrock in the bluff and arroyo profiles show that the sandstone has been eroded away to the depth of the creek bed near the foot of the bluff, but rises to the surface about $50 \mathrm{~m}$ back from the bluff's edge.

Figure 3 is an idealized cross section view of the geomorphological relationship between $41 \mathrm{GD} 30 \mathrm{~A}$ and $41 \mathrm{GD} 30 \mathrm{~B}$, based upon visible exposures of bedrock and from shovel tests conducted at the sites. At 41 GD 30A, the upper zone (Stratum 5) appears to be primarily aeolian in origin, while the lower zones are all thought to be alluvial terrace deposits. The heaviest concentration of cultural material is contained in the upper zone, although cultural material is found in the terrace deposits. The origin of sediments at $41 \mathrm{GD} 30 \mathrm{~B}$ is unclear, but they may be a mixture of an aeolian upper zone with a subsurface alluvium from hillslope denudation. Although no gravels were detected in excavations on this upper level, the possibility that 41 GD 30B 1ies on an older terrace cannot be as yet ruled out (cf. Evans 1962 for a discussion of sites on different terraces on the Rio Grande).

The upper zone soil (Stratum 5) is a brown, friable, loamy, fine sand, very rich in organic material and thought to represent ". . . a gradual and very slow accretion of wind-transported silt and fine sand derived mainly from the sand bars along the Coleto Creek channel together with the decompositional organic products of herbaceous and woody vegetation". (Evans 1979). This upper zone grades into a gray, medium-grained, siliceous sand (Stratum 4) characterized by 

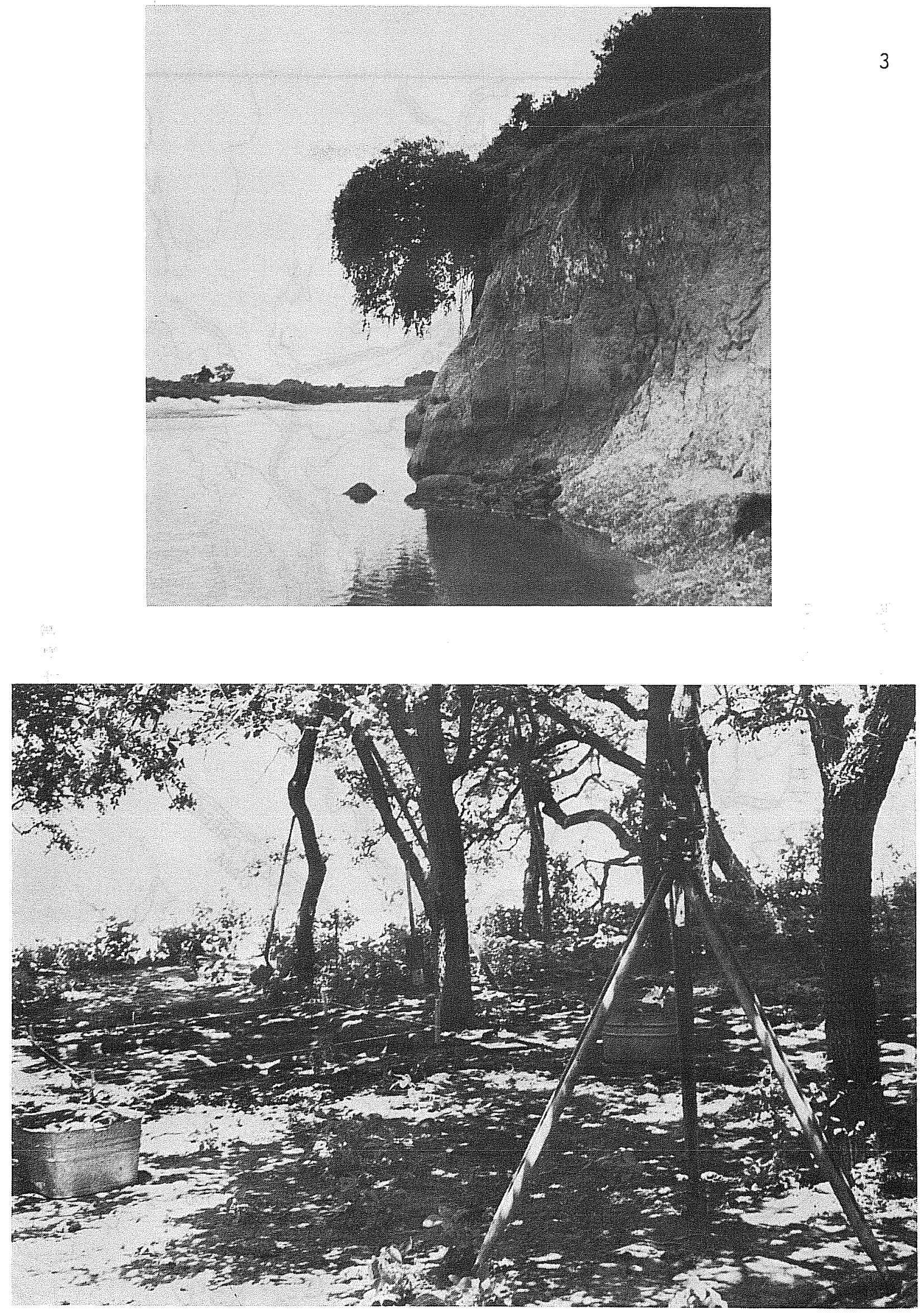

Figure 1. Views of Site 41 GD 30A. a, looking east at Berger Bluff; b, looking north at top of bluff. Initial 1979 excavation area is in left center. Immediately adjacent to the north is a $2-\mathrm{m}^{2}$ unit from 1977 investigations. 
This page has been

redacted because it

contains restricted

information. 


\section{The Berger Bluff Site 41GD30 \\ Idealized Cross-section View \\ Looking East}

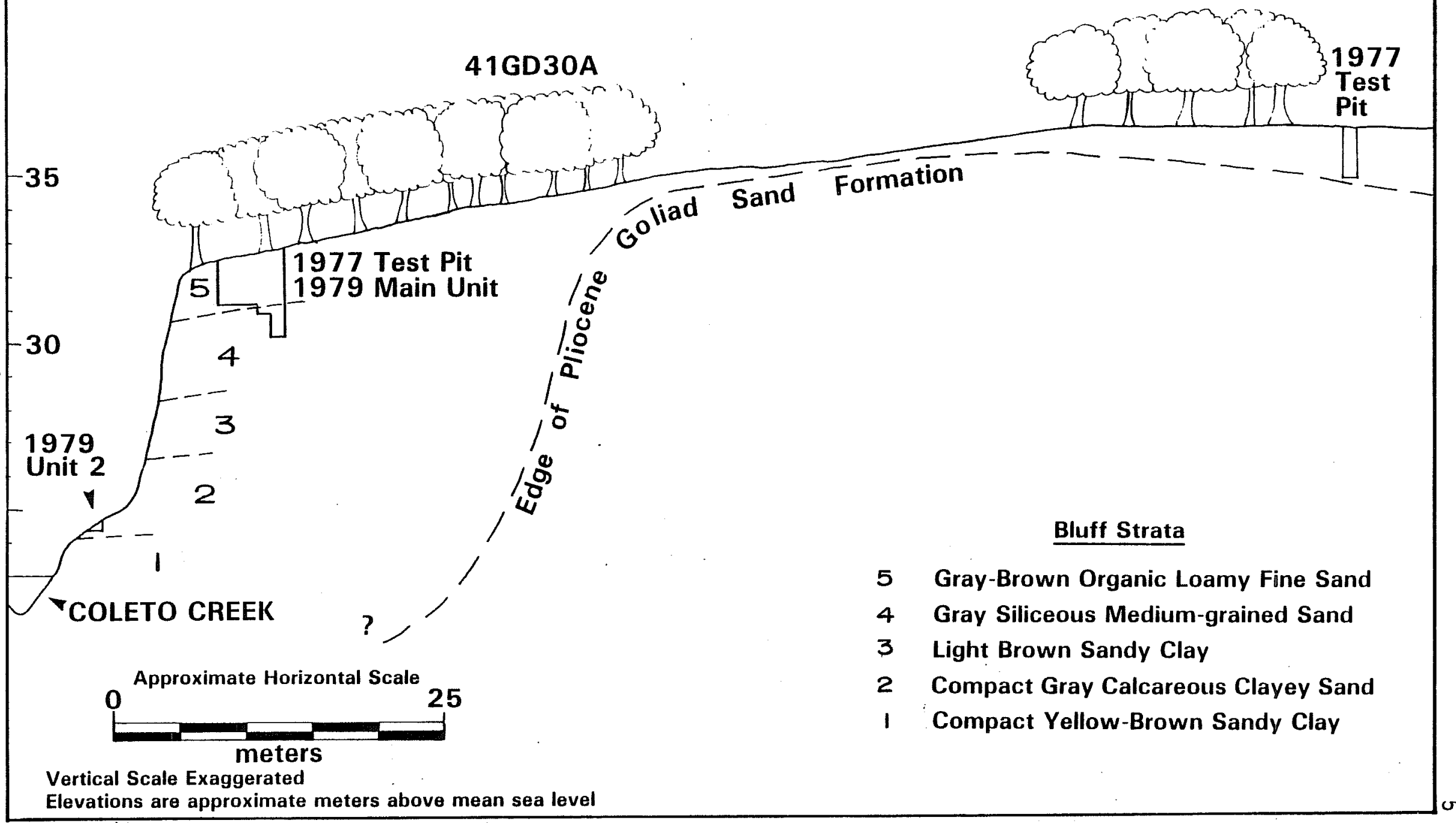

Figure 3. The Berger Blü6 Site--41 GD 30. Idealized cross section view looking east. 
the presence of a few small stream gravels and moderately abundant snail shell. Below this is a grayish brown, sandy clay with prominent vertical jointing and abundant snail shell (Stratum 3). Stratum 2 is a gray, hard calcareous clayey sand with occasional small siliceous gravels, snail, and cultural debris. Just above the waterline of the creek is a massive, very compact yellowish brown sandy clay (Stratum 1) with few mollusc shells present, but with some small lenses of siliceous gravel.

\title{
Biota
}

The vegetation in the main excavated area of $41 \mathrm{GD} 30 \mathrm{~A}$ consists of a mott of anaqua (Ehretia anacua) and hackberry (Celtis sp.) with some bluewood (Condalia hookeri) and persimmon (Diospyros texana) present. Underneath the tree canopy in the mott, there is almost no lower story growth; small clumps of unidentified short-stemmed grasses and a few isolated wildflowers are the only vegetation present. At the edges of the mott and at varying distances away from it, a number of different plant species were observed:

\author{
Scientific Name \\ Bumelia lanuginosa \\ Carpinus caroliniana \\ Morus sp. \\ Opuntia leptocaulis \\ Opuntia lindenheimeri \\ Prosopis glandulosa \\ Quercus marilandica \\ Quercus stellata \\ Quercus virginiana \\ Rhus toxicodendron \\ Vitis mustangenis \\ Zanthoxylum fagara
}

Common Name
Gum elastic
Ironwood
Mulberry
Tasajillo
Prickly pear
Honey mesquite
Blackjack oak
Post oak
Live oak
Poison oak
Mustang grape
Prickly ash

A list of fauna present in the general area was compiled for the archaeological testing report (Fox, Black, and James 1979:5-7) While working at the site, a number of different fauna or their signs were observed by the field crew: white-tailed deer, armadillo, jackrabbit, skunk, raccoon, cattle egret, wild turkey, mockingbird, various turtles, lizards, and frogs, as well as bass and perch.

\section{PREVIOUS ARCHAEOLOGICAL INVESTIGATIONS}

\section{Prehistoric Investigations}

The earliest professional investigations in the general Coleto Creek area were carried out at the Morhiss site (41 VT 1). on the Guadalupe River south of Victoria. A. T. Jackson tested the site in 1932, and between 1938 and $1940 \mathrm{a}$ Works Progress Administration (WPA) crew under the direction of $W$. A. Duffen completed excavation of the site (Campbel1 1976:82). Also in 1940, Duffen excavated portions of the Jackson site on the Guadalupe River north of Victoria (Fox and Hester 1976:6). 
Several recent studies of neighboring areas have helped to provide a clearer understanding of the prehistory of the region. These investigations reflect the increase in archaeological studies brought about by recent antiquities legislation. In nearby Jackson County, surveys of the Palmetto Bend Reservoir (Wakefield 1968; Mallouf, Fox, and Briggs 1973) were followed by a testing program (McGuff 1978). To the north of the Coleto Creek area, a survey was conducted along Cuero Creek for the proposed Cuero I Reservoir (Fox et al. 1974).

In recent years, amateur archaeologists in the Victoria area have contributed greatly to the knowledge of prehistoric cultures in south Texas. A number of prehistoric sites in both the Guadalupe River and Coleto Creek drainages were first recorded by amateurs. Among the more important of these sites are the Johnston-Heller site (Birmingham and Hester 1976), a deeply buried site on Rocky Creek not far from the Jackson site mentioned above, and the J-2 Ranch site on Arenosa Creek (Fox, Schmiedl in, and Mitchel1 1978), excavated by local amateurs and the Southern Texas Archaeological Association (STAA).

A 1975 survey of the Coleto Creek Reservoir located 49 archaeological sites, many of which would be impacted by dam and power plant construction. Twentyseven of these sites were recommended for further investigation (Fox and Hester 1976:72-74), and in spring 1977, archaeologists from the Center for Archaeological Research returned to Coleto Creek to test these sites. Two of the sites tested (41 GD 27 and 41 GD 30) were nominated to the National Register of Historic Places and were recommended for intensive testing (Fox, Black, and James 1979:63).

During December 1977 and January 1978, a team of archaeologists from the CAR excavated portions of 41 GD 21 (now divided into two separate sites, 41 GD 27 and $41 \mathrm{GD} 21 \mathrm{~A}$,) which were to be affected by construction of the Central Power and Light Coleto Creek power plant. This investigation provided data on prehistoric occupations in the area from the Middle Archaic period through the Late Prehistoric period (Fox 1979).

\section{Historic Investigations}

Between 1940 and 1941, the National Park Service and the WPA conducted excavations at the site of Mission Rosario in Goliad County (Gilmore 1974a). The Texas Parks and Wildlife Department undertook later excavations in 1973 and 1974 (Gilmore 1974b). Gilmore (1973) also analyzed material from the 1950 Texas Memorial Museum excavations at the Keeran site, the probable site of La Salle's Fort St. Louis colony.

The CAR has conducted testing at an early 18th-century Spanish site in Victoria City Park (Fox 1979) and also at the 19th-century Steiner-Schob site (Fox and Livingston 1979), in the Coleto Creek Reservoir. 


\section{COASTAL PLAIN PREHISTORY}

The Coleto Creek area and the Berger Bluff site lie in a transitional zone between the major cultural areas of the Texas coast and inland central Texas. The few sites excavated in the area indicate influences from both directions as well as distinct local developments. The presence of salt and brackish water clam species and asphaltum indicates trade or travel to the coast (Fox 1979:70), while the identification of numerous point styles associated with central Texas (Fox, Schmiedlin, and Mitchel1 1978:12) demonstrates strong influences from that direction. The Morhiss complex, in contrast, appears to be a locally centered development (Calhoun 1965:4).

Despite the paucity of excavated sites and radiocarbon dates from the area, a general chronological scheme can be postulated by interpolation from coastal and central Texas. The following sequence is essentially an expansion of the one proposed by Fox and Hester (1976:5) for the Coleto Creek area.

\section{The Paleo-Indian Period (9200-6000 B.C.)}

The earliest documented evidence of human occupation of the area is a clovis style projectile point, dated to 9200 B.C. found at the Johnston-Heller site, Victoria County (Birmingham and Hester 1976:20). A basal portion of a Clovis point, originally identified as a large Folsom point, was recovered from the Buckner Ranch sjte in Bee County (Campbe11 1940:1641). At the Buckner Ranch site, several species of Pleistocene megafauna occur within the same strata as cultural remains, and the tooth of a Columbian elephant Parelephas columbi, was found ". . . at the same level as and near some of the artifacts" (Sellards 1940:1632). Other than this site, there is little evidence in the coastal plain area of Texas to link these early hunters to the big game with which they have so often been associated.

While the Clovis complex people may have not concentrated solely on "big game hunting," there is definite evidence for a diversification of resource utiTization during the Late Paleo-Indian period (Hester 1976:8). Projectile points associated with this tradition (including Plainview, Golondrina, Angostura, Meserve, and Scattsbluf6) have been found at numerous sites in the area. Several of the sites already mentioned, including Johnston-Heller, J-2 Ranch, Morhiss site, and Buckner Ranch, have yielded these characteristic Late PaleoIndian projectile point styles. Two of the sites recorded during the Coleto Creek survey, 41 VT 16 and 41 VT 43, have Late Paleo-Indian components, and a possible Late Paleo-Indian point was reportedly found at 41 GD 31 just downstream from the Berger Bluff site (William W. Birmingham, personal communication).

The Pre-Archaic Period (6000-3500 B.C.)

Subsequent to the Late Paleo-Indian period, in many parts of Texas, is a poorly understood cultural tradition marked by the presence of a number of stemmed and notched points, but little other basic technological change. This period has been recognized on the central Guada,lupe River, along the edge of 
the Edwards Plateau, at the Strohacker site (Sollberger and Hester 1972). The characteristic projectile point styles of this tradition (Bell, Gower, Early Corner Notched, and Early Triangular) have been recognized at several sites in the lower Guadalupe-Coleto area, such as the J-2 Ranch, Johnston-Heller, and possibly the Buckner Ranch site (Sollberger and Hester 1972). In the Coleto Creek drainage, evidence of the Pre-Archaic period has been reported from several sites, including 41 VT 16, 41 VT 20, and 41 GD 22 (Fox and Hester 1976).

The Archaic Period (3500 B.C.-A.D. 700)

The Archaic period is marked by a diversification of resource utilization visible in the archaeological record as an increase in chipped stone tool types, particularly those which might indicate plant food processing, and the appearance of grinding implements. The Archaic is also noted as the beginning of a regional diversification of culture types.

Prior to this regional diversification, there are essentially no data on coastal cultures. Whether because of a change in the coastline or an actual cultural preference, there are no sites dated earlier than 2000 B.C. in the middle coastal area (Corbin 1976:92). Archaic sites along the coast are typically shell middens and can be separated into two broad temporal divisions on the basis of change in artifact style: an earlier group of artifacts, including stemmed projectile points such as Palmillas, Bulverde, and Morhiss, along with incised bone and marine she11 tools; and a later group without these stemmed points but with an increased frequency of triangular and side-notched points (which also occur in the earlier period) and much less emphas is on incised bone work and marine shell tools (Corbin 1976). One Archaic phase has been defined for the coastal area--the Aransas phase defined by Campbe11 (1947) at the Johnson site and later at the Kent-Crane site (Campbel1 1952). Corbin (1974:37) would redefine the original phase to include a more controlled temporal and spatial area or would drop the term phase in favor of the more inclusive term complex.

The Coleto Creek region is included within the area of the Morhiss phase, the only specifically defined archaeological phase of the Archaic period from the central coast plain (Calhoun 1965:4). First encountered in excavations at the Morhiss site, this complex of materials was later recognized at many sites throughout the lower Guadalupe drainage. Excavations at 41 GD 21A revealed an apparent Morhiss phase living floor tentatively dated to $800 \pm 370$ B.C. (Fox 1979:78).

Although excavations in the coastal plain area have shown an apparent sequence of artifact styles throughout the Archaic, with the exception of the Morhiss phase, little has been done to separate these styles temporally. On the other hand, in central Texas, the sequence has been discussed and refined many times. A simple tripartite division into Early, Middle, and Late Archaic is most common, with the occasional addition of a Transitional Archaic phase at the end of the Late Archaic (Gerstle, Kel1y, and Assad 1978:64). A tentative division into five named phases from earliest to latest has been made by Weir 
(1976): San Geronimo, Clear Fork, Round Rock, San Marcos, and Twin Sisters. These phases correspond roughly to the Pre-Archaic, Early Archaic, Middle Archaic, Late Archaic, and Transitional Archaic mentioned above.

Archaic materials of one sort or another are found at most of the sites in the region, and Archaic sites appear to be the most common type (Fox and Hester 1976:70-71). Projectile point styles identified with each of the divisions of the Archaic have been encountered at sites in the general area. Almost al1 of the sites recorded within the Coleto Creek Reservoir yielded Archaic style dart points.

The Late Prehistoric Period (A.D. 700-1528)

This period is generally characterized by the appearance of the bow and arrow and the gradual disappearance of the atlati. In central Texas, this period is divided into two phases, the Austin and Toyah. The Austin phase is characterized by the presence of Scallorn arrow points, Dare dart points, serrated flake tools, and other artifact styles (Jelks 1962:85-86). The appearance of bonetempered Leon Plain pottery and the presence of Perdiz and cliffton arrow point styles mark the beginning of the later Toyah phase (Jelks 1962:86-88).

Along the central coast, a single complex has been defined: the Rockport complex. This complex is identified by Rockport ceramics and various arrow point styles, including Perdiz, Scallarn, Cliffton, and Fresno (Corbin 1974:38). At the Ingleside Cove site, the upper zone yielded Rackport ceramics and Perdiz points (Story 1968:41); excavation a't the Anaqua site yielded Scallorn and Granbury points in association with a sandy paste pottery (Story 1968:65). The artifact assemblage of this period is not totally homogeneous; some variation is present which may eventually bring about further subdivision. Dating of the Late Prehistoric along the coast may vary somewhat from central Texas; four radiocarbon dates from the Archaic zone at the Ingleside Cove site fall between A.D. 1100 and 1250 (Story 1968:40) and suggest a Late Prehistoric date of post-A.D. 1250 for the coastal area.

One of the more important Late Prehistoric sites in the region may be the Berclair site in southern Goliad County. At this site, an essentially Toyah phase occupation shows distinct Rockport influences as we11 as other unidentifiable influences (Hester and Parker 1970:21, 22). The Morhiss site also has a light Late Prehistoric occupation (Campbe17 1976:64). Within the Coleto Creek Reservoir area, Late Prehistoric materials (possibly from Austin, Toyah, and Rockport phases) have been recovered from six sites, including 41 GD 21 and $41 \mathrm{GD} 30$.

The Historic Period (1528-present)

Technically, the Historic period began with the arrival of Cabeza de Vaca in 1528 , although it was many years later before any noticeable impact from European culture occurred. Archaeological visibility of European influence is limited to the post-1700 period (Corbin 1974:47), where European artifacts 
occur along with incised ceramics and bulbar-stemmed arrow points (Corbin 1974: 51). Another archaeologically visible trend is seen in material from the Spanish missions. A distinct new pottery type, Goliad ware, is associated with the mission Indians of the coastal plain (Mounger 1959; Gilmore 1974a).

Several historic Indian tribes are reported to have 1 ived or been observed near the Coleto Creek region. Foremost among these are the Coahuilteco speaking Aranama and Tamique who inhabited the area between the San Antonio and Guadalupe Rivers (Newcomb 1961:31). During the Spanish colonization period, the Aranama were gathered at the second and third locations of the Mission Espiritu Santo de Zúñiga (Newcomb 1961:37). The former 1ocation, in Mission Valley, is less than $16 \mathrm{~km}$ to the north of the Berger Bluff site, and the latter, in Goliad, is about $24 \mathrm{~km}$ to the west.

Along the coast to the south of the Coleto Creek region lived the Karankawanspeaking Cocos, Cujanes, Karankawa, Coapite, and Copano (Campbe11 1960:148), many of whom later appeared inland at the Goliad Mission (Rodnick 1973:10). However, it is uncertain how far inland these groups ranged in the pre-mission period (Fox et al. 1974:16). The historic Karankawas have been tentatively associated with the Rockport phase of the Late Prehistoric period (Campbe11 1958), although not without some problems (cf. Campbe11 1960:150; Corbin 1974: $49-52)$.

Another group reported in the area during the Historic period is the Tonkawa, who were there as early as 1690 (Fox et al. 1974:17). In central Texas, the Tonkawa have been suggested as a possible candidate for association with the Toyah phase (Suhm 1960:85), although this view is not universal (cf. Jelks 1962:99). In addition to the Tonkawa, another Plains tribe, the Lipan Apache, is reported to have raided the central coastal area between 1770 and 1850 (Campbel1 1960:149).

\section{SITE HISTORY OF 41 GD 30}

The Berger Bluff site has been known to local residents for many years. Human skeletal materials were reportedly observed washing out of the bluff after floods some 45 years ago (Fox and Hester 1976:36). Today several local collectors and amateur archaeologists have artifact collections from the site.

In the 1975 survey of the Coleto Creek Reservoir by the CAR, the site was visited and a surface collection made. That collection included bifaces, cores, numerous chert flakes, bone, mussel, and snail shells. In addition, two projectile points from the William $W$. Birmingham collection were illustrated in the report (Fox and Hester 1976:38). The site was recommended for further testing ". . . in order to determine more about site utilization and the age of the deposits" (Fox and Hester 1976). At that time it was pointed out that materials were eroding from the bluff to $6.5 \mathrm{~m}$ below the surface.

During the testing phase, a CAR crew under the direction of Anne A. Fox spent four days working at the site. A plane table map was prepared, and 18 shovel tests were conducted around the site in order to define the boundaries. 
Figure 4 shows the site and the locations of these shovel tests; Table 1 (adapted from Fox, Black, and James 1979:28, Table 1) 7ists the materials recovered. Based on these preliminary subsurface tests, the site was divided into two major areas: $41 \mathrm{GD} 30 \mathrm{~A}$, along the top of the bluff, and $41 \mathrm{GD} \mathrm{30B}$, along the arroyo to the southwest. These two areas are separated by a grassy area with little soil depth and a very low density of artifactual material (cf. Fig. 2).

A $1-\mathrm{m}^{2}$ unit was excavated to a depth of $165 \mathrm{~cm}$ in Area $B$, and a shovel test conducted in one quadrant of this unit revealed cultural material to a depth of $193 \mathrm{~cm}$. No clear sedimentary stratigraphy was visible in the profile, but the artifact count suggested a vertical separation between cultural zones in the upper and lower areas of the excavation. The only diagnostic projectile point found in this unit was a Travis point from the third level. This Early Archaic indicator (Weir 1976:29) was found $45 \mathrm{~cm}$ below the surface in the upper cultural zone, while Middle Archaic indicators such as Refugio and Pedernales points (Fox, Black, and James 1979:37) were found on the disturbed surface of the site.

In Area $A$, a $2-\mathrm{m}^{2}$ unit was excavated to $75 \mathrm{~cm}$, and a $1-\mathrm{m}^{2}$ unit continued below that; the eventual depth of excavation reached $190 \mathrm{~cm}$, with artifact recovery continuing. As with the other area, no stratigraphy was visible. Diagnostic artifacts recovered included several sherds of bone-tempered pottery from the Late Prehistoric period and an unidentified side-notched projectile point probably from a Late Archaic context (Fox, Black, and James 1979:37). Two clusters of burned rock, possibly hearths, but lacking charcoal, were excavated at 60 and $75 \mathrm{~cm}$ below the surface.

As a result of these excavations, it was determined that the site was eligible to be nominated to the National Register of Historic Places; it was also recommended that it be fully protected from any disturbances due to reservoir construction. In addition, it was recommended that further archaeological investigations be undertaken before the completion of the reservoir (Fox, Black, and James 1979:39).

\section{RESEARCH DESIGN}

Based on prior work at the site, several goals were established for the present investigation. These goals were influenced by the possibility that, when the reservoir is complete and the water level rises to the face of the bluff, the unconsolidated sand in the deposit might be rapidiy eroded by wave action (Evans 1979). With this priority in mind, the following goals were set:

1. Obtain a large sample of the cultural deposits that are in immediate danger from erosion of the bluff;

2. Excavate a wide horizontal area so that each cultural stratum excavated might have a relatively large complement of individual tools, features, and general living floor associations; 
This page has been

redacted because it

contains restricted

information. 
TABLE 1. MATERIALS RECOVERED FROM 1977 SHOVEL TESTS

\begin{tabular}{|c|c|c|c|c|c|c|c|c|c|c|c|}
\hline & 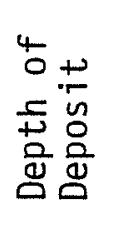 & 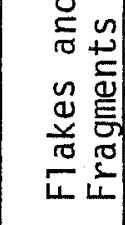 & $\begin{array}{l}n \\
d \\
\vdots \\
0 \\
0\end{array}$ & $\begin{array}{l}n \\
0 \\
0 \\
0 \\
0 \\
0\end{array}$ & 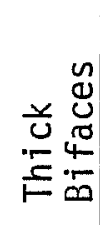 & 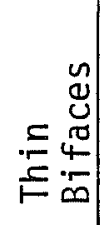 & 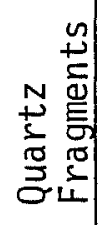 & 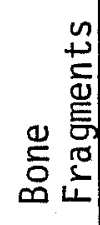 & $\begin{array}{l}\frac{n}{\sigma} \\
\tilde{n} \\
\sim\end{array}$ & 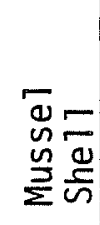 & $\stackrel{\text { 足 }}{\stackrel{5}{E}}$ \\
\hline Survey & - & 173 & 4 & & 1 & 5 & & $x$ & $x$ & $x$ & 183 \\
\hline Surface & - & 44 & 5 & 3 & & 1 & 1 & $x$ & & $x$ & 54 \\
\hline Test 1 & 20 & 3 & & & & & & & & $x$ & 3 \\
\hline 2 & 15 & 2 & & & & & & & & & 2 \\
\hline 3 & 75 & 11 & & & & & & & $x$ & $x$ & 11 \\
\hline 4 & 20 & 12 & & & 1 & & & & & & 13 \\
\hline 5 & 80 & 41 & & & & & & & $x$ & $x$ & 41 \\
\hline 6 & 105 & 74 & & & & & & $x$ & $x$ & $x$ & 74 \\
\hline 7 & 95 & 391 & & & & 4 & & $x$ & $x$ & $x$ & 395 \\
\hline 8 & 110 & 63 & 1 & & & & & $x$ & $x$ & $x$ & 64 \\
\hline 9 & 82 & 22 & & & & & & $x$ & $x$ & $x$ & 22 \\
\hline 10 & 50 & 61 & & & & & & & $x$ & $x$ & 61 \\
\hline 11 & 50 & 40 & 1 & & & & 3 & $x$ & & & 44 \\
\hline 12 & 5 & 1 & & & & & & & $x$ & $x$ & 1 \\
\hline 13 & 105 & 282 & 1 & & & & 6 & $x$ & $x$ & $x$ & 289 \\
\hline 14 & 30 & 30 & & & & & & & $x$ & $x$ & 30 \\
\hline 15 & 105 & 86 & & & & & & $x$ & $x$ & $x$ & 86 \\
\hline 16 & 83 & 545 & & & & 2 & 1 & $x$ & $x$ & $x$ & 548 \\
\hline 17 & 35 & 3 & & & & & & & $x$ & & 3 \\
\hline 18 & 78 & 1 & & & & & & $x$ & $x$ & & 1 \\
\hline TOTALS & & 1885 & 12 & 3 & 2 & 12 & 17 & & & & 1925 \\
\hline
\end{tabular}


3. Excavate vertically as much as nonmechanically practical to verify the existence of deeply buried strata at the site;

4. Obtain a large sample of diagnostic temporal and cultural indicators and any possible chronometric dates so that the site might be better placed in a regional, spatial, and temporal framework;

5. Obtain information on the paleoenvironment from any available sources so that cultural deposits might be correlated with a well-defined environmental system.

In addition to these general guidelines for data collection at the site, several more specific research objectives were considered before and during the excavation. The relative paucity of archaeological data from excavated sites in the region makes the formulation of specific hypotheses difficult; these objectives are best stated as questions that could be potentially answered by data from the site. At the least, they should be regarded as the first step in the formulation of a detailed set of hypotheses to be tested by further research in the area:

1. From other sites in the area, it is clear that the region has affinities with both coastal and central Texas, as well as local influences. Can sites in the area be classified as one or the other of these established culture areas with influence from the other, or should the inland coastal plain be regarded as a new and distinct cultural area?

2. Placing the above statement in a temporal perspective, it seems apparent that no single answer will hold throughout the entire period of occupation. In the Palmetto Bend area, McGuff (1978:30-32, 166169) hypothesizes that a truly coastal tradition evolved during the Transitional Archaic and Late Prehistoric. What are the implications of this development for inland cultures on the coastal plain after the Late Archaic?

3. At the Berclair site, Hester and Parker (1970) found what they believed to be a central Texas Toyah phase group with considerable evidence of contact with coastal groups. Is this an atypical site, or does this pattern occur at other Late Prehistoric sites in the area?

Data necessary to furnish answers to the above questions can be sought from several sources. In addition to the standard artifact recovery and analys is procedures, it is necessary to effect $100 \%$ recovery of faunal materials so that the subsistence strategy of the people involved can be outlined. This total collection of bone and shel1 insures against the loss of small bone or coastal shell tools that might be indicative of coastal influence. The use of water screening should aid in efficient recovery by protecting delicate fauna 1 materials that might be lost through dry screening. 
Although the analysis of the faunal remains could shed light on the past environment at the site, the most important technique for the paleoenvironmental reconstruction is the identification of opal plant phytoliths. This technique was used at 47 GD 21, and direct microregional and microclimatic correlations should be possible between the two sites (which are less than $10 \mathrm{~km}$ apart).

\section{EXCAVATION METHODS}

On the basis of prior investigations at the site, it was decided to excavate as large an area as possible in that portion of the site with the highest artifact densities. This was done in order to recover a reasonable sample of the variation in the artifact assemblages through time. A single large unit was selected rather than a number of smaller ones in order to allow more efficient excavation to depth and to allow direct correlation between materials found at various levels. A $3 \times 4-m$ unit was therefore excavated adjacent to and south of the $2-\mathrm{m}^{2}$ unit excavated in 1977 (the location of trees and the edge of the bluff allowed no other placement; Fig. 1,b).

A grid was laid out with the northeast corner of the excavation unit (the southeast corner of the 1977 unit) designated as an arbitrary $100 \mathrm{~m}$ north and $100 \mathrm{~m}$ east, and all horizontal proveniences are based upon this system. This grid was aligned on the earlier test unit, oriented $N 004^{\circ} 39^{-} W$. The excavation unit was then laid out in a series of $1-\mathrm{m}^{2}$ units designated by the southwest corner grid numbers. Exact measurements were recorded for features and artifacts recovered in situ, and plans were made for each unit containing potentially diagnostic artifacts or features. The $1-\mathrm{m}^{2}$ horizontal provenience was maintained for all other materials.

A11 vertical elevations were controlled by transit. A large nail was driven into a tree to the northwest of the excavation area at the same elevation as the highest corner of the excavation unit (southwest) and designated as an arbitrary 100 m elevation. The absolute elevation of this point could not be determined because of the lack of a nearby bench mark, but by comparison with GBRA topographic maps, it is close to 105 feet ( $31 \mathrm{~m}$ above mean sea level). Surface elevations for the entire unit were recorded, and excavations were begun in a series of arbitrary $15-\mathrm{cm}$ levels (the $19772-\mathrm{m}^{2}$ units was also excavated in 15-cm levels) with the first level floor at $99.80 \mathrm{~m}$. The level number and the arbitrary elevation were recorded on each bag of excavated material.

Because of a strong creekward slope of the blufftop, the use of large arbitrary levels created some problems in interpretation. There were two steps of numbered levels: in the southwest corner, Level 1 was from the surface to 99.80; while in the northeast, Level 1 was from the surface to 99.65. The total volume of each first level is also somewhat variable. Under the circumstances, no other excavation possibility was considered useful, and the problems were generally mitigated by the use of exact horizontal and vertical provenience where necessary.

Excavation was primarily by shovel, and trowels and more careful excavation procedures were used as required. The levels were usually taken out in 
vertical stages so that even material missed in the excavation could be given àn approximate vertical provenience within the $15-\mathrm{cm}$ unit.

A11 matrix was water screened through $1 / 4$-inch hardware cloth screens, with all collected material remaining in the screens bagged by unit and level. The material from one unit in each level (primarily N96 E97) was additionally screened through $1 / 8$-inch mesh in an attempt to watch for finer artifactual material and faunal material that might be lost from the 1/4-inch screen.

Soil samples were taken from selected locations within the excavation area in case laboratory time allowed the use of very fine screen or flotation recovery techniques to check for extra fine faunal and floral materials. In addition to the soil samples, a series of special samples was taken from $5-\mathrm{cm}$ intervals along the west profile near the southwest corner to be used for the identifications of phytoliths, a technique which proved useful in identifying the paleoenvironment at $41 \mathrm{GD} 21$ and $41 \mathrm{GD} 21 \mathrm{~A}$ (Fox 1979).

During the excavation, a careful watch was kept for charcoal that might be used for radiocarbon dates on the occupations at the site. Only a few isolated flecks were observed; they were not in apparent association with any of the prehistoric features, with the exception of a charcoal sample recovered from Unit 2, which is described below.

During the excavations, careful notes on all levels excavated and all suspected features were taken; photographs and scale drawings were made as needed. Two profile drawings were made of the main excavated unit, and a sketch profile (using transit control for shots on artifacts in situ and a minimum number of stratum control shots) was completed for the bluff.

In addition to the main excavation unit described above, a second $1-m^{2}$ unit was excavated to a depth of approximately $15 \mathrm{~cm}$ on a hard sand ledge at the base of the bluff. This unit was oriented to the slope of the bluff rather than the grid orientation, and because of the height of the bluff it was not located exactly within the grid system. The west corner is located at N114.4 E97.5. Material from this unit was only partially screened; the indurated nature of the sand made it almost impossible to screen. No cultural materials were recovered from the screened matrix, and the remainder of the unscreened backdirt was used to backfill the unit to protect the hearth left exposed.

\section{THE EXCAVATIONS}

The main excavation unit at the site was a $12-\mathrm{m}^{2}$ area which was carried down to a maximum depth of $2.54 \mathrm{~m}$ below the surface at the southwest corner. Only two of the $1-m^{2}$ units were excavated this deeply; the majority of the remaining units were near a meter deep. The approximate total volume of excavated material was just over $15 \mathrm{~m}^{3}$. Cultural materials (i.e., chipped stone and faunal remains) were recovered in varying quantities from the entire excavation unit. Beginning with the third level $(30-45 \mathrm{~cm})$ there was a general trend of decreasing amounts of artifactual material with depth. 
Within the excavation unit, a stratification of cultural materials was noted. Unfortunately, because of the surface slope and the relatively large levels, apparent cultural zones do not show clearly in the level counts of excavated material. Time constraints did not allow any option for smaller vertical levels, and the disadvantage of digging arbitrary units with a sloping wall floor outweighed the advantages. Therefore, careful control was maintained during excavation; artifacts found in situ were mapped in place as much as possible with transit elevations. In situ recovery of cultural material and the recognition of occupational floors of cultural strata during excavation was stressed.

Two distinct occupation floors (one of which was later subdivided on the basis of a bimodal trend in the recorded elevations) and several potential ones were recognized in the excavations. Laboratory study of the recorded artifact proveniences supports the field identification of these floors. Some of the characteristics of these floors are detailed in subsequent sections.

Artifactual material was recovered throughout the unit but, as mentioned above, in decreasing quantities toward the bottom. The lowest grouping of artifacts, which indicated in situ deposition, occurred near and possibly just below Feature 2 at just above a meter and a half below the surface. The function of this feature was not determined, but it was a clear nonrandom cluster of larger unmodified stone and chipping debris. Below this, the amount of artifactual material continued to drop; no clustering of elements was noted. It is possible that these lower materials were introduced from above by bioturbation (soil disturbance from the movements of burrowing animals, insects, and plant roots).

Final profiles of the south and west walls of the main unit (Figs. 5, 6) show the soil zones encountered in the excavation. It should be emphasized that the distinctions between zones was not as clear in the field as the profile would seem to indicate; the strata tended to grade into one another. Separation of the upper part of Zone 4 into three subzones in the south wall profile was made on the basis of slight changes in texture and the presence of a stratum with a relatively high concentration of gastropods. This zonation could not be distinguished in the west wall.

Zones $5 \mathrm{a}-\mathrm{c}$ in the main excavation unit profile are thought to be primarily aeolian in origin. It is within these zones that the majority of cultural material occurs. Zones $5 a$ and $5 b$ are separated on the basis of slight color and textural changes; the dividing line between the two seems to follow the line of Occupation Floor II. It is possible that the textural differences are due to compacting, which occurred during the Floor II occupation. However, no such changes were noticed at the Floor I level, which seemed to be a longer or at least a more intense occupation. Zone $5 \mathrm{c}$ is the same soil matrix as Zone $5 b$, but the former has no apparent cultural material showing in the profile and may represent sediments accumulated since the last occupation at the site. Zone 5d was easily recognized as a compacted layer of backdirt from the 1977 testing at the site.

Although the natural stratigraphy at the site is vague and only generally related to cultural materials, the evidence from the excavation suggests that 


\section{Berger Bluff Site \\ 41GD30A}

SOUTH WALL PROFILE

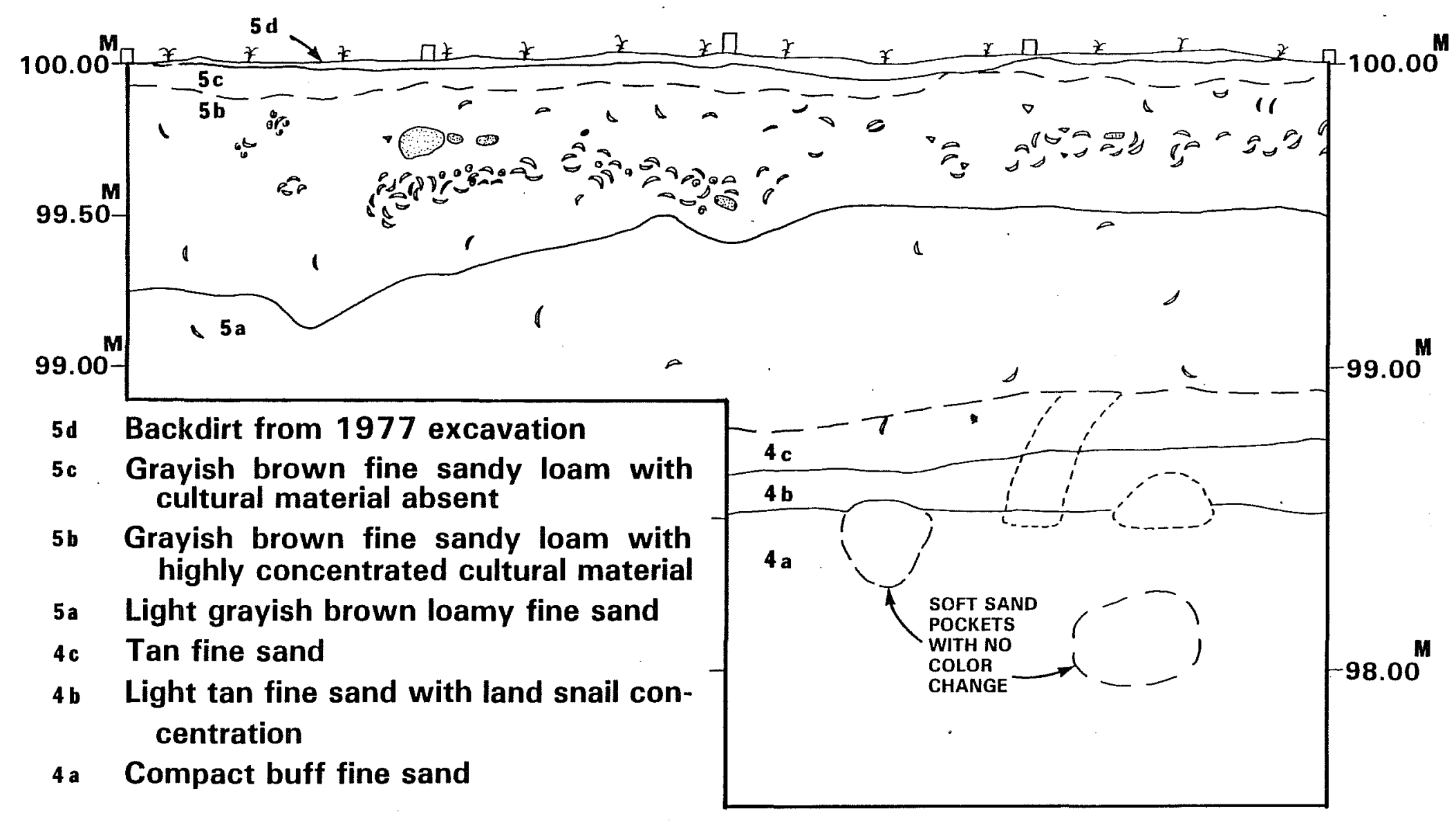

\section{LEGEND:}

$\triangle$ Flint $\triangle$ Mussel $\circlearrowleft$ Snail Sandstone Root or rodent disturbance Charcoal

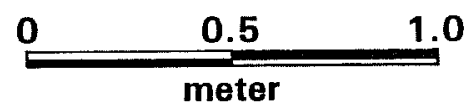




\section{Berger Bluff Site}

41GD30A

WEST WALL PROFILE

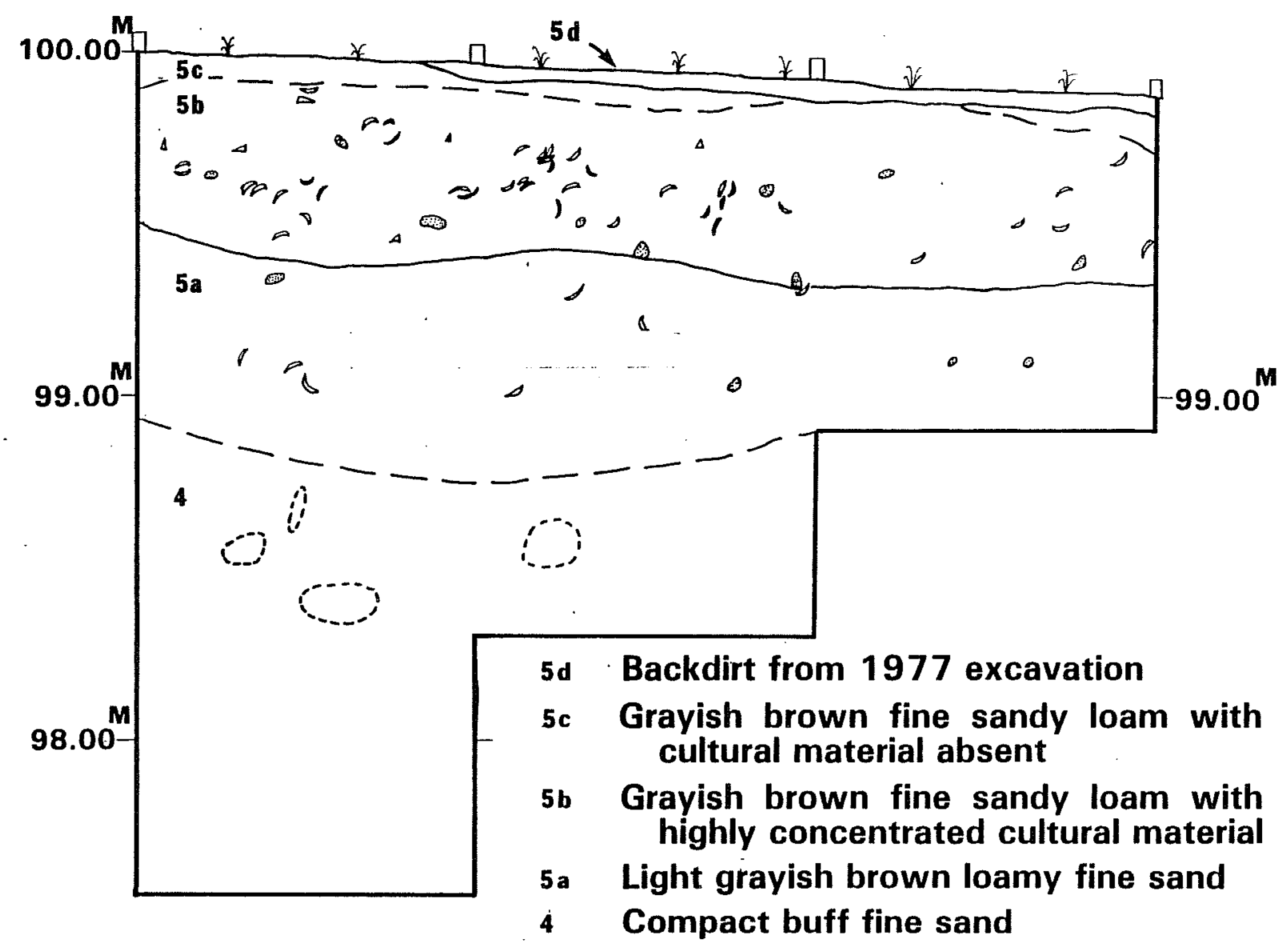

LEGEND:

$\triangle$ Flint $\triangle$ Mussel $\oplus$ Snail Sandstone ORoot or rodent disturbance Charcoal

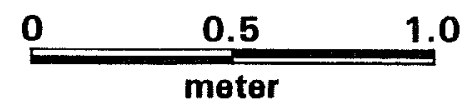

Figure 6. West wall Profile, 41 GD 30A. 
the layering of cultural deposits was minimally disturbed. The existence of definable cultural strata, the few features still intact, and numerous flat lying and apparently undisturbed artifacts all support the lack of major disturbances. In addition, there are essentially no inconsistencies in comparing the vertical record of artifacts with artifact sequences at other sites from central and southern Texas (the notable exception is the Marhiss point found at the same level as Late Prehistoric materials; its position and relation to the immediate surrounding materials argue that it was deposited contemporaneously with these later materials). In this respect, the Berger Bluff site stands in direct contrast to many of the sites in the reservoir area, which have been virtually destroyed by root disturbances and animal activity (Fox, Black, and James 1979).

\section{THE FEATURES}

Two features were recorded during the 1977 test excavations at the site (Fox, Black, and James 1979:37). Both were small clusters of burned sandstone which contained no charcoal, ash, or stained matrix. Although they could not be clearly identified as hearths, it is interesting to note that both contain more tightly clustered and larger rocks than any of the features identified in the 1979 excavations, with the exception of Feature 4. Feature 1 (1977) occurred at almost the level of 0ccupation Floor II and is probably related to the relatively dense cluster of material immediately to the south in $N 99$ E99 (where Fox, Black, and James [1979:37] predict it should be). Feature 2 occurs between Occupation Floor II and the Morhiss phase occupations.

During the 1979 excavations, five features were identified and numbered. A few dispersed clusters of smal1 sandstone chunks were of doubtful origin and were identified as features, although they are possibly the result of aboriginal activities at the site. Several large rocks in the corner of N97 E96 may have formed the periphery of a stone hearth to the south, but time did not permit further excavation. None of the features from the main excavation unit contained potentially datable amounts of charcoal. Feature 5 in excavation Unit 2 provided the only chronometric date from the site (see page 88 ). The features lacked associated diagnostic projectile points, al though several had peripherally associated diagnostics which appeared consistently distributed.

Feature 1 (Figs. 7 and 8)

When originally uncovered it was suspected that a few burned rocks in N99 E98 and N99 E97 might be part of a larger rock hearth. Further excavation showed no sign of a rock cluster or of burned earth or charcoal, but did reveal a large concentration of artifacts lying flat at approximately the same level. Most of the material occurred within a 5-10 cm elevation along a surface which appeared to closely parallel the original surface. The most common item from this feature was badly preserved mussel shell, which was difficult to retain in place during excavation; also on the floor were burned sandstone, chert cobbles, flakes, and biface fragments. 
This feature has the strongest association with a diagnostic projectile point: a Dare point at the periphery at the same elevation in N99 E98 and a large Morhiss point at approximately this elevation in the northwest corner of N97 E96. Note that these two points were found at different absolute elevations (the Dare at 99.50 and the Morhiss at 99.65), but both at the approximate elevation of the occupation debris and at similar elevations relative to the surface.

The total extent of this feature was somewhat unclear. An extremely dense cluster of material occurred in N99 E97 and N98 E97, which continued partially into al1 the surrounding units, but appeared to drop off in density away from this central cluster. Material thought to be associated with a short-term prehistoric occupation was found in small quantities throughout the entire excavation unit.

Feature 1 is directly associated with 0ccupation Floor I, which can be distinguished from the other floors by the density of material, especially mussel shel1. The feature itself can be interpreted as a midden or cluster of occupation debris within which must have been an early Late Prehistoric (Austin phase) campsite. No hearths or other distinct rock clusters occurred at this level, and no charcoal was available for dating. The mixed nature of the debris within the features suggests that it was either dumped here without any patterning or that whatever patterning might have existed within the cluster was disturbed by subsequent campsite activities.

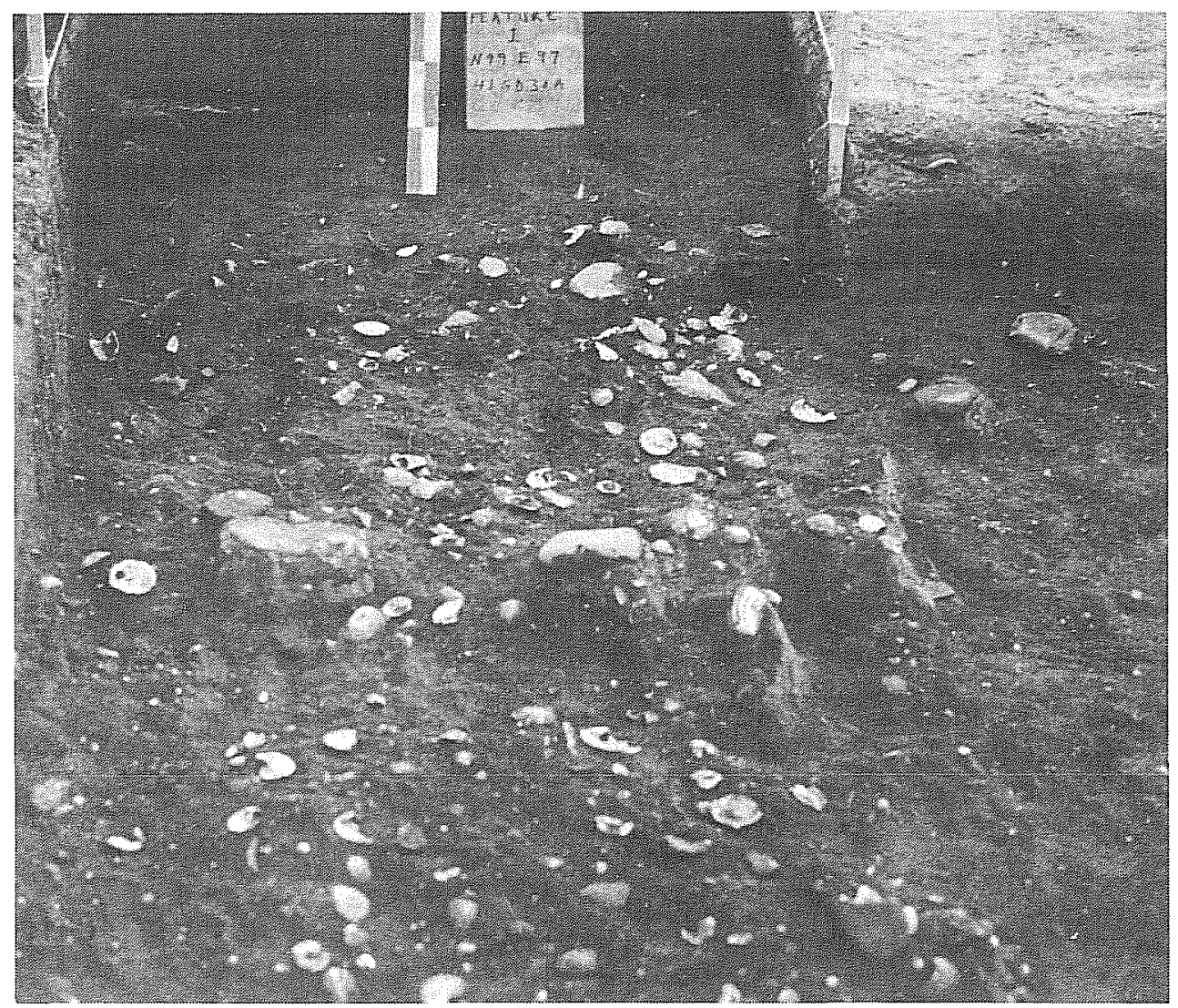

Figure 7. Views of Excavation Unit, 41 GO 30A. Looking north at midden, Feature 1 . 


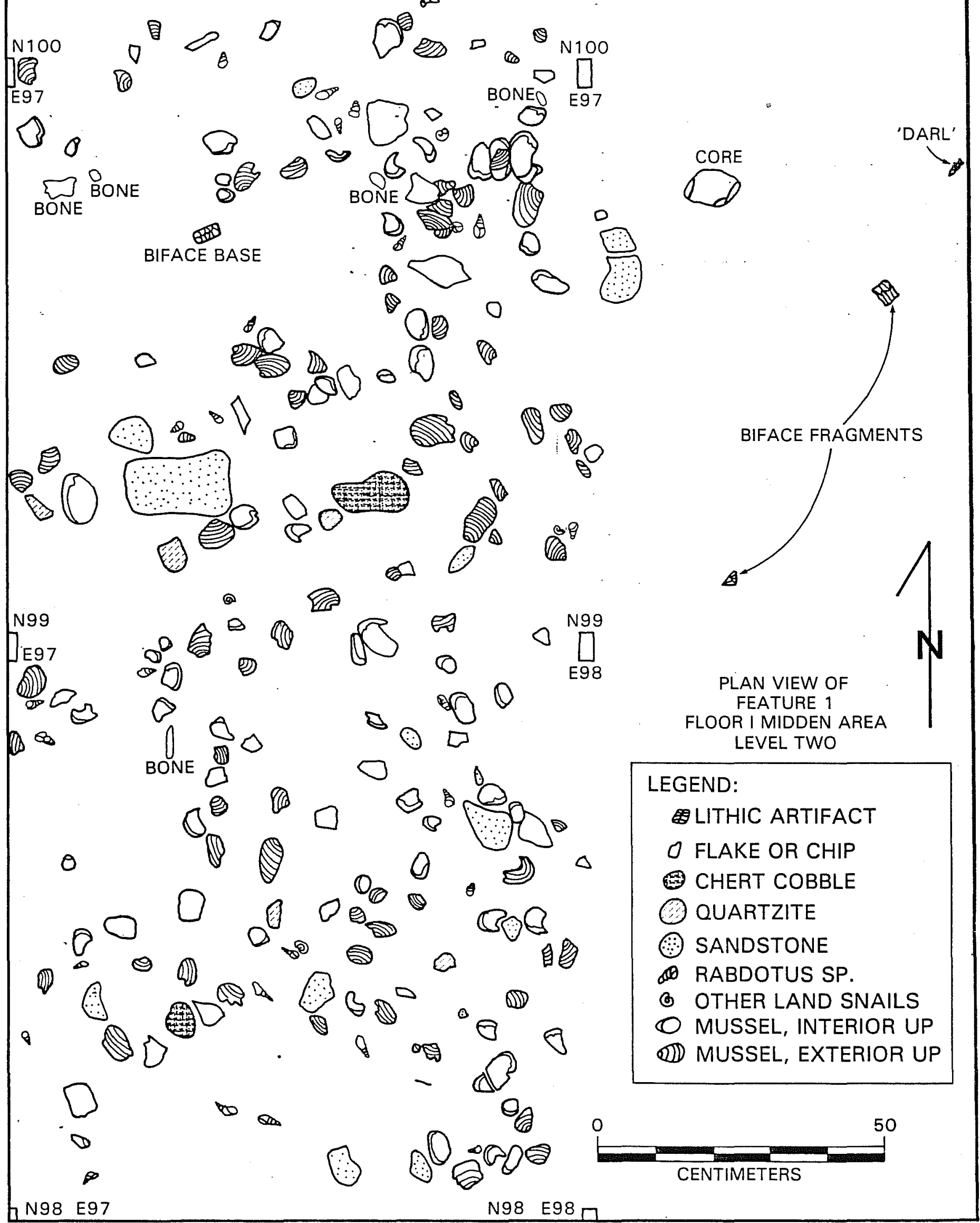

Figure 8. Plan Map of Austin Phase Midden, Feature 1. 
Feature 2 (

This feature was originally suspected as being a hearth during excavation, because of the presence of small flecks of charcoal in the surrounding matrix. However, no distinct cluster of burned rock nor concentration of burned earth or charcoal was encountered. This feature is comprised of five burned sandstone rocks of various sizes, three chert nodules, two small chert pebbles (one thermally altered and the other possibly a hammerstone), a large flake, and several smaller flakes. This feature lies $1.3 \mathrm{~m}$ below the ground surface at an arbitrary elevation of $98.6 \mathrm{~m}$.

This is the deepest feature recognized, and it is thought to relate to the deepest actual living floor in the upper occupation zone. Although cultural material was found below this level, there was an abrupt drop in density. This cultural level is at the base of and below the darker organic stained upper soil horizon (Zone $5 \mathrm{a}$ ). No diagnostic projectile points were recovered from this level of the excavation.

The small cluster of chert nodules at the west end of the feature suggests that it is undisturbed by later occupation or natural forces. However, the charcoal flecks throughout the two units also suggest that an earlier or a contemporaneous hearth had been disturbed in approximately the same locale. The feature is interpreted as unused raw material from a chipping or tool making event.

Feature 3 (Fig. 9,b)

This feature was originally discovered by observation of the profile after excavation of the adjacent unit. During excavation, a concentration of burned rocks and flint was noted near the bottom of Level 5 in N97 E97 and N97 E98, and the possibility of a hearth was mentioned in the notes. No differences in soil color or texture were noted during excavation, but afterwards a sma 11 pitlike depression filled with darker stained soil was observed. This pit cannot be clearly associated with the rocks found in the adjacent unit, but its shape and darker color definitely suggest that it is a cultural feature.

No diagnostic artifacts were recovered in clear association with this feature. From the surrounding units and possibly associated are the distal end of a large thin biface and an unfinished ovate biface. Although 0ccupation Floor II can only be tentatively traced into these squares, it appears that this pit would have been dug from a surface contemporaneous with Occupation Floor IIB.

This feature has a rounded basin-shaped profile with an approximate depth between $10-15 \mathrm{~cm}$. East-west extent is about $50 \mathrm{~cm}$.

This feature in association with a cultural floor and with a concentrated area of cultural materials argues for its inclusion as a pit excavated for some purpose during aboriginal times. The dark-stained matrix suggests the presence of organic material, possibly charcoal or decayed vegetal matter, and suggests that it was a fire or storage pit used by the 0ccupation Floor I inhabitants. 


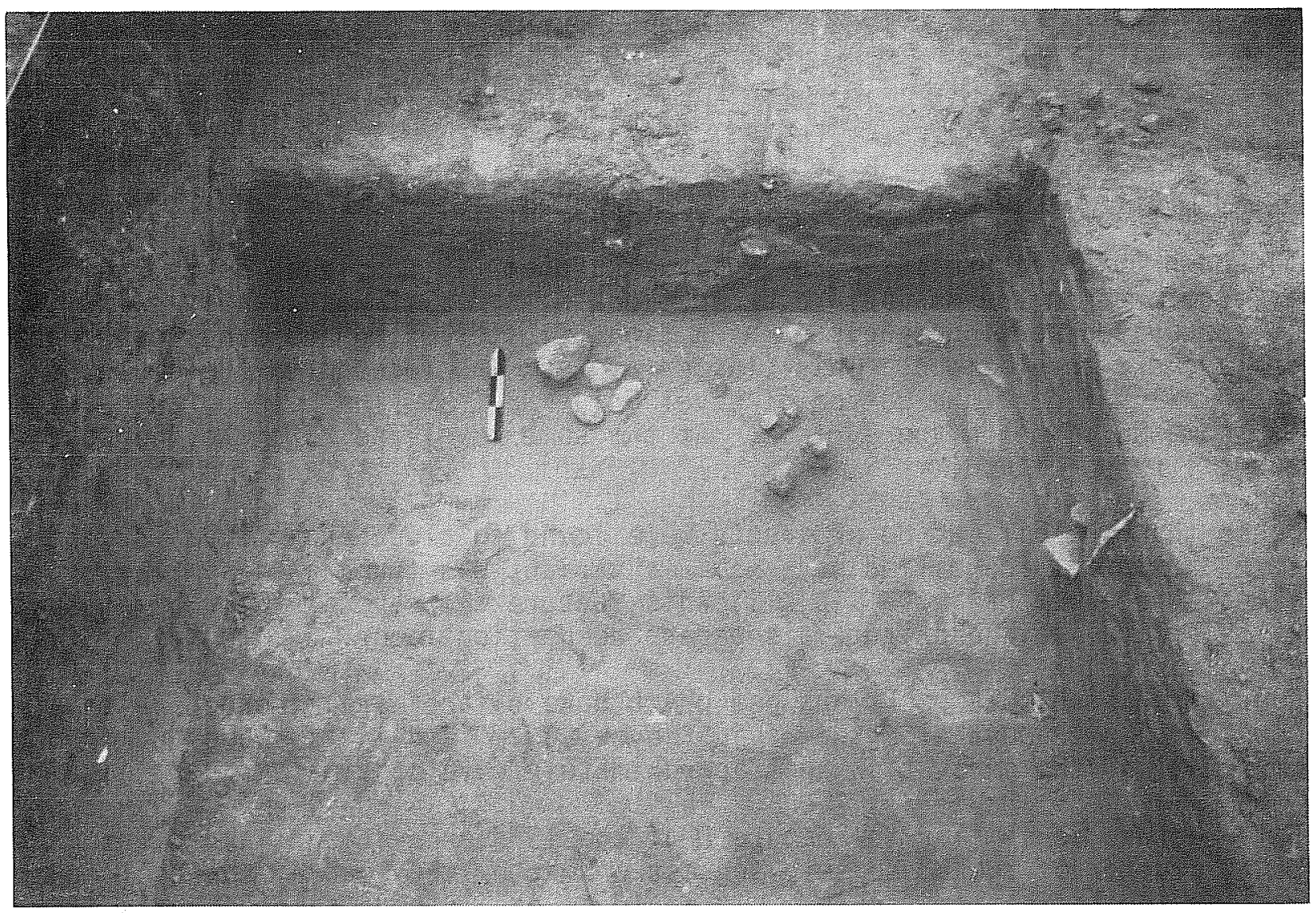

a

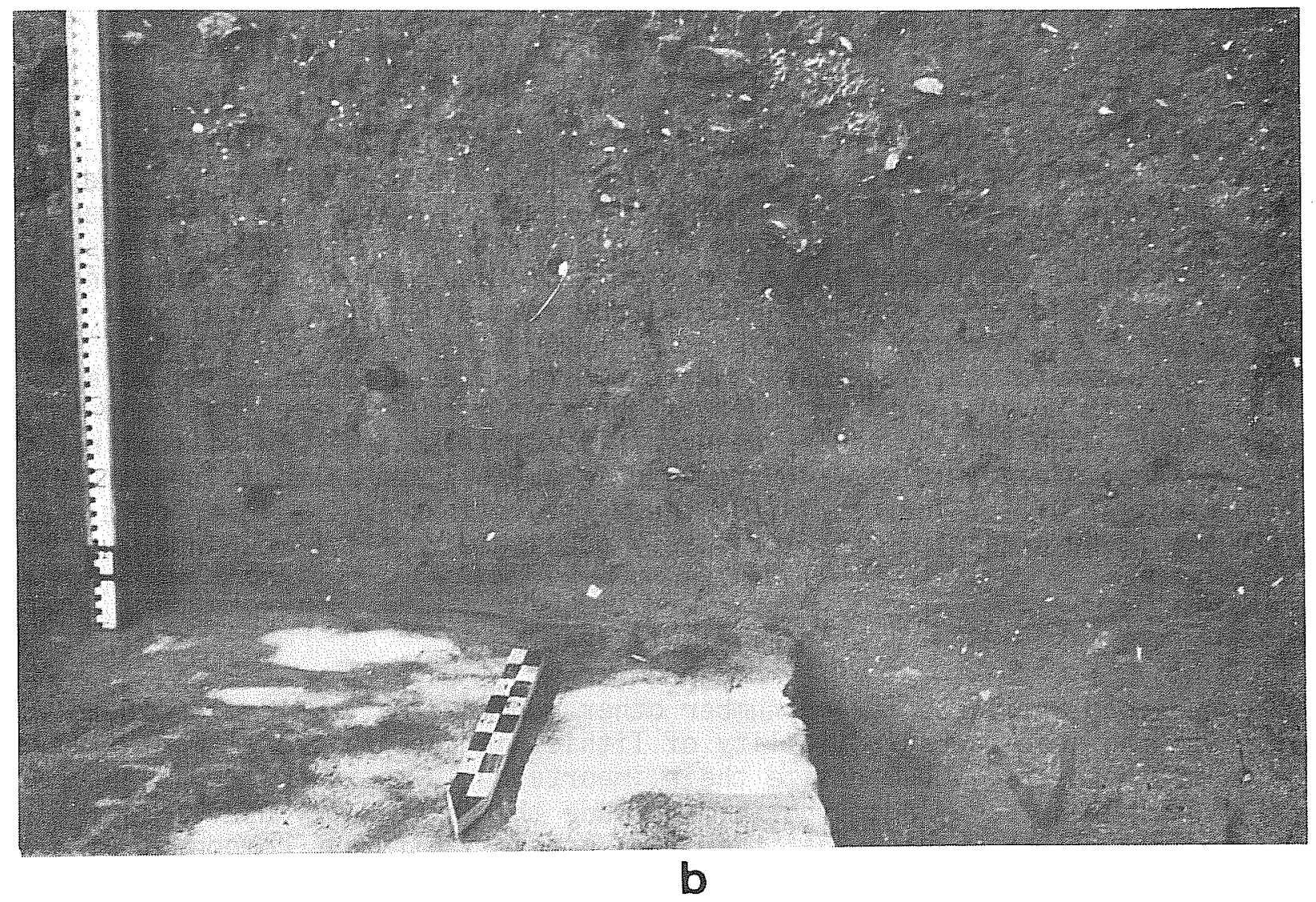

Figure 9. Views of Subsurface Features 2 and $3 . \quad$ a, Feature 2 is the deepest feature, at 1.30 inches below the surface; b, Feature 3 is a possible aboriginal pit in Occupation Floor II, exposed in profile. 
Feature 4 (Fig. 10,a)

Although this feature was never fully excavated (it was found in the wall below a large tree on the day before excavations ceased), it was clearly cultural. The excavated portion consisted of a tight cluster of burned sandstone cobbles and a chert core biface. This cluster of rock was located in the center of the east wall and near the bottom of Level 6 in N98 E99. The base of the cluster lay some $80 \mathrm{~cm}$ below the surface. At the same level and $25 \mathrm{~cm}$ to the west was a small thick biface.

Other than the biface, no artifacts were found in close proximity. A contracting stem dart point identified as a Morhiss variant was found at a similar depth almost three meters away. In a11, this feature and several thick bifaces found at this level may constitute a separate occupation floor.

Four large sandstone rocks and one chert core biface were recorded in this cluster. North-south length was just over $20 \mathrm{~cm}$, and it extended out from the east wall of the excavation unit approximately five centimeters.

This feature is similar to Feature 2 of the 1977 excavations, and although the tight cluster of rocks seems to suggest a hearth, the lack of charcoal makes such an identification tenuous. It could as easily be a pile of rocks from clearing a dwelling floor or a weight used to anchor a skin or pole.

\section{Feature 5 (Fig. 11)}

In late June 1979, smal1 bits of charcoal were noticed eroding from an erosional bench about $7.5 \mathrm{~m}$ below the blufftop. A small hearth or fired surface was buried in the sediments, now designated Feature $5 . A 1-\mathrm{m}^{2}$ unit oriented with the slope of the bench surface and not integrated with the grid system was laid out around the hearth and designated Unit 2. Excavation of this unit produced a radiocarbon sample $(T X-3569)$ and remains of some microfauna.

Additional excavations in these lower deposits, funded by the GBRA, were undertaken in November and December of the same year and were continued through Apri1 1980, when filling of the reservoir made it necessary to discontinue the excavations. Feature 5 was then removed in a block and taken to the archaeology laboratory at UTSA. The results of these excavations in the lower part of the site are to be presented in a separately published report (Brown n.d.).

\section{LITHIC ARTIFACTS}

Chipped stone artifacts far outnumber other modified materials from the site. Although the near indestructibility of lithics in a depositional context certainly tends to overemphasize their importance in the prehistoric technological system, that same indestructibility made them especially useful as tools. It is difficult to imagine that they were not a significant component of prehistoric material culture. Whatever their significance, they are potentially important to the archaeologist as indicators of the prehistoric culture. For this reason, lithics collected at the site are treated in some detail. 


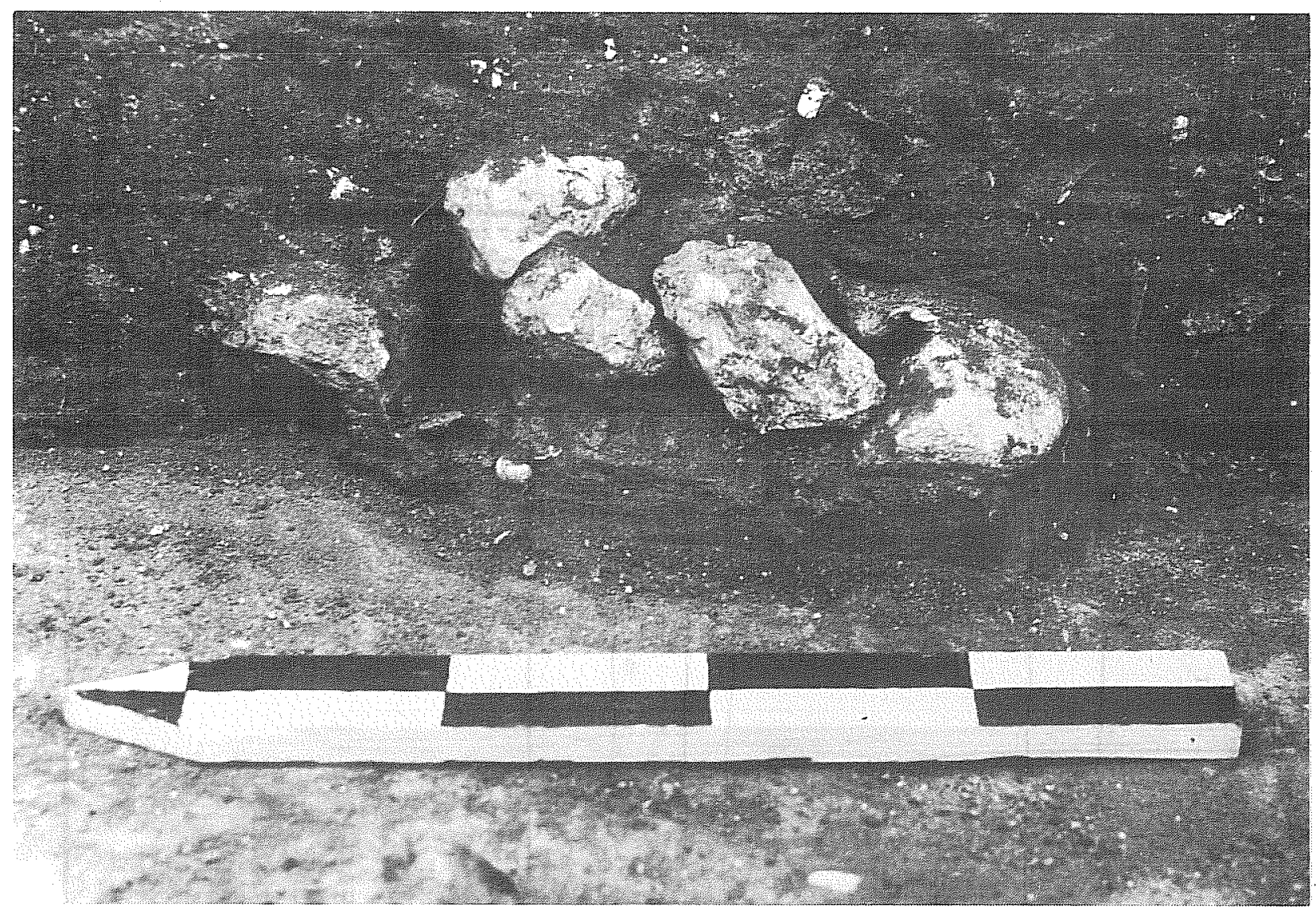

a

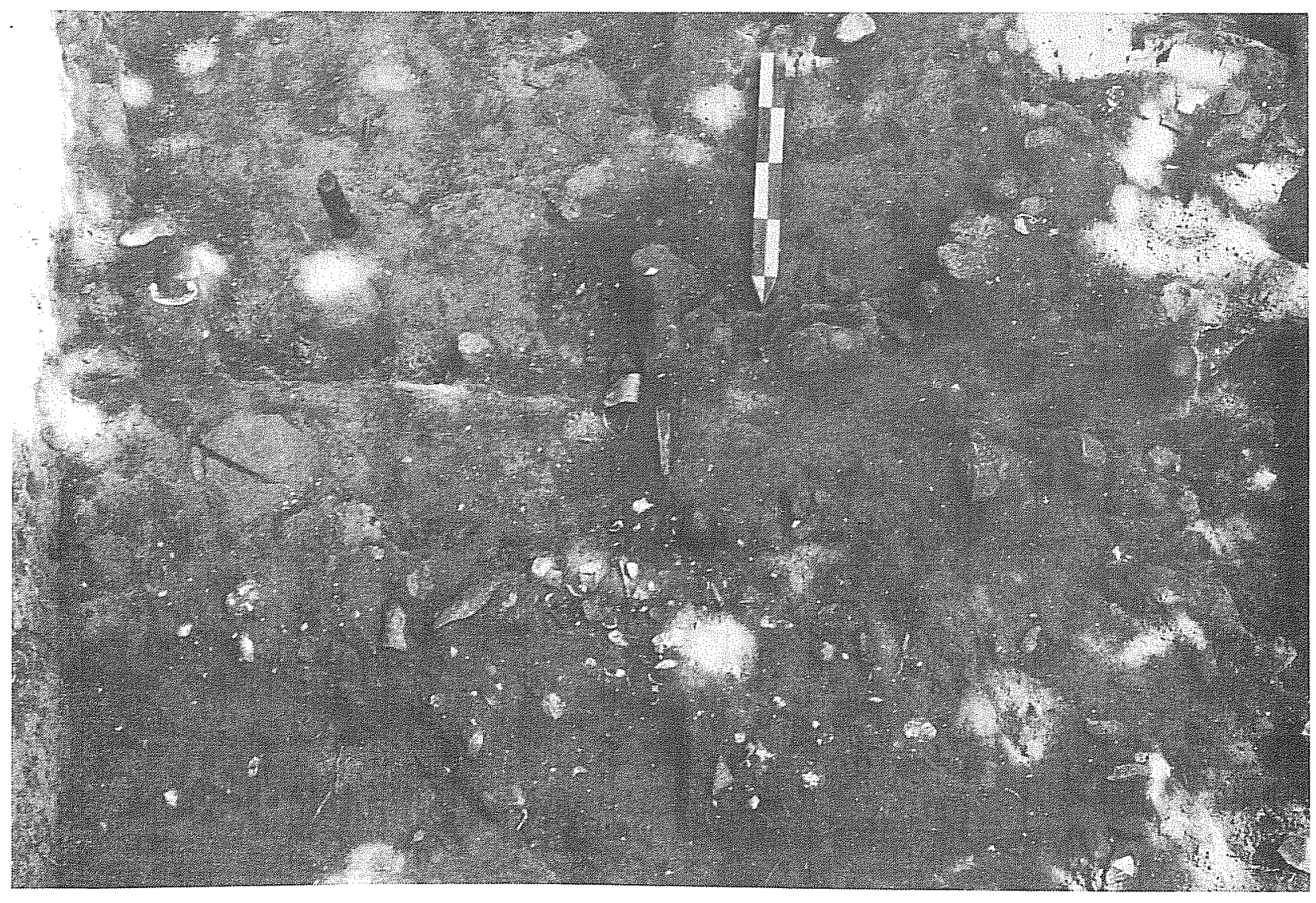

Figure 10. Views of Subsurface Feature 4 and Occupation Floor II. a, Feature 4 in east wall of excavation unit; b, Occupation Floor II. 


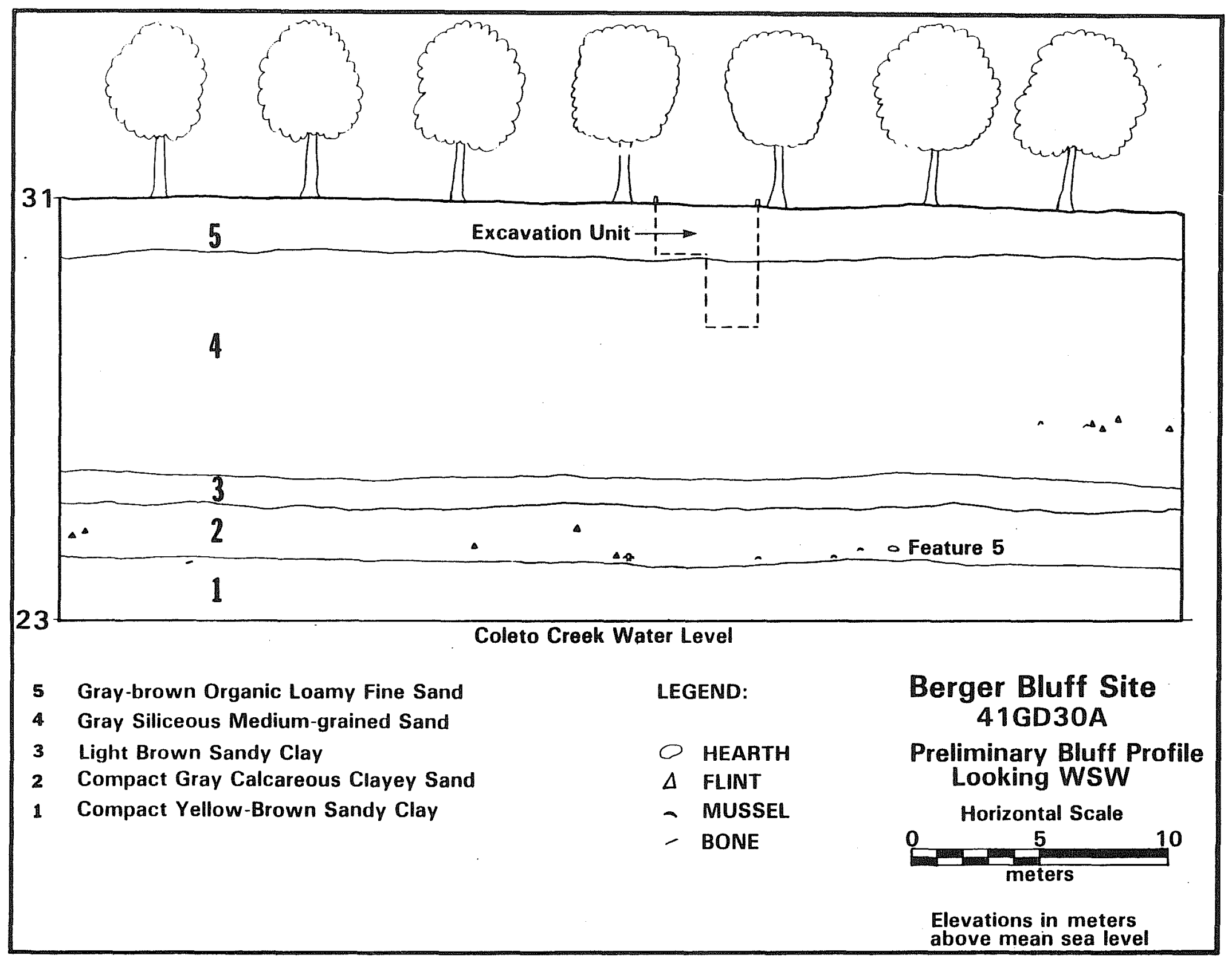

Figure 11. Profile of Berger Bluff. 
Material sources for stone tools occur now in several places along Coleto Creek (Fox, Black, and James 1979:41), and in many places the creek itself is an excellent source. At the Berger Bluff site, one has only to cross the creek to find numerous small cobbles strewn along the bank. And just $200 \mathrm{~m}$ upstream is 41 GD 28, a 1ithic workshop site which contains many large crude bifaces and cores, as well as unworked chert cobbles. The chert gravels from these sources may have eroded from basal exposures of the early Holocene-late Pleistocene terrace system of which the bluff at 41 GD 30 is a part.

A model for the production of chipped stone tools was described and illustrated in the report of the survey of the proposed Cuero I Reservoir $32 \mathrm{~km}$ to the north of the Coleto Creek area (Fox et al. 1974:24ff and Fig. 8). This model accurately reflects the production of stone tools at the Berger Bluff site and is used here with only slight modifications. One difference is that thick and thin bifaces are further divided into stages of the reduction process, a division used elsewhere with some success (Skinner 1971; Skelton 1977; Patterson 1977; Sharrock 1966). The model basically involves the reduction of a chert cobble or of a flake struck from a cobble into a tool by the removal of a number of flakes. Depending upon the type of tool needed, the form of the final tool and the amount and kind of waste flakes removed will vary. Archaeologists often assume (although rarely stated) that tool forms are nonrandom; that not only are certain forms intentionally produced, but that they are closely linked with function. It follows then that the technological process is also influenced by function (as well as possible nonfunctional cultural attributes such as style).

A basic technofunctional division separates the categories of chipped stone described below. The first, including cores and flakes, is made of material assumed to have been discarded during tool manufacture and never intended for use as a tool. With the exception of those cores that may have been intended as bifaces, but were rejected after only a few flakes were removed, and those flakes (and cores) which were utilized without leaving visible signs of wear, these categories are fairly accurate. The second group includes finished and unfinished tools.

Two major strategies of 1 ithic technology are represented in the lower Texas coastal area: the core tool and flake tool industries (Hester 1975:215). In the former, selected flakes from the core become the tools with little or no subsequent modification. The presence of both these reduction strategies is immediately apparent in the coleto Creek material. In order to detect possible temporal variation in the importance of these two industries, an attempt has been made in the analysis to separate those cores which were intended for the production of flake tools and those which are bifacial failures. This is not always possible, especially with cobbles with but few flakes removed, and it is not inconceivable that a given core could have served both purposes. Theoretically, however, the distinction between cores and core-bifaces should accurately reflect this distinction.

In the following section on the lithics from the Berger Bluff site, the materials from both the 1977 and 1979 excavations have been combined to give a broader picture of the overall lithic technology at the site (the exceptions are flake debitage and utilized flakes). Exact spatial and temporal provenience is detailed in the tables for each major artifact class. 
Cores (83 specimens)

A core is a chert cobble from which one or more flakes has been removed with the intention of producing a tool. Cores are assumed to be primarily material sources for flake tool products, although obviously some early stage bifacial cores may be included.

Cores are usually divided on the basis of their platform type and the orientation of the flake removals (Hester 1975:215-217; Gunn and Mahula 1977:152157; Montgomery 1978:63). The basic division between cortex and prepared platform cores used in the Coleto survey report (Fox, Black, and James 1979) is preserved here with the addition of various subdivisions reflecting more specific platform types and flake orientations. The breakdown of the 83 specimens is shown in Table 2. Small sample size within the categories precludes any definite statement, but the distribution appears to be relatively even. Group percentages are broken down by level in Table 3.

Cortex Platform Cores (10 specimens)

Flake removal from these cores are from natural cortex platforms only. They represent $12.0 \%$ of the entire sample of cores from $41 \mathrm{GD} 30 \mathrm{~A}$. Only one shows signs of thermal alteration.

\section{Group 1: Tested Cabbles (3 specimens)}

Each of these three specimens has one or two flake removals, and it is assumed that they were subsequently rejected for some deficiency in the material. They represent $3.6 \%$ of the total sample of cores and $30.0 \%$ of the cortex platform cores.

\section{Group 2: Multidirectional (7 specimens)}

Each of these cores has more than two removals with various combinations of flake orientation. Some may have been abandoned from inability to prepare an adequate decorticate platform. One is made from a split cobble or a large primary flake created by splitting a cobble down its long axis and could have been intended for bifacial reduction. One specimen has been thermaliy altered. They represent $8.4 \%$ of the total sample of cores and $70.0 \%$ of the cortex platform cores.

\section{Decorticate Prepared Platform Cores (68 specimens)}

These cores have one or more flake removals from a decorticate or prepared platform. Some have subsequent cortex platform removals as well. Nine show signs of thermal alteration. As a group, they represent $82.0 \%$ of the total sample of cores.

\section{Group 1: Single Facet Unidirectional Cores (12 specimens)}

This group is distinguished by the use of a single flake removal as a platform for the removal of a number of secondary and small tertiary flakes. One 
TABLE 2. CORES BY LEVEL

\begin{tabular}{|c|c|c|c|c|c|c|c|c|c|}
\hline \multirow[b]{2}{*}{ Leve1. } & \multicolumn{3}{|c|}{ Cortex Platform } & \multicolumn{5}{|c|}{ Decorticate Platform } & \multirow[b]{2}{*}{ Totals by Level } \\
\hline & Group 1 & Group 2 & Total & Group 1 & Group 2 & Group 3 & Group 4 & Total & \\
\hline 1 & & & & & & & 1 & 1 & 1 \\
\hline 2 & & 2 & 2 & $2(1)$ & $3(1)$ & 1 & $2(1)$ & $8(3)$ & $10(3)$ \\
\hline 3 & 1 & 3 & 4 & $3(1)$ & $5(1)$ & $7(2)$ & $8(2)$ & $23(6)$ & $27(6)$ \\
\hline 4 & 1 & $1(1)$ & $2(1)$ & 3 & $6(1)$ & $5(1)$ & $7(1)$ & $21(3)$ & $23(4)$ \\
\hline 5 & & & & $3(1)$ & & 2 & $2(1)$ & $7(2)$ & $7(2)$ \\
\hline 6 & 1 & & 1 & & & & 1 & 1 & 2 \\
\hline 7 & & & & & 1 & 1 & 1 & 3 & 3 \\
\hline 8 & & & & & & 1 & & 1 & 1 \\
\hline 9 & & & & 1 & & & 1 & 2 & 2 \\
\hline 10 & & 1 & 1 & & & & 1 & 1 & 2 \\
\hline$\nabla$ & & & & & & & & & 5 \\
\hline $\begin{array}{l}\text { Group } \\
\text { Totals }\end{array}$ & 3 & $7(1)$ & $10(1)$ & $12(3)$ & $15(3)$ & $17(3)$ & $24(5)$ & $68(14)$ & $83(15)^{*}$ \\
\hline
\end{tabular}

$\nabla$ Nonprovenienced cores from miscellaneous surface collections at the site.

* Totals reflect cores from 1977 and 1979 excavations. Figures in parentheses are 1977 totals only. 
TABLE 3. CORE GROUP PERCENTAGES BY LEVEL

\begin{tabular}{|c|c|c|c|c|c|c|c|c|c|c|}
\hline \multirow[b]{2}{*}{ Level } & \multicolumn{3}{|c|}{ Cortex Platform } & \multicolumn{5}{|c|}{ Decorticate Platform } & \multirow[b]{2}{*}{ Misc. } & \multirow{2}{*}{$\begin{array}{l}\text { Percentage } \\
\text { (sample)* }\end{array}$} \\
\hline & Group 1 & Group 2 & Tota 1 & Group 1 & Group 2 & Group 3 & Group 4 & Total & & \\
\hline 1 & & & & & & & 100.0 & 100.0 & & $1.2(1)$ \\
\hline 2 & & 20.0 & 20.0 & 20.0 & 30.0 & 10.0 & 20.0 & 80.0 & & $12.1(10)$ \\
\hline 3 & 3.7 & 11.1 & 14.8 & 11.1 & 18.5 & 25.9 & 29.6 & 85.2 & & $32.5(27)$ \\
\hline 4 & 4.3 & 4.3 & 8.7 & 13.0 & 26.1 & 21.7 & 30.4 & 91.3 & & $27.7(23)$ \\
\hline 5 & & & & 42.9 & & 28.6 & 28.6 & 100.0 & & $8.4(7)$ \\
\hline 6 & 50.0 & 50.0 & & & & & 50.0 & 50.0 & & $2.4(2)$ \\
\hline 7 & & & & & 33.3 & 33.3 & 33.3 & 100.0 & & $3.6(3)$ \\
\hline 8 & & & & & & 100.0 & & 100.0 & & $1.2(1)$ \\
\hline 9 & & & & 50.0 & & & 50.0 & 100.0 & & $2.4(2)$ \\
\hline 10 & & 50.0 & 50.0 & & & & 50.0 & 50.0 & & $2.4(2)$ \\
\hline$\nabla$ & & & & & & & & & 100.0 & $6.0(5)$ \\
\hline Total** & 3.6 & 8.4 & 12.0 & 14.5 & 18.1 & 20.5 & 28.9 & 82.0 & 6.0 & $100.0(83)$ \\
\hline
\end{tabular}

* Percentage of total number of cores per level (sample size from "Totals by Level" from Table 2). ** Percentages computed from "Group Totals," Table 2.

$\nabla$ No provenience. 
specimen is a split cobble with a single removal from the dorsal face; the ventral face has traces of platform abrasion and subsequent removals. This specimen may be an initial stage core-biface. Four of these cores show edge grinding or crushing as platform preparation for subsequent removals. None are thermal1y altered. These 12 specimens constitute $14.5 \%$ of the total sample of cores and $17.6 \%$ of the decorticate platform cores.

\section{Group 2: Multifaceted Bidirectional Cores (15 specimens)}

This group consists of those cores which have secondary removals from the original single or multifaceted decorticate platform. It also includes two specimens which are definitely multifaceted, but these removals may have been for prior platform preparation. One specimen is a split cobble as described in Group 2 of the cortex platform cores above. Ten cores show sign of abrasion or crushing for platform preparation. Many are probably not suitable for further reduction, but five or six could easily be worked further. None are thermally altered. These specimens represent $18.1 \%$ of the total sample of cores and $22.1 \%$ of the decorticate platform cores.

\section{Group 3: Multidirectional Cores (19 specimens)}

These cores have flakes removed from more than one platform surface and range from simple extensions of the Group 2 cores to seemingly random-flaked examples. Three are thermally altered. Most are exhausted in the sense that the platforms have been effectively destroyed by the removals, and there is not a good angle left for further removal of flakes. Eight have crushed or ground or battered edges, which may indicate platform preparation. These 17 cores constitute $20.5 \%$ of al1 cores from the site and $25.0 \%$ of all the decorticate platform cores.

\section{Group 4: Core Fragments (24 specimens)}

These small fragments included small exhausted cores, as well as fragments broken from larger ones. Orientation of flake scars and platforms are generally impossible to trace, but all are essentially decorticate platforms. Six are thermally altered. These specimens comprise $28.9 \%$ of the total sample of cores and $35.3 \%$ of a 11 the decorticate platform cores.

\section{Flakes}

\section{Unmodified Flakes}

Due to the large number of unmodified flakes recovered in the excavation, analysis of the unmodified flake sample was impossible. Casual observation of the debitage from the Coleto Creek site does not clearly reveal any changes through time at the Berger B.luff site in the technology of lithic tool production. There may be, however, some changes in the color and grain of the chert materials used through time. There is, perhaps, also some variation in the number of thermally altered flakes present throughout the levels. Unfortunately, time restrictions did not allow any of these observations to be tested quantitatively in the laboratory. It appears possible that quantification of 
material type variables might yield as much or more information about cultural change at the site as the standard technological type category.

Lithic technology at the Berger Bluff site as viewed from the unmodified flake debitage holds no surprises. It is similar to the vast majority of Archaic and Late Prehistoric sites in central and the coastal plain of Texas. As mentioned in the introduction to this section, there appear to be at least two major technological approaches. The unmodified flakes from the site must represent both flakes struck from cores in the production of bifaces and rejected and unused flake blanks. The large number of thick bifaces and the relatively few confirmed examples of flake blank bifaces (undoubtedly many bifaces are from flakes, but the only unquestionable examples are among the arrow points and arrow point preforms) suggests that debitage accounts for the vast majority of unmodified flakes.

In the 1977 excavations at the site, the possible presence of a blade technology was noted in the analysis of lithic materials from the site (Stephen $L$. Black, personal communication 1977). Such a blade technology has been recognized in south Texas (Hester 1975) and along the Texas coast (Hester and Shafer 1975). During separation of the unmodified debitage, it became clear that there were a few true blades and a number of bladelike, rectangular and semiprismatic flakes in the sample. Time did not permit a separation in the unmodified flake sample, but for comparative purposes flakes and bladelike flakes were separated in the utilized flakes. There the bladelike flakes comprise $29 \%$ of the sample of 203 flakes. This is not considered a valid percentage for the entire flake sample, because it seems likely that bladelike flakes were chosen preferentially for use, although it is hardly the case that every blade is utilized. The most important observation with respect to the blade technology at the Berger Bluff site is that there are no blade cores present. Several cores have obvious blade removal scars, and the preparation for these removals might have been quite intentional; however, not a single instance of multiple blade removal was observed in the sample of 83 cores from the site.

\section{Utilized Flakes and Chips (217 specimens)}

This category includes flakes and chips which exhibit patterned edge alteration suggestive of utilization. Although it is recognized that noncultural factors can damage thin flake edges (Duffield 1970), it has been demonstrated that flakes utilized in short-term, single function plant processing activities may show no obvious wear damage (Shafer and Bryant 1977). Therefore, any study of utilized flakes is likely to be skewed by misidentification of a certain number of specimens.

The flakes used in the present study were selected on the basis of patterned edge damage. Many showed such obvious wear that they could not be mistaken; the others combined various useful identifiers such as unifacial wear, edge selection (damage not randomly or evenly spaced on 011 edges), full edge utilization (damage occurring on all or most of the logical working edge), and unevenly distributed degree (heaviest wear concentrated to the middle or end of a working edge). These criteria may have eliminated some of the naturally fractured specimens, but it seems probable that a large number of minimally utilized flakes have gone unnoticed. 
The sample we have examined includes those flakes and chips used in tasks, which produce rather pronounced alteration after a minimum number of uses (such as cutting bone or wood), as well as flakes that were kept and reused on less damaging tasks many times. No attempt has been made to segregate these two categories, but it is obvious from the sample that different degrees, if not different kinds of wear are combined.

These specimens were divided into five groups on the basis of the edge modified, and within each category, flake types are noted. In examining the utilized flakes, it became obvious that a large number of prismatic blades and bladelike flakes were utilized. These were also separated within each group. Tables 4 and 5 present a summary of the various types by group. Table 6 shows the distribution of utilized flakes by level. Table 7 shows a percentage distribution of flakes.

Group 1: Unilateral (76 specimens)

This is the largest group of modified flakes. Only one lateral edge shows signs of utilization.

Group 2: Two-Edged (44 specimens)

In this group, both lateral edges have been altered. A relatively high percentage of blades and bladelike flakes occurs in this group (Table 7).

Group 3: Distal/Lateral (17 specimens)

This group combines distal and unilateral edge modification. It is the least common of the five groups, and only a single bladelike flake is present in the 17 specimens.

Group 4: Distal (31 specimens)

These flakes are utilized on the distal end only.

Group 5: Multilateral (35 specimens)

Both lateral and the distal edges were utilized on these flakes and flake blades. Only one secondary or partially corticate blade is found in this group.

\section{Trimmed Flakes (21 specimens)}

Trimmed flakes are defined as flakes that have been intentionally modified. These pieces have one or more edges that have been chipped as a means of shaping, altering the edge angle, or resharpening a utilized flake. Although it could occasionally be difficult to tell between small retouch flakes and use-wear (Ma11ouf, Fox, and Briggs 1973:67), only those specimens which exhibit a fairly obvious retouch have been included.

The groups discussed below are based on the location of retouch (and subsequent utilization) with respect to the flake platform. An exception to this is the 
TABLE 4. UTILIZED FLAKES BY TYPE OF REMOVAL*

\begin{tabular}{|c|c|c|c|c|c|c|}
\hline \multirow[b]{2}{*}{ Type of Utilized Flake } & \multicolumn{5}{|c|}{ Type of Removal } & \multirow[b]{2}{*}{ Totals } \\
\hline & $\begin{array}{l}\text { Group } 1 \\
\text { Unilateral }\end{array}$ & $\begin{array}{l}\text { Group } 2 \\
\text { Two-edged }\end{array}$ & $\begin{array}{c}\text { Group } 3 \\
\text { Distal/Lateral }\end{array}$ & $\begin{array}{l}\text { Group } 4 \\
\text { Distal }\end{array}$ & $\begin{array}{l}\text { Group } 5 \\
\text { Multilateral }\end{array}$ & \\
\hline $\begin{array}{l}\text { Secondary flakes } \\
\text { Secondary blades }\end{array}$ & $\begin{array}{r}27 \\
5 \\
\end{array}$ & $\begin{array}{l}6 \\
6 \\
\end{array}$ & $\begin{array}{l}8 \\
0 \\
\end{array}$ & $\begin{array}{l}8 \\
3 \\
\end{array}$ & $\begin{array}{l}0 \\
1 \\
\end{array}$ & $\begin{array}{l}49 \\
15 \\
\end{array}$ \\
\hline Total secondary platforms & 32 & 12 & 8 & 11 & 1 & 64 \\
\hline $\begin{array}{l}\text { Interior flakes } \\
\text { Interior blades }\end{array}$ & $\begin{array}{l}14 \\
13 \\
\end{array}$ & $\begin{array}{r}12 \\
8 \\
\end{array}$ & $\begin{array}{l}4 \\
1 \\
\end{array}$ & $\begin{array}{l}9 \\
1 \\
\end{array}$ & $\begin{array}{r}17 \\
8 \\
\end{array}$ & $\begin{array}{l}56 \\
31 \\
\end{array}$ \\
\hline Total interior platforms & 27 & 20 & 5 & 10 & 25 & 87 \\
\hline TOTAL NUMBER OF PLATFORMS & 59 & 32 & 13 & 21 & 26 & 151 \\
\hline $\begin{array}{l}\text { Corticate chips } \\
\text { Corticate blade fragments }\end{array}$ & $\begin{array}{l}6 \\
0 \\
\end{array}$ & $\begin{array}{l}2 \\
1 \\
\end{array}$ & $\begin{array}{l}1 \\
0 \\
\end{array}$ & $\begin{array}{l}0 \\
0 \\
\end{array}$ & $\begin{array}{l}0 \\
0 \\
\end{array}$ & $\begin{array}{l}9 \\
1 \\
\end{array}$ \\
\hline Total corticate fragments & 6 & 3 & 1 & 0 & 0 & 10 \\
\hline $\begin{array}{l}\text { Decorticate chips } \\
\text { Decorticate blade fragments }\end{array}$ & $\begin{array}{l}6 \\
5 \\
\end{array}$ & $\begin{array}{l}8 \\
1 \\
\end{array}$ & $\begin{array}{l}3 \\
0 \\
\end{array}$ & $\begin{array}{l}9 \\
1 \\
\end{array}$ & $\begin{array}{l}5 \\
4 \\
\end{array}$ & $\begin{array}{l}31 \\
11 \\
\end{array}$ \\
\hline Total decorticate fragments & 11 & 9 & 3 & 10 & 9 & 42 \\
\hline TOTAL FRAGMENTS & 17 & 12 & 4 & 10 & 9 & 52 \\
\hline GROUP TOTALS & 76 & 44 & 17 & 31 & 35 & 203 \\
\hline
\end{tabular}

* This table includes materials from the 1979 excavations only; 14 unidentified chips are not included. 
TABLE 5. UTILIZED FLAKES BY TECHNOLOGICAL CATEGORY*

\begin{tabular}{|c|c|c|c|c|c|c|}
\hline \multirow[b]{2}{*}{ Artifact } & \multicolumn{5}{|c|}{ Technological Category } & \multirow[b]{2}{*}{ Total } \\
\hline & $\begin{array}{c}\text { Group } 1 \\
\text { Unilateral }\end{array}$ & $\begin{array}{l}\text { Group } 2 \\
\text { Two-Edged }\end{array}$ & $\begin{array}{c}\text { Group } 3 \\
\text { Distal/Lateral }\end{array}$ & $\begin{array}{l}\text { Group } 4 \\
\text { Distal }\end{array}$ & $\begin{array}{l}\text { Group } 5 \\
\text { Multilateral }\end{array}$ & \\
\hline $\begin{array}{l}\text { Flakes } \\
\text { Chips }\end{array}$ & $\begin{array}{l}41 \\
12 \\
\end{array}$ & $\begin{array}{l}18 \\
10 \\
\end{array}$ & $\begin{array}{r}12 \\
4 \\
\end{array}$ & $\begin{array}{r}17 \\
9 \\
\end{array}$ & $\begin{array}{r}17 \\
5 \\
\end{array}$ & $\begin{array}{r}105 \\
40 \\
\end{array}$ \\
\hline Total & 53 & 28 & 16 & 26 & 22 & 145 \\
\hline $\begin{array}{l}\text { Blades } \\
\text { Blade fragments }\end{array}$ & $\begin{array}{r}18 \\
5 \\
\end{array}$ & $\begin{array}{r}14 \\
2 \\
\end{array}$ & $\begin{array}{l}1 \\
0 \\
\end{array}$ & $\begin{array}{l}4 \\
1 \\
\end{array}$ & $\begin{array}{l}9 \\
4 \\
\end{array}$ & $\begin{array}{l}46 \\
12 \\
\end{array}$ \\
\hline Total Blades & 23 & 16 & 1 & 5 & 13 & 58 \\
\hline TOTAL & 76 & 44 & 17 & 31 & 35 & 203 \\
\hline
\end{tabular}

* This table includes materials from the 1979 excavations only; 14 unidentified chips are not included. 
TABLE 6. 1979 UTILIZED FLAKES BY GROUP AND LEVEL

\begin{tabular}{|c|c|c|c|c|c|c|c|c|c|c|c|c|c|c|c|c|c|c|c|c|}
\hline Level & $\begin{array}{r}\mathbf{G} \\
\text { Uni } \\
\text { BTades } \\
\end{array}$ & $\begin{array}{l}\text { roup } 1 \\
\text { lateral } \\
\text { Flakes } \\
\end{array}$ & Total & $\begin{array}{r}G \\
T W \\
\text { Blades } \\
\end{array}$ & $\begin{array}{l}\text { roup } 2 \\
\text { o-Edged } \\
\text { Flakes }\end{array}$ & Total & $\begin{array}{r}\mathrm{Gr} \\
\text { Distal } \\
\text { Blades }\end{array}$ & $\begin{array}{l}\text { roup } 3 \\
1 / \text { Later } \\
\text { Flakes }\end{array}$ & Total & Blades & $\begin{array}{l}\text { roup } 4 \\
\text { Distal } \\
\text { Flakes }\end{array}$ & Total & $\begin{array}{c}\text { Mult } \\
\text { Blades }\end{array}$ & $\begin{array}{l}\text { Group } 5 \\
\text { tilatera } \\
\text { Flakes }\end{array}$ & Tot & $\frac{\text { All }}{\text { Blades }}$ & 1 Groups & Total & $\begin{array}{l}\text { Uniden- } \\
\text { tified }\end{array}$ & $\begin{array}{l}\text { Percentage } \\
\text { (Sample) }\end{array}$ \\
\hline 1 & 7.1 & 35.7 & 42.8 & & 14.3 & 14.3 & & & & & & 21.4 & & & & 7.1 & 71.4 & 78.5 & 21.4 & $6.5(14)$ \\
\hline 2 & 6.8 & 20.5 & 27.3 & 6.8 & 19.2 & 26.0 & 1.4 & 9.6 & 11.0 & 2.7 & 6.8 & 9.5 & 5.5 & 11.0 & 16.5 & 23.3 & 67.1 & 90.4 & 9.6 & $33.6(73)$ \\
\hline 3 & 15.6 & 23.3 & 38.9 & 8.9 & 7.8 & 16.7 & & 8.9 & 8.9 & 1.1 & 10.0 & 11.1 & 7.8 & 13.3 & 21.1 & 33.3 & 63.3 & 96.6 & 3.3 & $41.5(90)$ \\
\hline 4 & 13.6 & 22.7 & 36.3 & 9.1 & 9.1 & 18.2 & & 4.5 & 4.5 & 4.5 & 22.7 & 27.2 & 9.1 & & 9.1 & 36.4 & 59.1 & 95.5 & 4.5 & $10.1(22)$ \\
\hline 5 & & & & & 14.3 & 14.3 & & & & 14.3 & 57.1 & 71.4 & & 14.3 & 14.3 & 14.3 & 85.7 & 100.0 & & $3.2(7)$ \\
\hline 6 & & 60.0 & 60.0 & & 20.0 & 20.0 & & & & & & & & 20.0 & 20.0 & & 100.0 & 100.0 & & $2.3(5)$ \\
\hline 7 & & & & 100.0 & & 100.0 & & & & & & & & & & 100.0 & & 100.0 & & $0.5(1)$ \\
\hline 8 & & 100.0 & 100.0 & & & & & & & & & & & & & & 100.0 & 100.0 & & $0.5(1)$ \\
\hline 9 & & 50.0 & 50.0 & & 50.0 & 50.0 & & & & & & & & & & & 100.0 & 100.0 & & $0.9(2)$ \\
\hline$\dagger$ & & 100.0 & 100.0 & & & & & * & & & & & & & & & 100.0 & 100.0 & & $0.9(2)$ \\
\hline TOTAL* & $* * 10.6$ & 24.4 & 35.0 & 7.4 & 12.9 & 20.3 & 0.5 & 7.4 & 7.9 & 2.3 & 12.0 & 14.3 & 6.0 & 10.1 & 16.1 & 26.7 & 66.8 & 93.5 & 6.5 & $100.0(21$ \\
\hline
\end{tabular}

* Percentage of total number of utilized flakes by level (sample size from "Totals by Level," Table 6).

+ Miscellaneous surface.

** Percentages computed from "Group Totals," Table 6. 
TABLE 7. 1979 UTILIZED FLAKE PERCENTAGES

\begin{tabular}{|c|c|c|c|c|c|c|c|c|c|c|c|c|c|c|c|c|c|c|c|c|}
\hline evel & $\frac{\text { Uni }}{\text { Blades }}$ & $\begin{array}{l}\text { roup } 1 \\
\text { latera } \\
\text { Flakes }\end{array}$ & 1 & $\frac{T}{\text { Blades }}$ & $\begin{array}{l}\text { Group } 2 \\
\text { wo-Edged } \\
\text { Flakes }\end{array}$ & Total & $\begin{array}{r}\text { G } \\
\text { Dista } \\
\text { Blades }\end{array}$ & $\begin{array}{l}\text { Group } 3 \\
\text { al/Later } \\
\text { Flakes }\end{array}$ & Total & $\begin{array}{r}\mathrm{Gr} \\
\mathrm{D} \\
\text { Blades }\end{array}$ & $\begin{array}{l}\text { oup } 4 \\
\text { istal } \\
\text { Flakes }\end{array}$ & Total & $\begin{array}{c}\mathrm{G} \\
\text { Mult } \\
\text { BTades }\end{array}$ & $\begin{array}{l}\text { Group } 5 \\
\text { tilatera } \\
\text { Flakes }\end{array}$ & al & $\frac{\mathrm{Al}}{\text { Blades }}$ & 11 Groups & Total & $\begin{array}{l}\text { Uniden- } \\
\text { tified }\end{array}$ & $\begin{array}{l}\text { Percentage } \\
\text { (Sample)* }\end{array}$ \\
\hline 1 & 7.1 & 35.7 & 42.8 & & 14.3 & 14.3 & & & & & & 21.4 & & & & 7.1 & 71.4 & 78.5 & 21.4 & $6.5(14)$ \\
\hline 2 & 6.8 & 20.5 & 27.3 & 6.8 & 19.2 & 26.0 & 1.4 & 9.6 & 11.0 & 2.7 & 6.8 & 9.5 & 5.5 & 11.0 & 16.5 & 23.3 & 67.1 & 90.4 & 9.6 & $33.6(73)$ \\
\hline 3 & 15.6 & 23.3 & 38.9 & 8.9 & 7.8 & 16.7 & & 8.9 & 8.9 & 1.1 & 10.0 & 11.1 & 7.8 & 13.3 & 21.1 & 33.3 & 6.3 .3 & 96.6 & 3.3 & $41.5(90)$ \\
\hline 4 & 13.6 & 22.7 & 36.3 & 9.1 & 9.1 & 18.2 & & 4.5 & 4.5 & 4.5 & 22.7 & 27.2 & 9.1 & & 9.1 & 36.4 & 59.1 & 95.5 & 4.5 & $10.1(22)$ \\
\hline 5 & & & & & 14.3 & 14.3 & & & & 14.3 & 57.1 & 71.4 & & 14.3 & 14.3 & 14.3 & 85.7 & 100.0 & & $3.2(7)$ \\
\hline 6 & & 60.0 & 60.0 & & 20.0 & 20.0 & & & & & & & & 20.0 & 20.0 & & 100.0 & 100.0 & & $2.3(5)$ \\
\hline 7 & & & & 100.0 & & 100.0 & & & & & & & & & & 100.0 & & 100.0 & & $0.5(1)$ \\
\hline 8 & & 100.0 & 100.0 & & & & & & & & & & & & & & 100.0 & 100.0 & & 0.5 (1) \\
\hline 9 & & 50.0 & 50.0 & & 50.0 & 50.0 & & & & & & & & & & & 100.0 & 100.0 & & $0.9(2)$ \\
\hline+ & & 100.0 & 100.0 & & & & & & & & & & & & & & 100.0 & 100.0 & & 0.9 (2) \\
\hline TAL & $* * 10.6$ & 24.4 & 35.0 & 7.4 & 12.9 & 20.3 & 0.5 & 7.4 & 7.9 & 2.3 & 12.0 & 14.3 & 6.0 & 10.1 & 16.1 & 26.7 & 66.8 & 93.5 & 6.5 & $100.0 \quad(21$ \\
\hline
\end{tabular}

* Percentage of total number of utilized flakes by level (sample size from "Totals by Level," Table 6).

+ Miscellaneous surface.

** Percentages computed from "Group Totals," Table 6. 
last group, which is treated separately because its distinct retouching is thought to indicate functional differences. One small fragment could not be placed in a group and is not included in the tables. Sample specimens for each group have been examined microscopically, but obvious wear is slight where it exists at all. The distribution of trimmed flakes by excavation level is shown in Table 8. Percentages are shown in Table 9.

Group 1: Distally Trimmed ( 3 specimens; Fig. 12,f)

All are made on secondary flakes and exhibit a slightly convex edge with squared ends and are unifacial. One shows slight lateral edge utilization. One is made on a very large flake and measures $9.2 \times 5.4 \mathrm{~cm}$ and is $2.4 \mathrm{~cm}$ thick just below the bulb. The other two are small and rectangular, both about $3 \times 4 \mathrm{~cm}$. None are thermally altered. These three specimens represent $14.3 \%$ of the sample of trimmed flakes.

TABLE 8. TRIMMED FLAKES BY LEVEL

\begin{tabular}{|c|c|c|c|c|c|c|}
\hline Level & $\begin{array}{l}\text { Group } 1 \\
\text { Distal } 1\end{array}$ & $\begin{array}{l}\text { Group } 2 \\
\text { Unilateral }\end{array}$ & $\begin{array}{l}\text { Group } 3 \\
\text { Two-Edged }\end{array}$ & $\begin{array}{c}\text { Group } 4 \\
\text { Multilateral }\end{array}$ & $\begin{array}{l}\text { Group } 5 \\
\text { Serrated }\end{array}$ & $\begin{array}{l}\text { Totals } \\
\text { by Leve } 1\end{array}$ \\
\hline \multicolumn{7}{|l|}{1} \\
\hline 2 & & 1 & 1 & $3(2)$ & & $5(2)$ \\
\hline 3 & 2 & & 1 & {$[1] *$} & 2 & 5 \\
\hline 4 & $1(1)$ & & $2(1)$ & 1 & 1 & $5(2)$ \\
\hline 5 & & 1 & & & & $1+$ \\
\hline 6 & & $1(1)$ & & & & $1(1)$ \\
\hline$\nabla$ & & $2(1)$ & & 2 & & $4(1)$ \\
\hline $\begin{array}{l}\text { Group } \\
\text { Totals }\end{array}$ & $3(1)$ & $5(2)$ & $4(1)$ & $6(2)$ & 3 & $21(6)$ \\
\hline
\end{tabular}

Totals include material from both 1977 and 1979 excavations. 1977 totals only are in parenthesis.

* This indicates a fragment found in Level 3 (1979) which fits a larger flake from Leve1 2. It is not included in the totals.

+ An ungrouped fragment from Level 5 (1979) is not included in the table.

$\nabla$ Unprovenienced specimens. 
TABLE 9. TRIMMED FLAKE PERCENTAGES BY LEVEL

\begin{tabular}{|c|c|c|c|c|c|c|}
\hline Level & $\begin{array}{l}\text { Group } 1 \\
\text { Dista1 }\end{array}$ & $\begin{array}{l}\text { Group } 2 \\
\text { Unilateral }\end{array}$ & $\begin{array}{l}\text { Group } 3 \\
\text { Two-Edged }\end{array}$ & $\begin{array}{c}\text { Group } 4 \\
\text { Multilateral }\end{array}$ & $\begin{array}{l}\text { Group } 5 \\
\text { Serrated }\end{array}$ & $\begin{array}{l}\text { Percentage } \\
(\text { Sample })^{\star}\end{array}$ \\
\hline \multicolumn{7}{|l|}{1} \\
\hline 2 & & 20.0 & 20.0 & 60.0 & & $23.8(5)$ \\
\hline 3 & 40.0 & & 20.0 & & 40.0 & $23.8(5)$ \\
\hline 4 & 25.0 & & 50.0 & 25.0 & 25.0 & $23.8(5)$ \\
\hline 5 & & 100.0 & & & & $4.8(1)$ \\
\hline 6 & & 100.0 & & & & $4.8(1)$ \\
\hline \multicolumn{2}{|c|}{$\begin{array}{l}\text { Misce } 11 \text { aneous } \\
\text { Surface }\end{array}$} & 50.0 & & 50.0 & & $19.0(4)$ \\
\hline TOTALS & ** 74.3 & 23.8 & 19.0 & 28.6 & 14.3 & $100.0 .(21)$ \\
\hline
\end{tabular}

* Percentage of total number of trimmed flakes by level (sample size from "Totals by Level," Table 8.

** Percentages computed from "Group Totals," Table 8.

\section{Group 2: Unilaterally Trimmed (5 specimens)}

These specimens have been retouched along the dorsal face of one lateral edge. One of these flakes is a secondary blade, while the others may have been either secondary or primary flakes. One large specimen (Fig. 12,c) appears to be a split cobble. This cobble is the only specimen which is not strictly unifacial; several large flake scars show on the ventral surface. This specimen does not exhibit any obvious wear and could conceivably be intended for further bifacial reduction. None have been thermally altered. These five specimens constitute $23.8 \%$ of the sample of trimmed flakes.

Group 3: Two Edges Trimmed (4 specimens)

This group of flakes has working edges on both lateral edges. Retouch is unifacial and is generally slight as if for resharpening. Some use-wear is apparent on three of the specimens. Two specimens are secondary blades with the distal end missing and could actually belong to Group 4; both have been thermally altered. One large specimen has a number of large flakes removed, creating an irregular or almost serrated edge, but this specimen differs considerably from the serrated flakes in Group 5. These four specimens comprise $19 \%$ of a 11 the trimmed flakes. 
Group 4: Multilaterally Trimmed (6 specimens; Fig。 12,b,e)

These specimens have a working edge which extends all the way around the tool. Retouch is generally unifacial, more extensive than in most of the other groups. These came closest to being modified in overall shape. None are thermally altered. They constitute $28.6 \%$ of the trimmed flake sample.

Group 5: Serrated Flakes ( 3 specimens; Fig. 12,a,d)

These three small interior flakes have distinct serrations formed by small regularly spaced unifacial retouch. All are bilaterally trimmed, although one shows some wear on the distal end. All of these are longer than they are wide, and one is clearly a blade. None are thermally altered. These specimens represent $14.3 \%$ of the trimmed flakes.

\section{Bifaces (209 specimens)}

Bifaces are defined as lithic tools or tool blanks which have been produced by the removal of flakes from opposite sides of a chert core in order to create a sharp working edge. The production of bifaces is a more involved and complex process than that used for any other stone tools found at the Berger Bluff site, and a large number of rejected attempts or failures are present, as they usually are at any site where tool making was done. Examination of the finished tools along with the failures show a linear progression from unmodified raw materials to finished tool, which entails overall shaping, edge formation, and mass reduction.

The process of biface production is envisioned as a series of slightly overlapping, but nonetheless definable stages, each of which involves the removal of more material, each of which results in a more finished looking artifact, and each of which requires an increase in the cumulative amount of energy expended in tool production. At the Berger Bluff site this process is best summarized in six stages. The initial stage contains cores or core-bifaces. The final stage is assumed to contain only tools or finished bifaces; but does not preclude the presence of finished tools in other stages. However, a finished tool at an earlier stage is more likely to imply less energy expended in manufacture and to look less finished beside a final stage artifact.

Similar sexpartite divisions of the lithic reduction process have been used elsewhere (Skinner 1971; Sharrock 1966; Skelton 1977), and the following categories are based loosely upon these. There are, however, slight differences which may reflect either sampling or actual variations in production at the Berger Bluff site.

As in most attempts to divide a continuum, there are problems of definition in the boundary areas between stages (cf. Collins 1975); the bifaces from the Berger Bluff site are no exception. However, although there are some borderline cases where placement was difficult, most of the specimens fell clearly within one of the categories. It was, in fact, the obvious modal distribution of the artifacts themselves which suggested the subdivisions. For this reason, the classification is felt to be (within the narrow limits imposed by classifier bias) an inherent rather than an imposed ordering. 

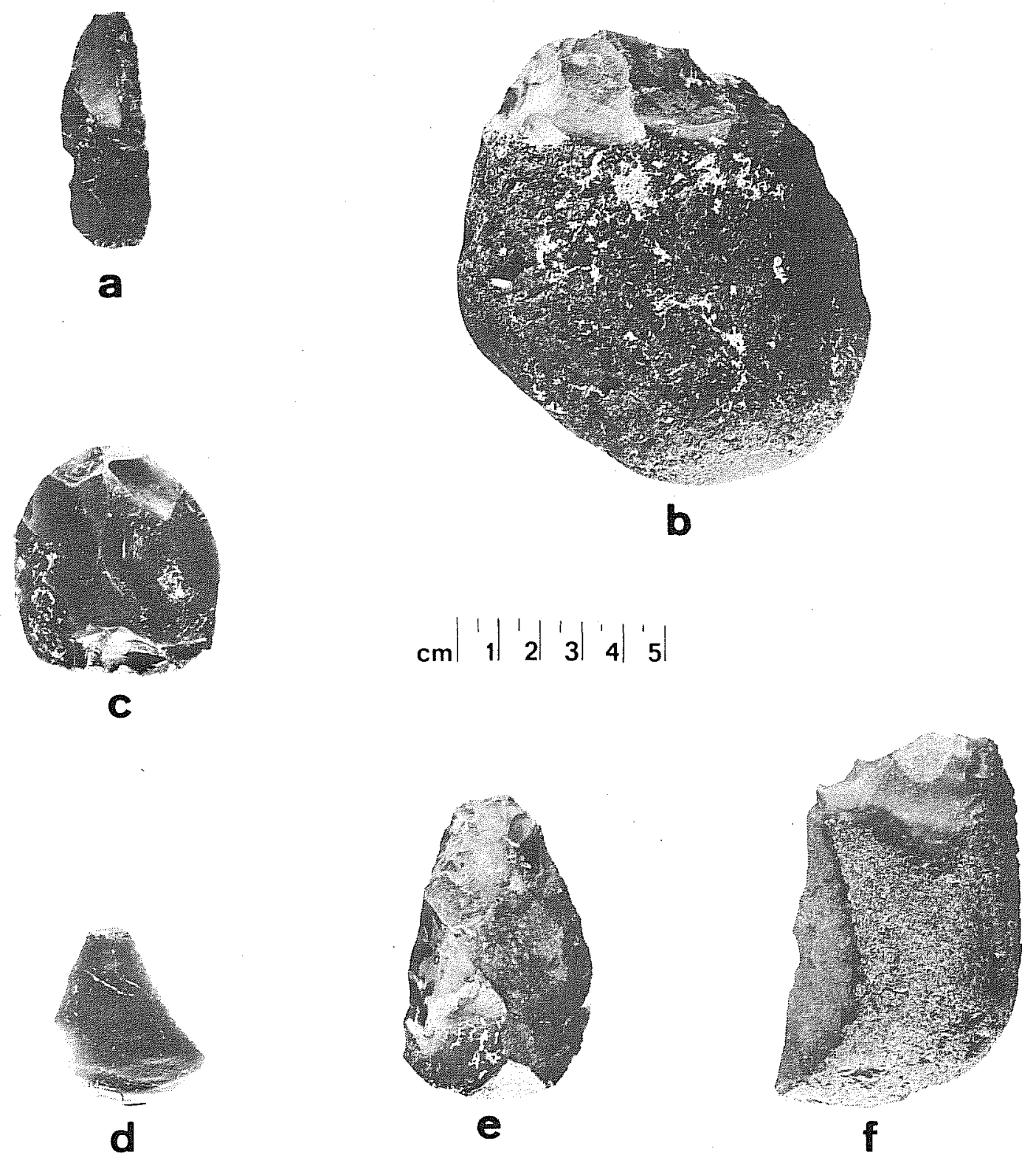

Figure 12. Trimmed Flakes. a, serrated flake (Group 5): N97 E98, Leve1 4; b, multilaterally trimmed flake (Group 4): miscellaneous surface; c, unilaterally trimmed flake (Group 2): miscellaneous surface; d, serrated flake (Group 5): N98 E99, Level 3; e, multilaterally trimmed flake (Group 4): miscellaneous surface; f, distally trimmed flake (Group 1): N99 E97, Leve1 3. 
Stage I: Core-Bifaces (24 specimens)

These specimens represent the initial attempt at biface production from a chert cobble. Flakes have been removed from both sides, but cortex still remains on one and often both faces. Reduction technique appears to be exclusively freehand hard hammer percussion. Flake scars are often wide and deep and not a lways regularly spaced. On some of the specimens, platform preparation is evidenced by crushed and ground edges and small unifacial hinge scars. Edges are irregular and usually very sinuous. On all the pieces, cortex comes to one edge, and on several, cortex comes around an unformed edge. Dimensions vary within the groups, but within the stage as a whole maximum thicknesses range between 1.8 and $4.5 \mathrm{~cm}$, and width-to-thickness ratios vary between $1.4: 1$ and $2.9: 1$.

This stage is comparable to Core-Biface Group II from the Cuero I report (Fox et al. 1974:37) and Core-Biface Group I from the Coleto Creek testing report (Fox, Black, and James 1979:46). This stage also combines Skelton's (1977:148, 149) Stages I and II, as wel1 as Skinner's (1971:174-176) Stages A and B. With a larger sample, it might be possible to distinguish between these two stages at the Berger Bluff site. Some of the Stage I bifaces at the Berger Bluff site may have been classified as cores, because of the difficulty in differentiation in the early stages of reduction between a core-biface and a core for flake blanks.

This stage is divided into four groups that are technologically different from one another. Within this stage and within each group are included several forms, which might be classified as core tools or core choppers, except for the lack of obvious wear.

Table 10 shows the distribution of the various groups by excavation level. Table 11 gives the percentages of core bifaces compared with other thick bifaces for each excavation level.

Group 1: Cobble Blanks (8 specimens)

These specimens have cortex on both sides and a generally poorly developed edge. They are only minimally reduced from their original cobble shape. All are of medium-sized round river cobbles, except for one flat chert pebble. A11 are brown and grayish brown local cherts. They are generally thick, ranging between 3.0 and $4.5 \mathrm{~cm}$ in thickness. Width-to-thickness ratios range between 1.6:1 and 1.8:1. One specimen of a somewhat grainy chert appears to be thermally altered along one edge, apparently after it was chipped. Another specimen has severe hinge fractures at either end and would have been difficult to reduce further. None show signs of utilization.

Group 2: Split Cabble Blanks (4 specimens)

These specimens are manufactured from split cobbles which are essentially large primary flakes obtained by splitting a chert cobble along its central longitudinal axis. They characteristically have a plano-convex cross section with the convex dorsal face almost entirely cortex and the ventral face totally decorticate. All are of a tan, fine-grained chert. Thicknesses range from 2.2 to $3.3 \mathrm{~cm}$, and width-to-thickness ratios vary between $1.9: 1$ and 2.3:1. They 
have a more distinct shape and a more regular edge than the Group 1 CoreBifaces and could have functioned as tools, although none have any obvious usewear. Two are lanceolate, one is triangular, and one is rectangular. The reason for abandonment is not obvious in any of these.

Group 3: Flake Blanks (4 specimens)

These four specimens are made on large flakes. Three have some cortex remaining and are apparently secondary flakes; the largest of the four is an interior flake. All are of brown variegated chert. Thicknesses range between 1.8 and $2.9 \mathrm{~cm}$, and width-to-thickness ratios are between $2.3: 1$ and 2.5:1. The ventra1 surface of one is patinated. None show any sign of utilization.

TABLE 10. THICK BIFACES BY LEVEL

\begin{tabular}{|c|c|c|c|c|c|c|c|c|}
\hline Level & Group 1 & $\frac{\text { Stage I }}{\text { Group } 2}$ & $\frac{\text { ore-Bifa }}{\text { Group } 3}$ & $\frac{\text { es }}{\text { Group } 4}$ & Tota1 & Stage II & Stage III & $\begin{array}{l}\text { Totals by } \\
\text { Level }\end{array}$ \\
\hline 1 & & & & & & 1 & 1 & 2 \\
\hline 2 & 1 & & .1 & 1 & 3 & 1 & $4(1)$ & $8(1)$ \\
\hline 3 & 5 & & 2 & & 7 & $5(1)$ & $4(7)$ & $16(2)$ \\
\hline 4 & & $2(1)$ & & 2 & $4(1)$ & $7(3)$ & 3 & $14(4)$ \\
\hline 5 & & & & 1 & 1 & 6 & 2 & 9 \\
\hline 6 & 1 & & 1 & 1 & 3 & 5 & 3 & 11 \\
\hline 7 & & $1(1)$ & & 1 & $2(1)$ & $2(1)$ & 1 & $5(2)$ \\
\hline 8 & & & & & & 1 & & 1 \\
\hline 9 & & & & & & & & \\
\hline 10 & & & & & & 1 & & 1 \\
\hline 11 & & & & & & 1 & & 1 \\
\hline$\nabla$ & $1(1)$ & $1(1)$ & & $2(2)$ & $4(4)$ & $1(1)$ & 2 & $7(5)$ \\
\hline $\begin{array}{l}\text { Group } \\
\text { Totals }\end{array}$ & $8(1)$ & $4(3)$ & 4 & $8(2)$ & $24(6)$ & $31(6)$ & $20(2)$ & $75(14)$ \\
\hline
\end{tabular}

* Totals include material from both 1977 and 1979 excavations. 1977 totals only are in parentheses.

$\nabla$ Unprovenienced specimens. 
TABLE 11. THICK BIFACE PERCENTAGES BY LEVEL

\begin{tabular}{|c|c|c|c|c|c|c|c|c|}
\hline Leve 1 & Group 1 & $\begin{array}{r}\text { Sta } \\
\text { Group } 2 \\
\end{array}$ & $\begin{array}{l}\text { I Core-B } \\
\text { Group } 3\end{array}$ & ces & Total & Stage II & Stage III & $\begin{array}{l}\text { Percentage } \\
\text { (Sample)* }\end{array}$ \\
\hline 1 & & & & & & 50.0 & 50.0 & $2.7(2)$ \\
\hline 2 & {$\left[\begin{array}{c}33.3]+ \\
12.5\end{array}\right.$} & & $\begin{array}{c}{[33.3]} \\
12.5\end{array}$ & $\begin{array}{c}{[33.3]} \\
12.5\end{array}$ & 37.5 & 12.5 & 50.0 & $10.7(8)$ \\
\hline 3 & $\begin{array}{c}{[71.4]} \\
31.3\end{array}$ & & $\begin{array}{c}{[28.6]} \\
12.5\end{array}$ & & 43.8 & 31.3 & 25.0 & $21.3(16)$ \\
\hline 4 & & $\begin{array}{c}{[50.0]} \\
14.3\end{array}$ & & $\begin{array}{c}{[50.0]} \\
14.3\end{array}$ & 28.6 & 50.0 & 21.4 & $18.7(14)$ \\
\hline 5 & & & & {$\left[\begin{array}{c}{[100.0]} \\
11.1\end{array}\right]$} & 11.1 & 66.7 & 22.2 & $12 \quad(9)$ \\
\hline 6 & $\begin{array}{c}{[33.3]} \\
9.1\end{array}$ & & $\begin{array}{c}{[33.3]} \\
9.1\end{array}$ & $\begin{array}{c}{[33.3]} \\
9.7\end{array}$ & 27.3 & 45.5 & 27.3 & 14.7 (11) \\
\hline 7 & & $\begin{array}{c}{[50.0]} \\
20.0\end{array}$ & & $\begin{array}{c}{[50.0]} \\
20.0\end{array}$ & 40.0 & 40.0 & 20.0 & $6.7(5)$ \\
\hline $\begin{array}{l}8 \\
9\end{array}$ & & & & & & 100.0 & & $1.3(1)$ \\
\hline 10 & & & & & & 100.0 & & $1.3(1)$ \\
\hline 11 & & & & & & 100.0 & & $1.3(1)$ \\
\hline$\nabla$ & $\begin{array}{c}{[25.0]} \\
14.3\end{array}$ & $\begin{array}{c}{[25.0]} \\
14.3\end{array}$ & & $\begin{array}{c}{[50.0]} \\
28.6\end{array}$ & 57.1 & 14.3 & 28.6 & $9.3(7)$ \\
\hline TOTAL ** & $\begin{array}{c}{[33.3]} \\
10.7\end{array}$ & $\begin{array}{c}{[16.7]} \\
5.3\end{array}$ & $\begin{array}{c}{[16.7]} \\
5.3\end{array}$ & $\begin{array}{c}{[33.3]} \\
10.7\end{array}$ & 32.0 & 41.3 & 26.7 & $100.0(75)$ \\
\hline
\end{tabular}

* Percentage of total number of thick bifaces by level (sample size from "Totals by Level," Table 10).

** Percentages computed from "Group Totals," Table 10.

+ Bracketed percentages are within Stage I only.

$\nabla$ Unprovenienced specimens. 


\section{Group 4: Miscellaneous Blanks (8 specimens)}

These small amorphous core-bifaces are of indeterminate origin. All have cortex on a single face only and generally sinuous edges. They are smaller than Group 1 or 2 specimens and may represent unidentified, further reduced examples of these two groups. Thicknesses range between 2.7 and $4.3 \mathrm{~cm}$, and width-to-thickness ratio fal1 between $1.4: 1$ and 2.9:1. Those few specimens with the higher width-to-thickness ratios are extreme for this stage; this and the relatively large amount of energy expended in their production would place several of the members of this group within the next stage were it not for their total lack of form. Despite their amorphous character, microscopic examination of two small specimens shows slight traces of bifacial wear along portions of unbroken edges. The function of these pieces is not known.

\section{Stage II: Initial Thick Bifaces (31 specimens; Fig. 13,a,b)}

Specimens belonging to this stage represent an increased additive energy expenditure over the Stage I core-bifaces. This stage includes the cruder and thicker of chipped stone artifacts usually described as thick bifaces. While their general size and shape is still a function of the original cobble or flake blank, they have been thinned considerably. Edges are generally sinuous, but much variation is present. Cortex is present on some of the specimens. Maximum thicknesses range from 1.8 to $4.5 \mathrm{~cm}$, and width-to-thickness ratios vary between 1.2:1 and 3.2:1.

It is no longer clearly possible at this stage to distinguish between the original blank types, although two of the specimens have a ventral flake surface on one face and would have been Group 2 or 3 core-bifaces. Several others have plano-convex cross sections and may have originated as Group 2 coreBiface Cobble Blanks.

Variation in size, shape, and flaking style are apparent, but no separation into groups has been attempted. This is because the morphological and technological diversity present is represented by many unique individual attribute combinations rather than distinct clusters of attributes. A few are almost triangular or subtriangular, while most are some variant of ovate.

Possibly because of the increased amount of energy expenditure represented, reasons for abandonment become more obvious in the various examples of this stage than in the previous stage. Twelve specimens are broken. Seven specimens would be difficult to reduce further because of manufacturing errors. Some have irreducible humps; others are too narrow for their thickness, and still others have too irregular an edge for the amount of material left. One specimen is a reject for material defects; it has a large central calcareous inclusion.

Artifacts belonging to this stage are included in the thick biface category in the Coleto Creek testing report (Fox, Black, and James 1979:46-47) and in the Cuero I survey report where they are best approximated by Group 1 thick bifaces (Fox et al. 1974:37). They are also generally comparable to Stage 3 bifaces in Skelton (1977:149) and Stage C bifaces in Skinner (1971:176). 
Stage III: Secondary Thick Bifaces (20 specimens; Figs. 13,c,d)

These specimens are characterized by more regular edges and a more distinct shape. On the whole they are thinner in cross section and have smaller and more regular flake removals. The edges may be formed using soft hammer percussion. With the exception of an ovate specimen, there is a clear distinction between distal and proximal ends in all of the complete examples. Thickness varies between 1.4 and $2.6 \mathrm{~cm}$, while width-to-thickness ratios vary between 1.4:1 and 4.2:1 (the 1.4:1 measurement is from a we11-chipped biface with a large knot in the middle, Fig. 13,d; measurement off of the knot would raise the minimum ratio to $2.1: 1)$. The sample is too small to be divided into groups or form categories. None of the specimens is thermally altered. Sixteen are broken. One of the four remaining specimens, the one with the large knot mentioned above, is obviously not reducible, while the other three could possibly be. Only one specimen, an ovate biface, has any cortex present. No use wear was observed on any of the specimens.

Thicker than the requisite $1.3 \mathrm{~cm}$, these bifaces would be classified as thick bifaces in the Coleto Creek testing report (Fox, Black, and James 1979:46). A] though not identified as a particular group or form in that report, they would comprise the more regularly shaped and thinner of the thick bifaces. This stage is also comparable to Stage 3 in the lithic reduction sequence from the North Fork Reservoir area in Williamson County (Patterson 1977:72).

Stage IV: Thin Biface Blanks (41 specimens; Figs. 13,e,f).

These specimens are thinner than Stage III bifaces. Thicknesses range from $0.6 \mathrm{~cm}$ to $1.8 \mathrm{~cm}$, while width-to-thickness ratios increase only slightly, varying from $1.7: 1$ to $4.3: 1$. Most of the flake scars present are longer than they are wide with barely noticeable bulb scars. Some of the edges appear to be pressure flaked in places. More attention is given to basal shape with a continuum going from almost equal to well rounded. Thirty-five specimens are broken. Four of the complete specimens have large lumps on one face and appear irreducible, while the other two have twisted and irregular edges and would be difficult to thin further. The sample is too small to separate into groups. None of the specimens shows any macroscopic evidence of use wear.

This stage includes the cruder, larger, and less well shaped of the thin bifaces as described in the Coleto Creek testing report (Fox, B.lack, and James 1979:47ff). Since thickness was not used as a sole distinguishing factor, several of the bifaces included within this stage are thicker than $1.3 \mathrm{~cm}$, but are technologically equivalent to the thinner specimens. Some of those thicker than $1.3 \mathrm{~cm}$ are only so because the measurement of maximum thickness was made at small humps not representative of the overall thickness. This stage is comparable to Skelton's (1977:149) Stage 4 bifaces.

Stage V: Preforms (50 specimens)

This stage contains bifaces which are often described as preforms, al though many of these specimens may have functioned as finished artifacts. Within this group are a few specimens that might be classed as Pandora and Abasolo points, 


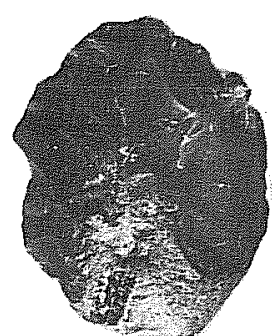

a

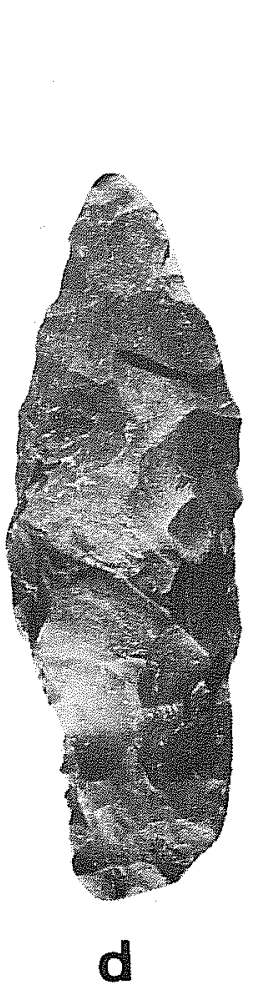

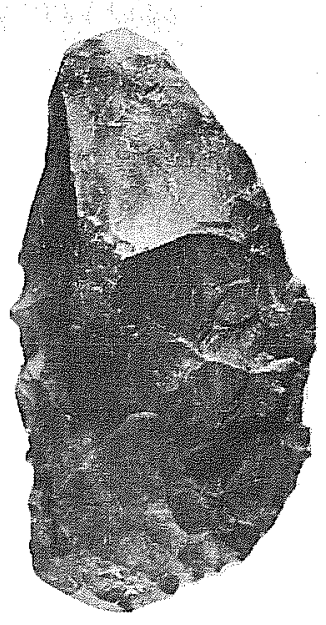

b

$$
\mathrm{cm}\left|\begin{array}{l|l|l|l|l|}
\mid & \mid & \mid & \mid & \mid \\
& 1 & 2 & 3 & 4
\end{array}\right|
$$

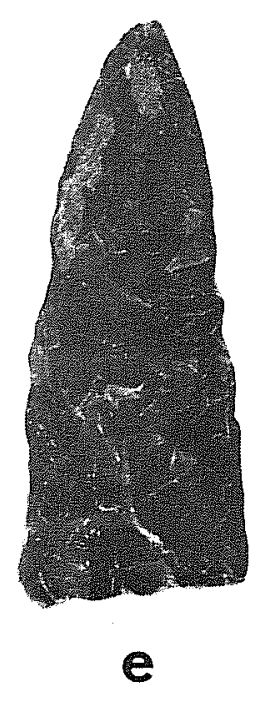

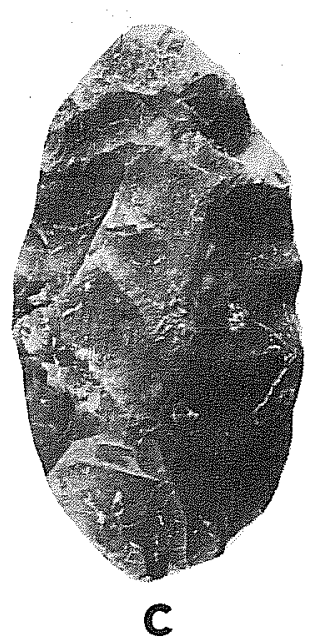

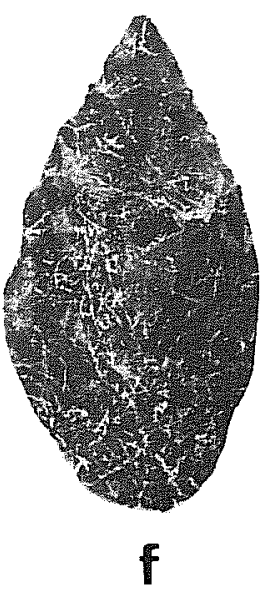

Figure 13. Bifaces: Stage II Through Stage IV. a, smal1 Stage II thick biface (N98 E96, Level 4); b, Stage II thick biface (N97 E99, Level 5); c, Stage III thick biface (N99 E99, Level 6); $d$, Stage III thick biface (Level 4); e, Stage IV thin biface (N99 E96, Level 3); f, Stage IV thin biface (N97 E97, Leve1 7). 
but the workmanship and/or the basal preparation was too minimal to include them with the obviously finished artifacts of Stage VI. Thickness in this stage ranges from 0.4 to $1.2 \mathrm{~cm}$ with width-to-thickness ratios varying between 2.5:1 and 4.6:1. Al1 of these specimens have we11-defined edges, and most show smal1, well-controlled flake scars that are probably indicative of pressure flaking. Considerable attention is given to basal thinning and shaping, and bases range from distinctly concave to round.

Forty-three specimens are broken. A small narrow biface has a partially broken base which could have been reworked. A small bifacially trimmed flake could easily have functioned as an arrow point. Another larger round-based biface could have functioned as a dart point.

Included in this stage are several preforms that are suspected unfinished arrow points, but are outside this category because of physical dimensions. They are included in Group 2 Small Preforms.

Three specimens are thermally altered. After viewing with a microscope, none of the specimens shows use wear.

The distribution of these specimens by level is shown in Table 12.

Group 1: Large Preforms (19 specimens)

This group includes those specimens which might be described as dart points or $\mathrm{knife}$ preforms. Thicknesses range from 0.6 to $1.2 \mathrm{~cm}$, and width thickness ratios vary from 2.5 to $4.6: 1$. Although the specimens in this group are similar in many respects, four forms can be distinguished on the basis of basal morphology.

Group 1, Form 1: Concave Based (1 specimen; Fig. 14,a)

One proximal fragment has a concave base, the distinguishing feature of this form. Maximum width is $2.4 \mathrm{~cm}$, and thickness is $0.8 \mathrm{~cm}$. Width-to-thickness ratio is $3: 1$.

Group 1, Form 2: Square Based (6 specimens; Figs. 14,b,c)

These specimens are subtriangular and/or parallel sided, with an approximate square base. All are fragmentary; two specimens were put together from four fragments found in different units. One of these is thermally altered.

Thicknesses vary from 0.7 to $1.2 \mathrm{~cm}$. Some of these specimens could probably be classified as Pandora points (Suhm and Jelks 1962:233).

Group 1, Form 3: Subround Based (5 specimens; Fig. 14,d)

These five basal fragments have bases which are slightly concave or square with rounded corners. In general, they appear better made than any of the other form categories. The smallest has been thermally altered, appearing gray and 
TABLE 12. UNFINISHED THIN BIFACES BY LEVEL

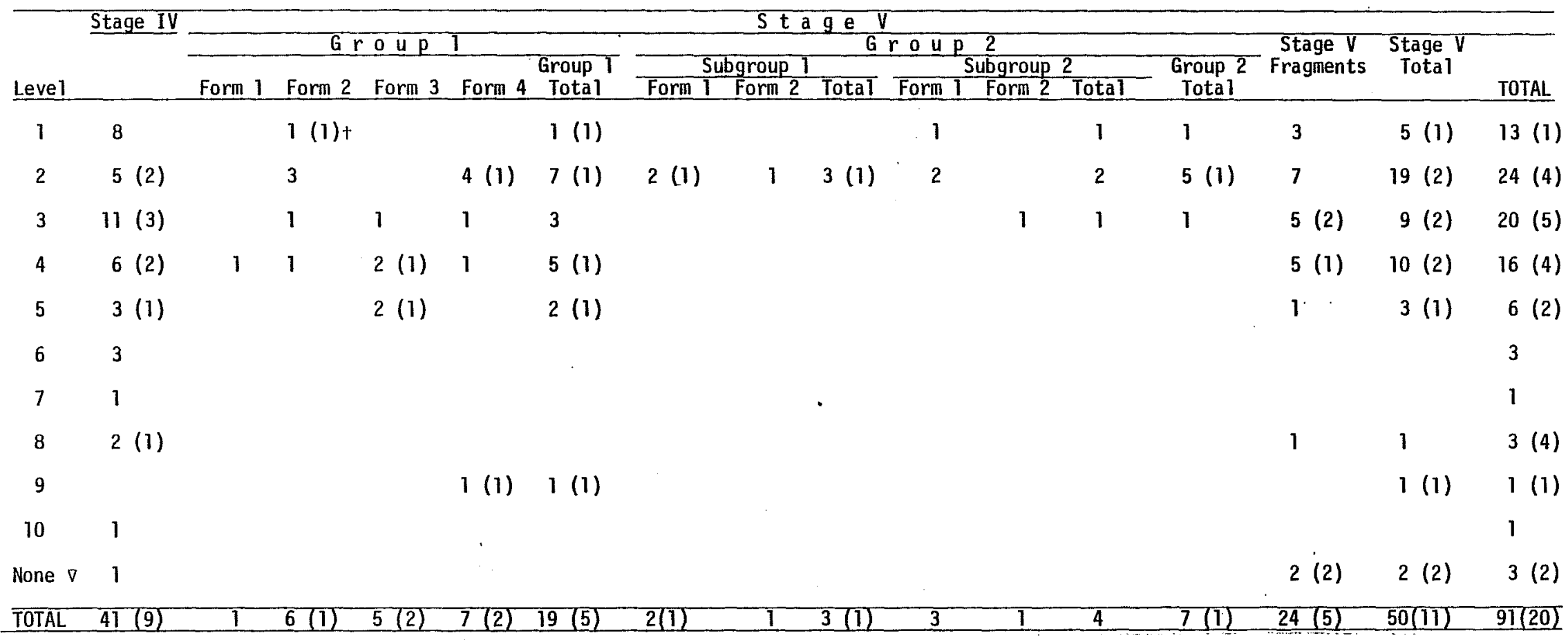

* Totals include materials from 1977 and 1979 excavations; total in parentheses report 1977 totals only.

+ This biface, collected while clearing the surface of the 1977 excavation unit, is included here with Level 1 for convenience.

$\nabla$ Unprovenienced specimens. 
white and potlidded on both sides. Thicknesses vary from 0.6 to $0.9 \mathrm{~cm}$. As with Form 2, some of these specimens might also fit the Pandora type.

Group 1, Form 4: Round Based (7 specimens; Fig. 14,e)

The distinguishing mark of these specimens is their rounded base. Six of the seven are broken. The seventh (Fig. 14,e) shows no trace of wear, and the reason for its abandonment is unclear. Two of the members of this form show a reddish tint in places, but it is not known if this is thermal alteration or natural color. Thicknesses vary from 0.7 to $0.9 \mathrm{~cm}$. Some of these specimens might be typed as Refugio points (Suhm and Jelks 1962).

\section{Group 2: Small Preforms (7 specimens)}

This group includes those specimens thought to be arrow point preforms and/or minimally chipped finished points. They are separated into subgroups by their basal preparation: four are stemmed and three unstemmed. Five are made from flakes and exhibit only minimal retouch on the ventral surface. Only one of these is thermally altered. Thicknesses vary from 0.3 to $0.5 \mathrm{~cm}$.

Subgroup 1: Unstemmed Sma11 Preforms

Group 2, Form 1: Subtriangular Round Based (2 specimens; Fig. 14,f)

These two specimens are the only fully worked bifacial specimens within this group. They are subtriangular with a rounded base and could have functioned as finished projectile points. Although both are broken, they could conceivably have been rechipped. One specimen was cross mended from two fragments found several meters apart, one in the 1977 excavation and the other in the recent excavation. Thicknesses are 0.4 and $0.5 \mathrm{~cm}$.

Group 2, Form 2: Foliate (1 specimen; Fig. 14,g)

This small leaf-shaped biface was made on a small flake that was only minimally retouched on both sides. It is smaller and shaped somewhat differently from Form 1 and shows a different manufacturing technique. It is $0.3 \mathrm{~cm}$ in thickness.

\section{Subgroup 2: Stemmed Sma11 Preforms}

Group 2, Form 1: Contracting Stem (3 specimens; Fig. 14,h)

These three specimens have contracting stems and are primarily unifacial with slight bifacial retouch on the lateral edges and the stem. Two have medial fractures; one of these has been thermally altered. Two are morphologically similar to the cliffiton point (Suhm and Jelks 1962:269), while the third, larger in size and with a broad but we11-chipped base, fits better within the Perdiz category (Suhm and Jelks 1962:283). This last specimen is unifacially modified on one lateral edge with a bifacially finished base and is relatively 


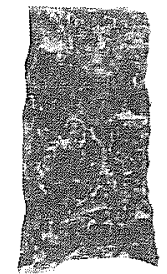

2
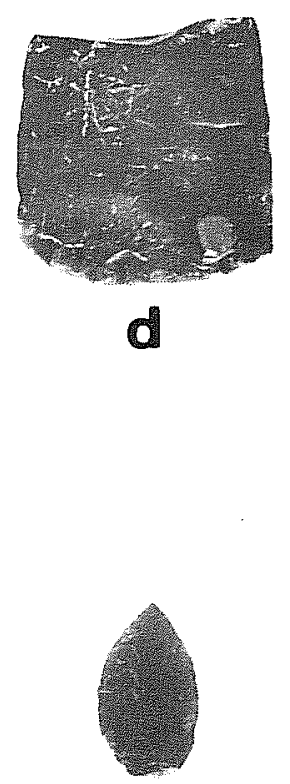

$\mathbf{g}$

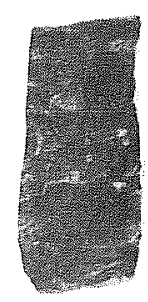

b
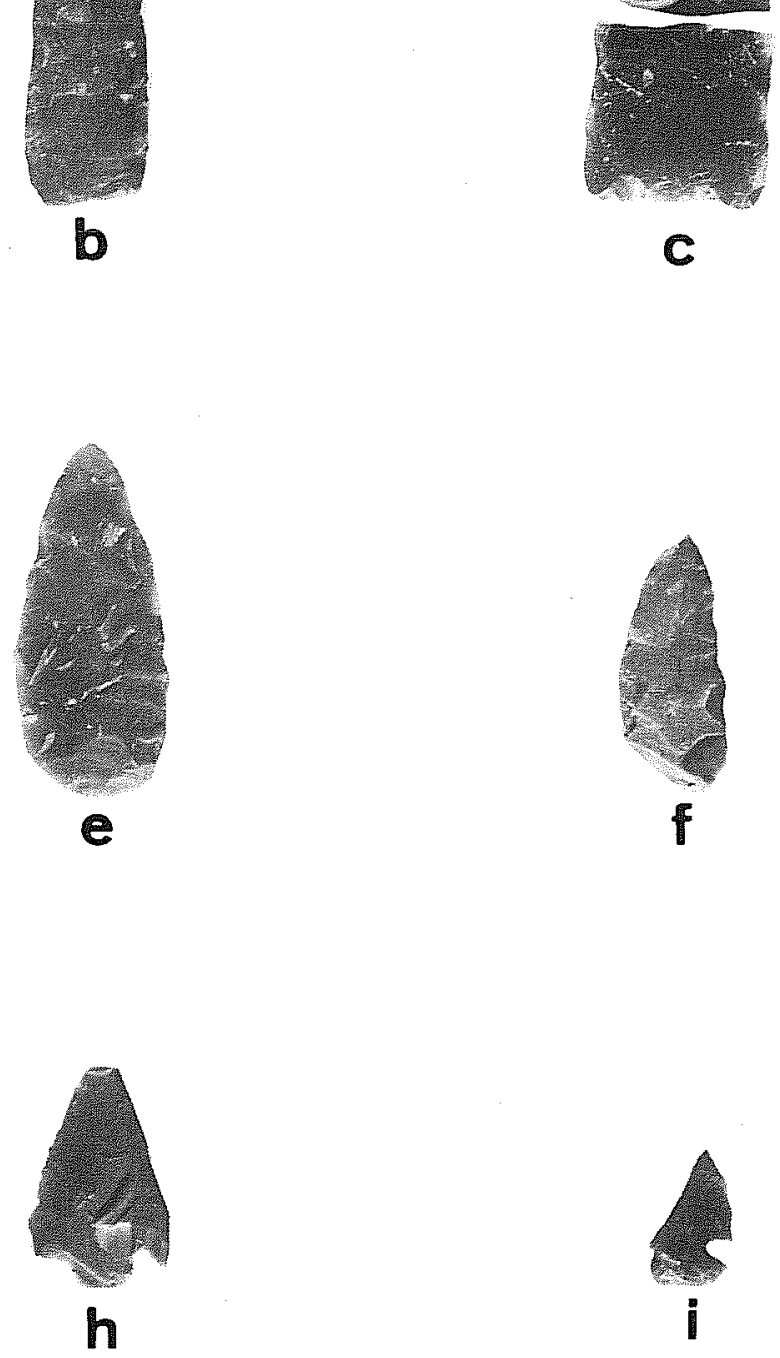

C

f

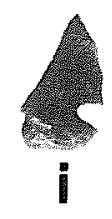

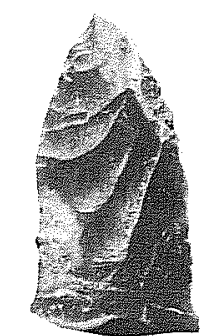

\section{$\mathbf{c m}\left|\begin{array}{l|l|l|l|l|l}1 & 1 & 1 & 1 & 1 \\ 1 & 2 & 3 & 4 & 5\end{array}\right|$}

Figure 14. Stage $V$ Preforms. a, concave-based dart point preform (Group 1 , Form 1--N97 E96, Leve1 4); b, square-based dart point preform (Group 1, Form 2-N99 E97, Leve1 2); c, square-based dart point preform (Group 1, Form 2--upper half of N99 E98, Level 4, and lower half of N98 E96, Level 4); d, subroundbased dart point preform (Group 1, Form 3--N99 E99, Leve1 4); e, round-based dart point preform (Group 1, Form 4--N98 E97, Leve1 4); f, subtriangular round-based arrow point preform (Group 2, Subgroup 1, Form 1--N97 E97, Leve1 2); g, foliate (Group 2, Subgroup 1, Form 1--N99 E99, Leve1 2); i, Scallorn preform (Group 2, Subgroup 2, Form 2--N97 E99, Leve1 3). 
large (original length may have been over five centimeters). A central ridge on the dorsal surface parallel to the edge suggests it may have been made on a blade (cf. Hester and Shafer 1975:178).

\section{Group 2, Form 2: Expanding Stem (1 specimen; Fig. 14,i)}

This single specimen is a small unfinished arrow point with an expanding stem. It is primarily unifacial with bifacial retouch in the notched area and around the stem edges. One notch is considerably deeper than the other, and it appears that the specimen may have broken from end shock during notching. The specimen corresponds to the Scallorn type (Suhm and Jelks 1962:285).

\section{Miscellaneous Stage V Biface Fragments (24 specimens).}

Because the group and form categories within Stage $V$ are dependent upon basal morphology, distal and medial fragments could not be ascribed to specific categories within the stage. Despite the lack of a base, additionally used as an indicator of general membership within Stage $V$, the following fragments evidence quality of workmanship and edge regularity that corresponds to that of other bifaces within the stage category.

\section{Distal Fragments (23 specimens)}

Three of these are thermally altered. Two are unifacially chipped in the manner of the arrow point preforms in Group 2. One specimen is made of petrified wood.

Medial Fragment (1 specimen)

This small specimen is very close to the distal end of a biface.

\section{Stage VI: Finished Tools (43 specimens)}

Bifaces belonging to this stage are thought to be finished tools and for the most part represent projectile points and knives. On the whole they are distinguished from Stage $V$ by a sharper edge and a more clearly defined base. Pressure flaking is present in almost all cases. Generally, even fragmentary bifaces belonging to this stage show a distinct shape. They are divided into groups on the basis of whether or not they have a stem. In this respect, the stemmed group is much easier to separate from unfinished Stage $V$ stemmed

preforms than are the unstemmed group members. Thicknesses range from 0.2 to $1 \mathrm{~cm}$, and the width-to-thickness ratio varies between 8 and $3: 1$. The distribution of Stage VI bifaces is shown in Table 13.

\section{Group 1: Unstemmed (10 specimens)}

These bifaces are all finished or very close to it. They are very difficult to separate into form categories, because each is a unique specimen. The 
TABLE 13. FINISHED STAGE VI THIN BIFACES BY LEVEL

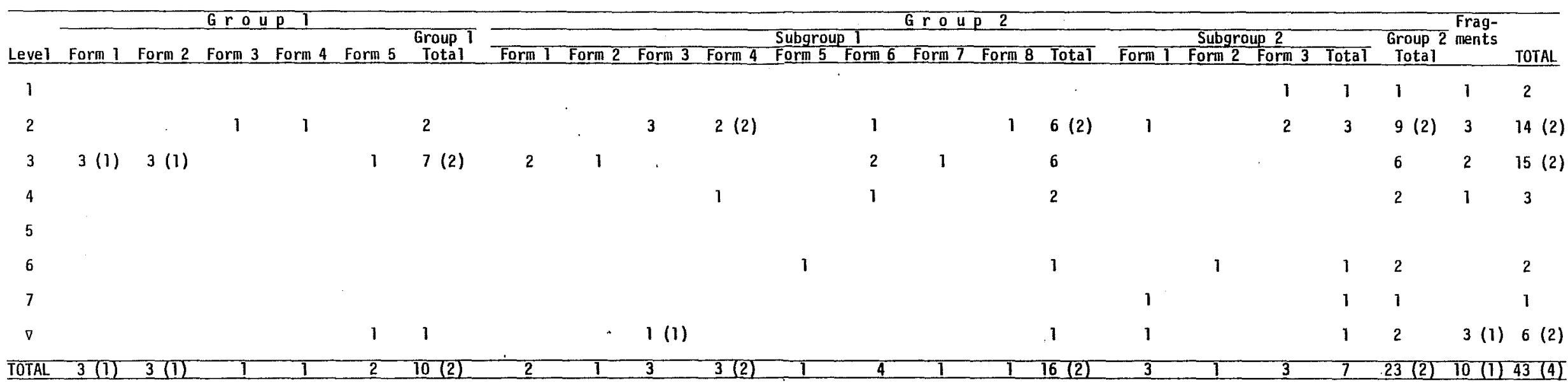

* Totals include materials from 1977 and 1979 excavations; totals in parentheses are 1977 materials only.

$\nabla$ Unprovenienced specimens. 
following categories lump the specimens according to gross morphological similarities with a brief description of each specimen.

Group 1, Form 1: Triangular, Square Based, Large (3 specimens)

These three bifaces form the most cohesive group of all. In size, chipping style, and provenience (Level 3) they are markedly similar. A11 three show some evidence of bifacial wear on the edges.

The first specimen (Fig. 15,a) is the largest of the three, but typical in triangular outline and chipping style. It is also the most complete specimen. It has bifacial wear on both lateral edges with smooth, polished surfaces on the ridges between flake scars. It was found at approximately $34 \mathrm{~cm}$ beneath the surface or about $6 \mathrm{~cm}$ below the average depth of 0ccupation Floor I (28 $\mathrm{cm}$ in depth). It is $3.7 \mathrm{~cm}$ at maximum width and $0.7 \mathrm{~cm}$ at maximum thickness, and although a small portion of the tip has broken off, it is more than $7 \mathrm{~cm}$ in length. It is made of a tan-colored, fine-grained waxy chert.

Another specimen was cross mended from fragments found in adjacent squares. The basal fragment occurred at $36 \mathrm{~cm}$ or just above the Ensor/Marcos point depth of $38 \mathrm{~cm}$. This specimen is made of a brown chert, which has been thermally altered and partially patinated (over the burned areas). Possible wear shows on both lateral edges. It is $0.7 \mathrm{~cm}$ thick and $3.1 \mathrm{~cm}$ wide. A small portion of the tip is broken, but the remainder is $5.5 \mathrm{~cm}$ long (Fig. 15,b).

The third example of this group is a basal fragment made of a gray and black vitreous fine-grained chert observed in several other bifaces and debitage at the site. It is thinner and may have even been larger than the others. The lateral edges on this specimen are somewhat thinner and sharper. Portions of the edge show bifacial wear. This specimen was found in Level 3 of the 1977 excavation. Width is $3.2 \mathrm{~cm}$, and thickness is $0.5 \mathrm{~cm}$.

The first two of these specimens could fit into Tortugas (Suhm and Jelks 1962:249) or Late Triangular (Hester 1971:80), but the third is uncertain. Note that none are beveled.

\section{Group 1, Form 2: Concave-Based Large Triangular (3 specimens)}

These three specimens all have approximate parallel sides near the base and a concave basal profile. They were all found in Level 3 of the excavations, two in 1979 and one in 1977. Although none fits precisely within an established type, two fall within the range of Kinney point specimens (Suhm and Jelks 1962:201). The first specimen is a deeply concave basal fragment of a banded buff chert. It is crudely chipped, but appears finished or very close to it. Maximum width is $3.6 \mathrm{~cm}$, and thickness is $0.7 \mathrm{~cm}$. It does not appear to have any obvious wear present. The base of this biface has slightly projecting sides (Fig. 15, C).

Another specimen (illustrated in Fox, Black, and James 1979:49) is a finely chipped, brown-banded chert triangular piece with a slight concavity and ground basal and lower lateral edges. Maximum width is $2.9 \mathrm{~cm}$, and thickness 


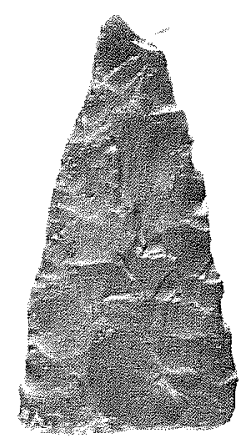

a

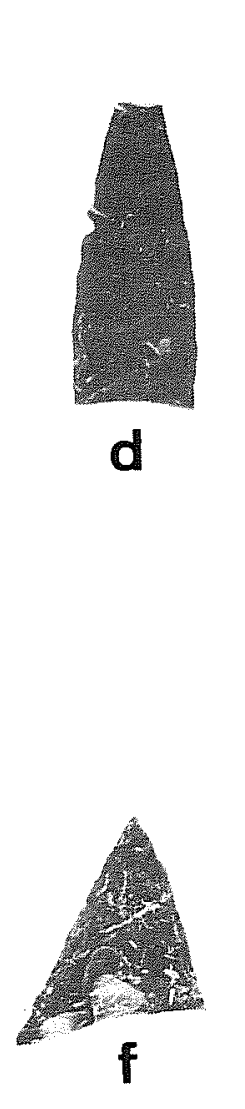

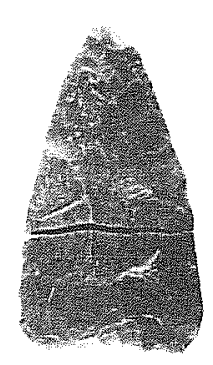

b

$\mathrm{cm}\left|\begin{array}{lllll|l|l}1 & 12 & 1 & 3 & 1 & 1 \\ \end{array}\right|$

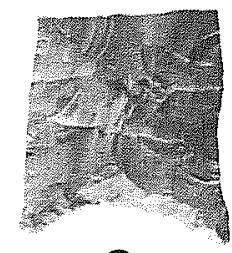

C

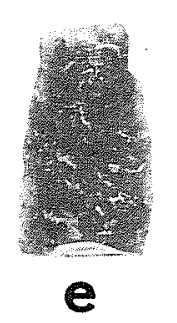

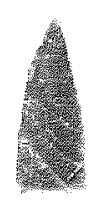

g

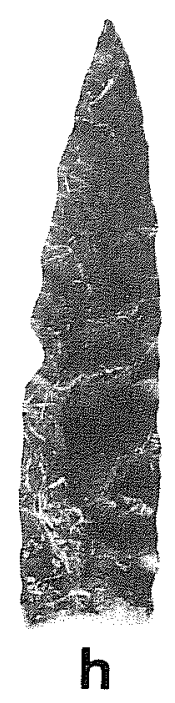

Figure 15. Stage VI Finished Tools. a, square-based large triangular (Group 1, Form 1--N97 E98, Leve1 3); b, square-based large triangular (Group 1, Form 1-distal N98 E99, Leve1 3, and proximal N99 E98, Leve1 3); c, concave-based large triangular (Group 1, Form 2--N99 E98, Level 3); d, parallel sided (Group 1, Form 5--N99 E98, Leve1 3); e, parallel sided (Group 1, Form 5--miscellaneous surface); f, barbed fragment (N98 E98, Leve1 3); g, smal1 triangular (N97 E98, Level 2); h, concave-based large triangular (Group 1, Form 2--N99 E97, Level 3). 
is $0.5 \mathrm{~cm}$. Overall length is $6 \mathrm{~cm}$. This specimen has been compared to thin, well-made triangular specimens from Late Prehistoric sites in the Palmetto Bend area (Robert Stiba, personal communication). The third member in this category could belong in a class by itself. It is a long, narrow triangular biface made of a grainy light brown chert (Fig. 15,h). Length is $10.2 \mathrm{~cm}$, and maximum width is $2.7 \mathrm{~cm}$. Thickness is $0.9 \mathrm{~cm}$. It was found at the bottom of Level 3 of the 1979 excavation unit at a depth of approximately $46 \mathrm{~cm}$ beneath the ground surface. It was at the same depth and apparently associated with nearby Occupation Floor II debris. Although it cannot be identified with an estab7 ished type, it is similar to several unfinished and broken specimens at the Berger Bluff site and is thought to be a distinct form which may ultimately be diagnostic of the Occupation Floor II level.

Group 1, Form 3: Square-Based Triangular, Small (1 specimen; Fig. 15,g)

This small triangular biface was found in Level 2 of the 1979 excavation at a depth of approximately $24 \mathrm{~cm}$ below the ground surface. This depth is slightly above the recorded depth of most of the Scallorn points from the site and below that of most of the Perdiz points. Its relationship to the cultural strata defined at the site is uncertain. It is made of a light brown chert and is bifacially worked with a base that appears only partially finished. Length is $3.1 \mathrm{~cm}$, and width is $1.2 \mathrm{~cm}$. Thickness is $0.2 \mathrm{~cm}$. Typologically this point is close to the Fresno arrow point type (Suhm and Jelks 1962:273).

Group 1, Form 4: Round Based (1 specimen)

This single basal fragment is of tan chert and is comparable to specimens in Stage V, Group 1, Form 4, but is generally better made than the Stage V specimens. It is too fragmentary to type accurately, but the curvature of the base is compatible with the Refugio type (Suhm and Jelks 1962:241).

Group 1, Form 5: Miscellaneous Parallel Sided (2 specimens)

Both of these biface fragments have some affinities with Paleo-Indian style points, although neither can be typed.

The first (Fig. 15,e) contracts to a squarish base almost resembling an Angostura point (Suhm and Jelks 1962:167), but it lacks ground edges and a concave base. It came from the surface at the base of the bluff and thus, cannot be related to any specific context. It is made of a coarse-grained brown chert about $2.3 \mathrm{~cm}$ at maximum width and $0.7 \mathrm{~cm}$ thick.

The other is a medial fragment of red chert with a controlled transverse flaking pattern reminiscent of that found on some Scottsbluff points (Fig. $15, d)$. However, it lacks a base, and the blade only marginally fits into the size range given for Scottsblufo in the Handbook of Texas Archaeology (Suhm and Jelks 1962:245). This specimen, found in Level 3, is thought to be a fragment of a Paleo-Indian point. Length of the fragment is $5.1 \mathrm{~cm}$, maximum width is $2 \mathrm{~cm}$, and maximum thickness is $0.7 \mathrm{~cm}$. This projectile point fragment (which could have been stemmed) shows some indication of being heat treated, 
and at least one modern-day flintknapper has been able to secure this deep red color from brown Guadalupe River chert by careful heat treating (Ralph Robinson, personal communication).

\section{Group 2: Stemmed (23 specimens)}

This group includes projectile points and other hafted bifaces, that have basal preparation as taking the form of notching or stem manufacture. In theory, this group represents the ultimate expenditure of energy in the production of a hafted stone tool (generally more so than the unstemmed tools), but there are practical problems: (1) there is differential quality of workmanship on even finished tools; thus, some of the specimens would probably not be classed as Stage VI were they not notched; (2) there is an obvious differential energy expenditure between the smal1 arrow points produced from flakes and the larger dart points from cobbles or large flakes. Therefore, other than the finished notching effort or stem production, there is little technological unity among the group. This group is divided into three subgroups based upon the type of stem.

\section{Subgroup 1: Expanding Stem (16 specimens)}

Group 2, Form 1: (2 specimens; Fig. 16,g,h)

These two specimens are both side notched with distinct expanding stems and are almost identical in size. Both generally fit the Ensor category (Suhm and Jelks 1962:189). One is a brown chert with rounded shoulders and is crudely chipped (Fig. 16,g). It is $3.5 \mathrm{~cm}$ in length with a maximum blade width of $2 \mathrm{~cm}$. Neck width is $1.3 \mathrm{~cm}$, and stem width is just less than $2 \mathrm{~cm}$. Thickness is almost $0.8 \mathrm{~cm}$. It has some tiny black specks, which may be traces of asphaltum on the face at the neck constriction.

The other specimen is a light brown chert and has a prominent, squared-off shoulder; the other is broken off $(\mathrm{Fig} .16, \mathrm{~h})$. It is $3.4 \mathrm{~cm}$ in length with a maximum remaining blade length of $2.2 \mathrm{~cm}$. Neck width is $1.3 \mathrm{~cm}$, and maximum stem width is just less than $2 \mathrm{~cm}$. This point has black residue on both faces of the stem, which has been chemically tested and shown to be asphaltum.

Group 2, Form 2: (1 specimen; Fig. 16,f)

This specimen is a corner-notched version of Form 1 and occurs at the same elevation in the same context at this site. It is, however, larger than the two Form 1 specimens and chipped somewhat differently. Morphologically, it is between the Ensor (Suhm and Jelks 1962:189) and Marcos (Suhm and Je1ks 1962:209) dart point styles. Unlike many Ensor points, it is corner notched with sma11 barbs and a broad base. However, unlike Marcos, the barbs are small, and the base extends out as far as the barbs. Made of a brown chert, it has an overa11 length of $4.5 \mathrm{~cm}$. Maximum blade and stem width are both $2.3 \mathrm{~cm}$. Width at the neck is $1.5 \mathrm{~cm}$, and the thickness is just less than $0.6 \mathrm{~cm}$. 
Figure 16. Stemmed Projectile Points.

a, Stage VI, Group 2, Subgroup 1, Form 3, Dare arrow point, N98 E98, Leve1 2;

b, Stage VI, Group 2, Subgroup 1, Form 7, Scallorn-1ike arrow point, N97 E99, Level 3;

c, Stage VI, Group 2, Subgroup 1, Form 6, Scallorn, N98 E97, Leve1 4;

d, Stage VI, Group 2, Subgroup 2, Form 3, Perdiz, N99 E99, Level 2;

e, Stage VI, Group 2, Subgroup 2, Form 3, Perdiz, N99 E96, Leve1 1;

f, Stage VI, Group 2, Subgroup 1, Form 2, Ensor-Marcos, N97 E99, Leve1 3;

g, Stage VI, Group 2, Subgroup 1, Form 1, Ensor, N98 E98, Leve1 3;

h, Stage VI, Group 2, Subgroup 1, Form 1, Ensor, N97 E97, Level 3;

i, Stage VI, Group 2, Subgroup 1, Form 5, expanding stem, N97 E99, Leve1 6;

j, Stage VI, Group 2, Subgroup 1, Form 4, expanding stem, N97 E99, Leve1 4;

k, Stage VI, Group 2, Subgroup 2, Form 1, Morhiss, N97 E99, Leve1 7;

1, Stage VI, Group 2, Subgroup 2, Form 1', Morhiss, N97 E96, Leve1 2;

m, Stage VI; Group 2, Subgroup 2, Form 2, Morhiss-variant, N99 E97, Leve1 6. 


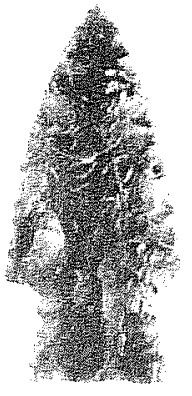

a

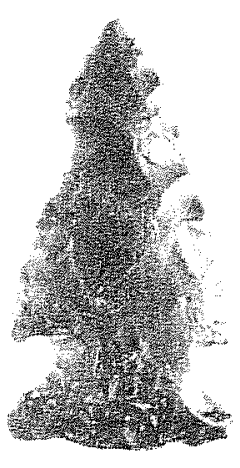

$f$

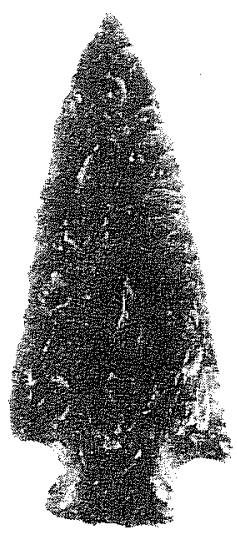

j

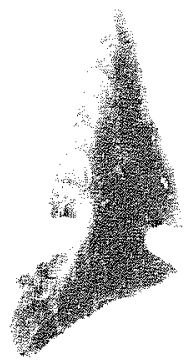

b

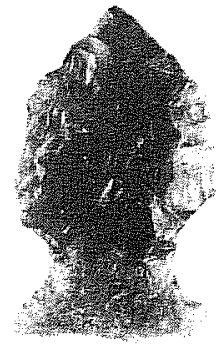

9

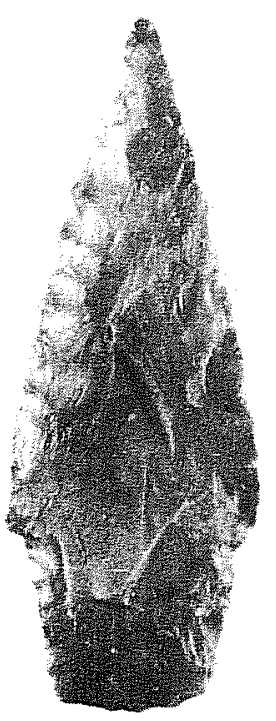

k

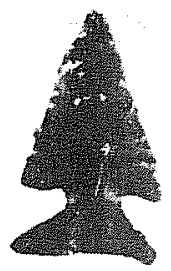

c
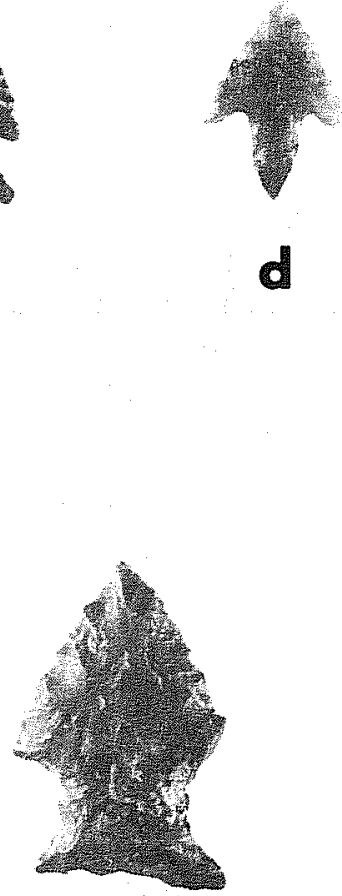

d

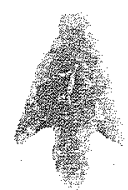

e

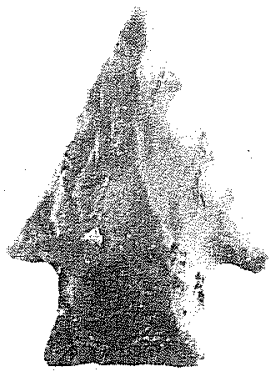

h

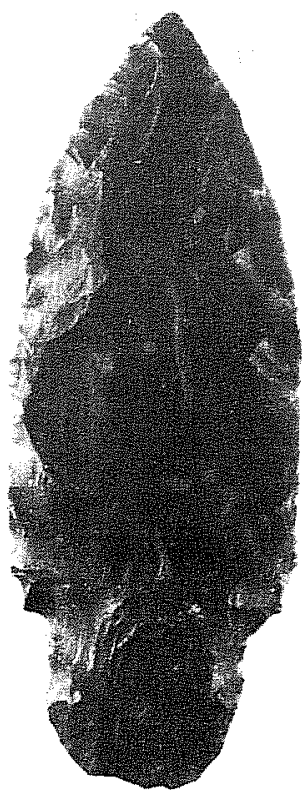

I

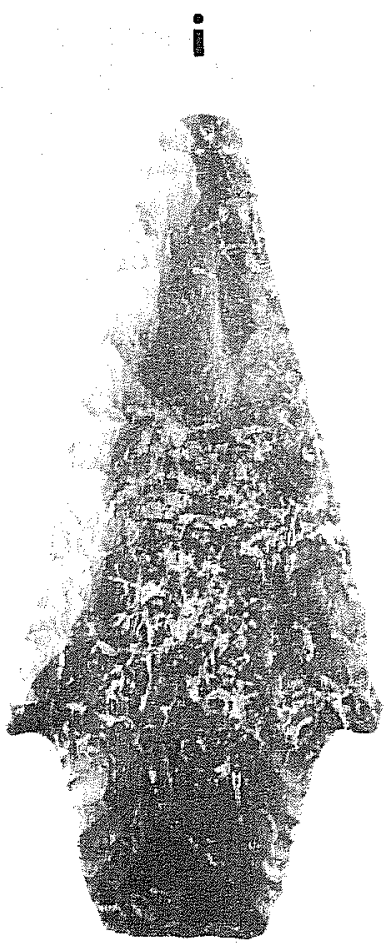

m

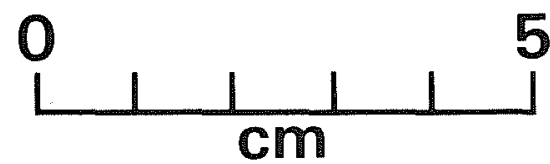


This point was mapped in place in $N 97 \mathrm{Eg9}$, Level $3,38 \mathrm{~cm}$ below the surface. This depth is thought to be characteristic of the Ensor/Late Archaic zone.

Group 2, Form 3: (3 specimens; Fig. 16,a)

One small expanding stem point is well made. It has slight, almost squared shoulders and a straight base. It fits well within the Dare category (Suhm and Jelks 1962:179). Overall length is $3.9 \mathrm{~cm}$, and maximum blade width is $7.8 \mathrm{~cm}$. Maximum stem width is $1.5 \mathrm{~cm}$, and stem length is $1 \mathrm{~cm}$. Thickness is $0.5 \mathrm{~cm}$. It is thermally altered and red, with some crazing and a pot lid removed from one face. This point was mapped in place in $\mathrm{N} 99 \mathrm{E} 98$, Level 2 , at $28 \mathrm{~cm}$ below the surface and in close association with Feature 1 (Occupation Floor II).

Two small expanding stem fragments were recovered from the site, and both are likely representations of this type. Maximum stem width on one is $1.4 \mathrm{~cm}$ and on the other is $1.6 \mathrm{~cm}$. Thickness on the former is $0.4 \mathrm{~cm}$ and on the latter is $0.6 \mathrm{~cm}$. Both are similar in flaking style to the whole specimen, and both are also thermally altered. The smaller specimen came from Shovel Test 6 in the earlier excavation, and the larger from the screened matrix of Feature 1 . This latter has traces of probable asphaltum present.

Group 2, Form 4: (3 specimens; Fig. 16,j)

Two specimens do not fit any established type, but could be best termed as Darl-1ike. One specimen, of light brown fine-grained chert, is long and narrow with rounded shoulders and a short stem. Overall length is $6.4 \mathrm{~cm}$, and the maximum width (at about $1.5 \mathrm{~cm}$ above the shoulders) is $2.5 \mathrm{~cm}$. The stem expands from 1.1 to $1.3 \mathrm{~cm}$ and is $0.8 \mathrm{~cm}$ in length. Maximum thickness is $0.5 \mathrm{~cm}$. This specimen came from Leve 2 of the 1977 excavations and probably fits in the same time period as the Form 3 specimens.

The other Form 4 point is more carefully flaked. It actually has a transverse parallel style seen in some Paleo-Indian points (see above), but is thought to be coincidental or imitative in this case. Overal1 length is $5.2 \mathrm{~cm}$, and maximum width is more than $2.3 \mathrm{~cm}$. The stem expands from 1.1 to $1.3 \mathrm{~cm}$ and is $0.7 \mathrm{~cm}$ in length. Maximum thickness is $0.6 \mathrm{~cm}$. This specimen is thermally altered. It was found in $\mathrm{N} 97 \mathrm{E97}$, Leve 14 of the recent excavations and is either associated with the Ensor/Marcos occupation or the somewhat lower part of Occupation Floor II.

In addition to the two definite specimens described above, a medial fragment has rounded shoulders and is similar in size and chipping style to the former specimen above. It was also found in Level 2 of the 1977 test pit.

Group 2, Form 5: (1 specimen; Fig. 16,i)

This small expanding stem point cannot be classified in any established type category. It is made of a light tan chert and has a broad short blade with smal1 barbs above a wide, slightly expanding base. Overall length is $3.7 \mathrm{~cm}$, and maximum width is $2.9 \mathrm{~cm}$. The stem expands from $1.5 \mathrm{~cm}$ to $1.8 \mathrm{~cm}$, and is 
$1.1 \mathrm{~cm}$ in 1ength. Thickness is $0.7 \mathrm{~cm}$. The stem of this point is covered with a black substance that chemical testing shows to be asphaltum. A pronounced ring across the neck shows the location of the hafting. This specimen came from N97 E99, Level 6 of the recent excavations and is stratigraphically above the Morhiss level and below the Occupation Floor II level. It is the only potentially diagnostic tool recovered from between these two levels.

Group 2, Form 6: (4 specimens; Fig. 16,c)

This form corresponds to the Scallorn type (Suhm and Jelks 1962:285). One specimen is complete, and three are represented by bases only. All show varying degrees of thermal alteration. The complete specimen is $2.6 \mathrm{~cm}$ in length. Maximum blade and stem widths are both $1.5 \mathrm{~cm}$. Neck width is $0.6 \mathrm{~cm}$. Thickness is $0.4 \mathrm{~cm}$. Stem width of the only complete specimen is $1.8 \mathrm{~cm}$.

Group 2, Form 7: (1 specimen; Fig. 16,b)

This asymmetric specimen shows definite affinities with the Scallorn type. It has a narrow triangular blade with a narrow neck and a pronounced expanding stem. One ear of the stem, however, is more than twice as long as the other. It has been included in a different form category because it appears to be a finished projectile point; this separation is intended to emphasize its uniqueness. It is made of a light brown chert. Overall length is $3.6 \mathrm{~cm}$, and maximum width is $1.5 \mathrm{~cm}$. Neck width is $0.7 \mathrm{~cm}$, and the maximum stem width (measured diagonally along the base) is $1.9 \mathrm{~cm}$. Thickness is $0.4 \mathrm{~cm}$.

This point was mapped in place in Unit N9.7 E99, Level 3 of the recent excavations at a depth of Occupation Floor I associated debris (see Form 3). The other Scallorn points came from generally similar elevations.

\section{Group 2, Form 8: (1 specimen)}

This small arrow point has a slightly expanding stem which is, unfortunately, broken (or left unfinished) near the base. It may either be a Perdiz point with a slightly expanding midstem area, or it may be a variant of the bulbarstemmed point reported by Corbin (1974:42) at coastal sites. Portions of the distal and proximal ends of this point are missing; remaining length is $2.2 \mathrm{~cm}$. Maximum width is $1.3 \mathrm{~cm}$. Stem width is $0.6 \mathrm{~cm}$. Thickness is less than $0.3 \mathrm{~cm}$. Note that unlike any of the Perdiz points collected at this site, this specimen is bifacially worked.

\section{Subgroup 2: Contracting Stem (7 specimens)}

Group 2, Form 1:: (3 specimens)

These contracting stem forms closely resemble Morhiss types (Suhm and Jelks 1962:221). They have rounded shoulders with a rounded slightly contracting stem. Stem size and blade thickness are very similar among the three, but blade shape and size are variable. 
The largest specimen is of a gray chert and has a distinct convex blade shape with a stem that has almost straight sides and a rounded base (Fig. 16,1). It is $8.8 \mathrm{~cm}$ in length and $3 \mathrm{~cm}$ in width. Stem width is $1.9 \mathrm{~cm}$, and stem length is $1.8 \mathrm{~cm}$. Thickness is $0.85 \mathrm{~cm}$. It was found associated with Occupation Floor I debris in Level 2 of N97 E96.

The smallest specimen is also of a gray chert with slightly convex edges, a rounded base, and contracting stem edges. It is $5.6 \mathrm{~cm}$ in length and $2.7 \mathrm{~cm}$ in width. Maximum stem width is $1.9 \mathrm{~cm}$, and length of stem is almost $1.7 \mathrm{~cm}$. Thickness is almost $0.9 \mathrm{~cm}$. This point was found on the surface below the bluff.

The last specimen is of a mottled light brown chert. It has straight (and possibly resharpened) blade edges, a squared-off stem base, and contracting stem edges (Fig. 16,k). Overall length is $7 \mathrm{~cm}$, and width is $2.5 \mathrm{~cm}$. Maximum stem width is $2.1 \mathrm{~cm}$, and stem length is $1.7 \mathrm{~cm}$. Thickness is $0.85 \mathrm{~cm}$. This point came from Level 7 in $N 97$ E97.

\section{Group 2, Form 2: (1 specimen; Fig. 16,m)}

This single specimen is a large contracting stem point with fairly prominent angular shoulders and an unfinished stem base (it otherwise appears to be a finished projectile point). In shape, it corresponds almost exactly to a specimen illustrated as a Bulverde in the Handbook of Texas Archaeology (Suhm and Jelks 1962:170, Plate 858). However, it is extremely thick for a Bulverde and does not have the "classic" Bulverde wedge-shaped base (Suhm and Jelks 1962:169). It generally falls much closer to the range of Morhiss than Bulverde and is technologically very similar to the Morhiss points described above and also to specimens in the collection from the Morhiss site (TARL collection, Austin). In fact, several of the Bulverde points identified at the Morhiss site are closer to Morhiss variants than they are to central Texas Bulverde specimens. It was excavated from approximately the same level as the deeper Marhiss point above. Maximum length is $8.2 \mathrm{~cm}$, and width is $3.8 \mathrm{~cm}$. Maximum stem width is $2.7 \mathrm{~cm}$, and length is $2.0 \mathrm{~cm}$. Thickness is $1 \mathrm{~cm}$.

\section{Group 2, Form 3: (3 specimens; Fig. 16,d,e)}

Two specimens are obvious examples of the Perdiz type (Suhm and Jelks 1962: 283), and a third specimen with a broken, but apparently contracting stem is also an example of this type.

One specimen of 7 ight brown chert (Fig. 16,d) is $2.1 \mathrm{~cm}$ in overall length and $1.5 \mathrm{~cm}$ in width. Stem length is $0.9 \mathrm{~cm}$, and thickness is $0.25 \mathrm{~cm}$. The other complete specimen (Fig. 16,e) has the distal end broken, but $1.9 \mathrm{~cm}$ remains of the length. It is $1.2 \mathrm{~cm}$ wide, and stem length is $0.6 \mathrm{~cm}$. The thickness is $0.2 \mathrm{~cm}$. The remaining broken specimen's length is $2.9 \mathrm{~cm}$, and width is $1.6 \mathrm{~cm}$. The thickness is $0.3 \mathrm{~cm}$. A11 specimens are from Levels 1 and 2 of the recent excavations. 
Miscellaneous Stage VI Biface Fragments (10 specimens)

As with the Stage $V$ fragments, none could be placed into a group or form category because of the lack of a base. A partial exception to this is the barbed fragment described below; it was clearly a Group 2 stemmed point. The shape of that stem is unknown, however.

Barbed (1 specimen; Fig. 15,f)

One wel1-made dart point has most of the blade and one barb remaining. It is of a red chert almost identical to that used on the Stage VI, Group 1, Form 4 specimen. It was found in direct association with Occupation Floor II materials; although the lack of a stem makes it unidentifiable, it is suggested that well-made barbed points such as this are diagnostic of 0ccupation Floor II. Maximum remaining width is $3.3 \mathrm{~cm}$. Barb length is $0.7 \mathrm{~cm}$, and width is $0.4 \mathrm{~cm}$. Maximum thickness is $0.5 \mathrm{~cm}$. This fragment is definitely thermally altered.

\section{Gouge Fragment (1 specimen)}

This small distal gouge fragment was difficult to assign to a manufacturing stage, much less a form category, so it has been included with the misce11 aneous unclassifiable fragments from Stage VI. It is apparently a finished artifact showing macroscopic unifacial wear on one face of the bit end. Some of the more pronounced ridges show some polish wear. Its width-tothickness ratio (2.4:1) places it outside of the range of both Stage $V$ and Stage VI artifacts, and in chipping style it is somewhat intermediate between Stage $V$ and Stage VI. Its status as a finished artifact argues for its inclusion here. Since it very likely had no stem, it might be included with Group I artifacts, but basal preparation can only be guessed at since it does lack a proximal end.

This piece is made of a grayish brown, medium-grained chert with a slightly waxy luster. It is biconvex in profile. Maximum width is $3.9 \mathrm{~cm}$. Thickness is $1.6 \mathrm{~cm}$. Probably more than half the piece is missing, but the remaining length is $5.3 \mathrm{~cm}$. It was found lying at the base of the bluff and may have fallen from much higher up.

\section{Distal Fragments (5 specimens)}

These five specimens are tentatively placed in the Stage VI category, because of the quality of workmanship present. One of these is thermaliy altered.

\section{Medial Fragments ( 3 specimens)}

One of these 3 fragments is thermally altered and resembles Stage VI, Group 2, Subgroup 1, Form 4 in size and workmanship. 
Ground and Pecked Stone

The distribution of ground and pecked stone is shown in Table 14.

TABLE 14. GROUND AND PECKED STONE BY LEVEL

\begin{tabular}{|c|c|c|c|c|c|}
\hline Leve1 & $\begin{array}{l}\text { Flat } \\
\text { Ground Stone }\end{array}$ & Abraders & $\begin{array}{l}\text { Total } \\
\text { Ground Stone }\end{array}$ & $\begin{array}{l}\text { Possible } \\
\text { Hammerstones } \dagger\end{array}$ & TOTAL* \\
\hline 1 & $1(1)$ & & $1(1)$ & & $1(1)$ \\
\hline 2 & $4(2)$ & $1(1)$ & $5(3)$ & 8 & $13(3)$ \\
\hline 3 & $16(6)$ & & $16(6)$ & 16 & $32(6)$ \\
\hline 4 & $10(1)$ & & $10(1)$ & 13 & $23(1)$ \\
\hline 5 & 4 & & 4 & 7 & 11 \\
\hline 6 & 2 & & 2 & 2 & 4 \\
\hline 7 & & & & & \\
\hline 8 & $1(1)$ & & $1(1)$ & 1 & $2(1)$ \\
\hline 9 & & & & 2 & 2 \\
\hline 10 & & 1 & 1 & & 1 \\
\hline 11 & & & & 1 & 1 \\
\hline$\nabla$ & $2(2)$ & & $2(2)$ & & $2(2)$ \\
\hline TOTAL & $40(13)$ & $2(1)$ & $42(14)$ & 50 & $92(14)$ \\
\hline
\end{tabular}

* Totals include materials from both 1977 and 1979 excavation units; totals in parentheses are 1977 materials only.

+ A7though a number of possible hammerstones were identified from the 1977 excavations, those specimens are not included here.

$\nabla$ Unprovenienced specimens.

Ground Stone (42 specimens)

A total of 42 potential specimens of ground stone were sorted from the thousands of small pieces of sandstone excavated from the site, Almost al1 of the specimens show very slight wear, and most are very fragmentary. No intact 
grinding slabs or metates were present, and only a few of the larger stones may have been intact manos. Two grooved stones or abraders, one from each season of excavation, were collected. Both show a single deep groove of probable intentional origins, since the area is not known to have ever been plowed. The deeper of the two specimens was found a meter and a half beneath the surface. One of the flat surfaces has traces of a red pigment. The distribution of ground stone artifacts (Table 14) parallels that of altered quartzite cobbles from the site.

\section{Pecked Stone (50 specimens)}

Out of the hundreds of quartzite cobbles and fragments excavated from the 1979 main excavation unit, 50 specimens exhibited signs of pecking or battering wear. These are interpreted primarily as hammerstones used in the manufacture of chipped stone tools, and the relatively large number correlates well with the obvious emphasis on chipped stone tool manufacture at the site. Many of the specimens, however, may have been utilized in other tasks, including food preparation and hide working. The primary wear pattern on all the specimens indicates usage by force of impact rather than grinding or polishing.

The amount of wear present on the specimens varies considerably, from very light wear in only a single spot to moderate wear in multiple locations. The lack of very heavily utilized specimens and the relative abundance of lightly or moderately used pieces may be an indication of the abundance of quartzite cobbles present both in the excavation unit and below the bluff in the creek bed. Many of the altered cobbles show signs of thermal fracturing and discoloration.

It can be seen from Table 14 that most of the specimens occur in Levels 2 through 5 with more than half of the total 50 examples coming from Levels 3 and 4. This parallels the overall occurrences of cultural materials at the site. Note that the 50 specimens reported here and in Table 14 do not include altered quartzite cobbles recognized in the 1977 excavation.

\section{NONLITHIC ARTIFACTS}

The distribution of nonlithic artifacts is shown in Table 15.

Ceramics (4 specimens)

Only one sherd was found during the 1979 excavations. It is a very smal1 fragment of bone-tempered ware with a lightly burnished brown exterior and slightly smoothed black interior. The tempering material is finely crushed and occurs almost exclusively near the exterior surface with some particles showing in the vessel wal1. Thickness is $0.6 \mathrm{~cm}$.

Three sherds of similar bone-tempered pottery were found in the 1977 excavations. All of these sherds appear more closely related to Leon Plain and related types in central and south Texas rather than the local coastal pottery, Rockport ware, or the late inland pottery, Goliad ware. They would fit fairly 
TABLE 15. NONLITHIC MODIFIED MATERIALS BY LEVEL

\begin{tabular}{|c|c|c|c|c|c|c|c|c|c|c|}
\hline \multirow[b]{2}{*}{ Level } & \multirow[b]{2}{*}{ Ceramics } & \multirow[b]{2}{*}{$\begin{array}{c}\text { Shell } \\
\text { Ornaments }\end{array}$} & \multicolumn{7}{|c|}{ B 0 ne ToOl } & \multirow[b]{2}{*}{$\begin{array}{l}\text { Total } \\
\text { by Leve1 }\end{array}$} \\
\hline & & & Awls & $\begin{array}{l}\text { Ulna } \\
\text { Tool }\end{array}$ & $\begin{array}{l}\text { Antler } \\
\text { Flaker }\end{array}$ & $\begin{array}{l}\text { Antler } \\
\text { Tines }\end{array}$ & $\begin{array}{l}\text { Polished } \\
\text { Bone }\end{array}$ & $\begin{array}{l}\text { Cut } \\
\text { Bone }\end{array}$ & Total & \\
\hline 1 & $4(3)$ & & 1 & & & & & & 1 & $5(3)$ \\
\hline 2 & & 1 & & $1(1)$ & 1 & 3 & 1 & & $6(1)$ & $7(1)$ \\
\hline 3 & & $3(1)$ & $3(1)$ & & & 1 & & & $4(1)$ & $7(2)$ \\
\hline \multicolumn{11}{|l|}{4} \\
\hline 5 & & & & & & 1 & & & 1 & 1 \\
\hline$\nabla$ & & & $1(1)$ & & & & 1 & $1 *$ & $3(1)$ & $3(1)$ \\
\hline TOTAL & $4(3)$ & $4(1)$ & $5(2)$ & $1(1)$ & 1 & 5 & 2 & 1 & $15(3)$ & $23(7)$ \\
\hline
\end{tabular}

* This specimen is probably from a depth equivalent to Level 1.

$\nabla$ Unprovenienced specimens. 
well within Hester and Hi11's (1971:197) Miscellaneous Bone-Tempered group. It is interesting to note that Hester and Hill note the presence of grog- and sand-tempered pottery, as wel1 as Rockport ware sherds, at the Berclair site in southern Goliad County. At the Burris site $9 \mathrm{~km}$ to the south, several sandtempered sherds, one with asphaltum, were observed (see Appendix I). On the other hand, numerous sherds of an almost identical type (to that found at 41 GD 30A) were excavated at nearby 41 GD 21 and 41 GD $21 A$.

Shell (4 specimens; Fig. 17,a)

No marine shel1 was recovered from the excavations, and four shell ornaments were the only examples of worked shell. A7l are nearly square with two holes drilled near one long edge. A11 are about one centimeter long by one centimeter wide. The holes are generally about $0.2 \mathrm{~cm}$ wide and the center $0.5 \mathrm{~cm}$ apart. Although none were recovered in situ, their distribution appears to paralle1 that of the Austin phase floor.

Similar shell ornaments have been reported from the excavations in the Alamo Plaza report (Fox, Bass, and Hester 1976:70-72), and a somewhat similar specimen is illustrated from a Late Prehistoric zone at the Venom Hill site at Palmetto Bend (McGuff 1978).

Bone

Ulna Flaker (1 specimen)

One flaker made from a modified deer ulna was recovered from the 1977 excavation and is illustrated in the report by Fox, Black, and James (1979:55). It is from Level 2.

\section{Awls ( 5 specimens; Fig. 17,e)}

Four awls or fragments were recovered, two in $1977^{\prime}$ and three in 1979. A11 are apparently made from split deer metatarsals. One complete specimen measures just over $14 \mathrm{~cm}$ in length (illustrated in Fox, BTack, and James 1979:55). Three of the definite specimens are from Level 3; one from the 1977 Shovel Test 7. The other specimen is from Level 1 of the 1979 excavation. Two other possible fragments are included under polished bone.

Antler Flaker or Billet (1 specimen; Fig. 17,d)

A distal end of an antler tool was found in Level 2 of the 1979 excavation. It is sma11, badly worn (eroded?), and burned.

Antler Tines ( 5 specimens)

Five antler tines were recovered, but they are too fragmentary to determine if they were used or even cut. 
Figure 17. Bone, Shell, and Burris Site Artifacts.

a, mussel shell ornament;

b, cut bison bone;

c, polished bone (awl fragment);

$d$, antler flaker or billet;

e, awl bone tool;

$f$, Stage VI, large ovate thin biface;

g, Stage VI biface--Ensor-Marcos projectile point;

$h$, Stage V, Group 1, Form 4, thin biface basal fragment. 

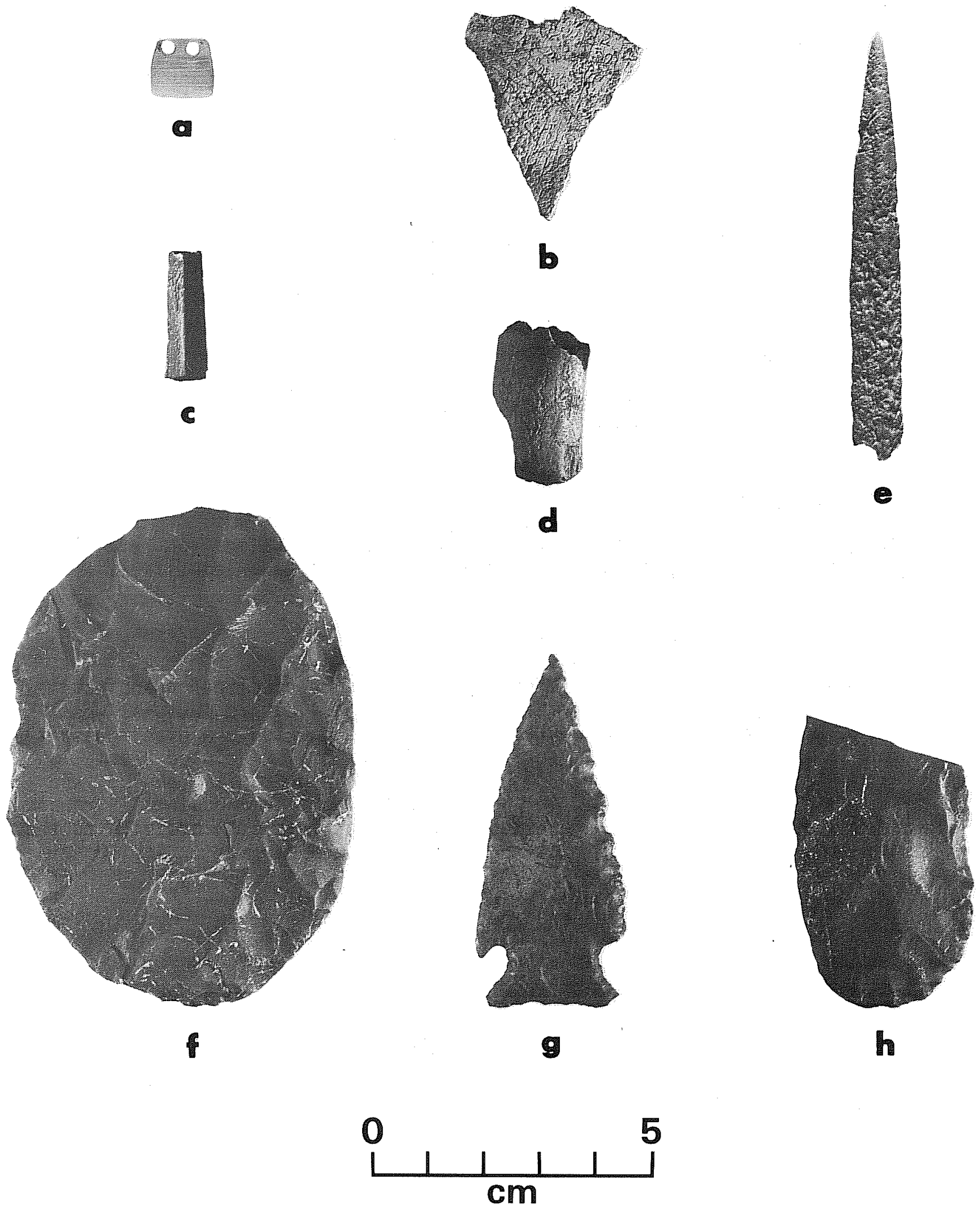
Polished Bone (2 specimens; Fig. 17,c)

These pieces of bone show evidence of polish. One is burned. Both could have been awl fragments, although one is apparently an ulna midsection.

Cut Bone (1 specimen; Fig. 17,b)

One piece of apparent bison bone, which was cut in several directions, was found eroding from the face of the bluff just below the ground surface. It was the only obvious piece of butchered bone present.

\section{Brass Cartridge Case (1 specimen)}

One .22 caliber cartridge case marked "US," which has an extremely heavy off-center circular firing pin impression, was from Level 1.

\section{Miscellaneous Metal (1 specimen)}

A small fragment of a round, thin iron container (excavated from Level 1) with an overlapping, but apparently unfolded seam has not been identified.

\section{NONART IFACTUAL REMAINS}

The enormous amount of cultural debris from the site precluded quantitative analysis of nonartifactual materials from the site. Lithic material was present in almost every level; much of this was undoubtedly a direct result of human occupation at the site. Nonartifactual materials included thermally fractured chert and quartzite, unmodified chert and quartzite cobbles, and sandstone. Probably unrelated to the occupation were numerous small, rounded sandstone and stream-rolled chert and quartzite gravels. In addition to the above, a few lumps of burned clay were found in Level 1 .

\section{FAUNAL AND FLORAL REMAINS}

\section{Vertebrate Fauna}

The analysis of vertebrate fauna is presented in Appendix II. Preservation was generally good through the first few levels, but declined rapidly below that. Although some fragments of bone are found in the lower levels, they are generally poorly preserved. Whether or not the preservation is due to age or not is unknown, but a major factor in preservation seems to be the dividing line between soil zones $5 \mathrm{~b}$ and $5 \mathrm{a}$. Material below $5 \mathrm{~b}$ is poorly preserved. 
Invertebrate Fauna

Gastropods

Seven different genera of land and freshwater gastropods were identified from the site. These include Helicina sp., Polygyra sp., Rabdotus sp., Mesodon sp., Praticolella sp., Stenotrema sp., and Helisoma sp. Rabdotus has been suggested before as a possible prehistoric food source in south Texas (Hester and Hill 1975:16; Guntharp 1978). These snails form a large portion of the gastropod sample from the site, especially in the lower levels.

In the upper levels Polygyra is the dominant type and often more numerous than all other types combined. Rabdotus and Helicina are the next most frequent type with Rabdotus often dominant in the lower levels. Mesodon and Praticolella are present in many levels in low quantities, while Stenotrema and Helisoma are somewhat rare.

Members of the family Polygyridae (Polygyra, Mesodon, Praticolella, and Stenotrema) generally inhabit wooded environments, although they are capable of surviving drought by burrowing into the soil (Cheatum and Fullington 1971a:2). Helicina are also woodland inhabitants and are absent from grassland areas (Fullington and Pratt 1974:8). Rabdotus, unlike the others, are arid and semiarid habitat dwellers (Fullington and Pratt 1974:14). Helisoma are a freshwater snail of the family planorbidae and sometimes occur at water margins as well as in bottoms or on aquatic vegetation (Cheatum and Fullington 1971b:2, 15). No quantitative analysis of gastropods from the site has been undertaken.

\section{Pelecypods}

Only two genera of pelecypods have been positively identified in the collection from the site. These are Amblema plicata and Quadrula quadrula. Several other unidentified species are also present in the sample. For a discussion of archaeological mollusc remains from the general area, see D. Fox (1979:57-61). Comparison of the mussel remains between 41 GD 21 on an intermittent stream and 41 GD 30 on a more permanent stream might be useful, but time did not allow the quantification of pelecypod data.

\section{Floral Remains}

A number of hackberry seeds was recovered from the upper levels, but they seemed to decline with depth, perhaps due to preservation factors. Numerous small flecks of charcoal were collected and, although unsuitable for dating purposes because of their relative scarcity and dispersion, could possibly be used at some later date for wood species identification. Since pollen was not preserved at the site (Fox, Black, and James 1979), an analysis of biosilica from specially collected samples has been undertaken. This data will be published at a later date. 


\section{INTERPRETATIONS}

\section{Cultural Sequence}

Earlier test excavations at the site demonstrated the presence of both Late Archaic and Late Prehistoric occupations in the bluff top area. The present investigations have confirmed this presence and provided a more detailed look at the material culture of the occupants. Despite the lack of clear separation between soil zones, there was some stratification evident in the cultural materials from the site. The following section discusses the cultural implications of each strata and their relationship to established phases. Figure 18 offers a schematic artifact sequence in relation to these phases of occupation.

\section{Toyah Phase Occupation}

A cultural assemblage which closely parallels the central Texas Toyah phase (Jelks 1962) seems to be the most recent aboriginal occupation at the site. The possible presence of a bulbar-stemmed point is the only evidence of potential post-Toyah or protohistoric occupation at the site. Because of the lack of corroborating materials, it is felt that this arrow point is more likely to be a.Perdiz variant.

Although little clear evidence of an occupation floor relating to the Toyah phase was found, a number of artifacts appear to date from this period. The most obvious of these include three Perdiz arrow points and four sherds of bone-tempered pottery. Also included are two clifbton arrow points (or probable Perdiz preforms) and a preform which might be an unfinished Perdiz. These artifacts were from the upper two levels. Materials from Level 1 appear to include only Toyah-related artifacts, while Level 2 contains both Toyah and Austin phase artifacts, the latter found only at the base of the level, and below.

Artifacts occurring in Level 1 and thought to be related to the Toyah occupation include 14 utilized flakes, one exhausted core, and eight Stage IV bifaces. Although the sample from Level 1 is extremely sma11, some trends are suggested. Of the eleven relatively whole utilized flakes from this level, only one could be construed as a blade. This is the lowest blade-to-flake ratio above Level 6 (Table 16) and may be indicative of a decline in blade usage in post-Austin phase times. However, such a trend does not occur elsewhere in Toyah phase sites (T. R. Hester, personal communication).

On the other hand, overall usage of utilized flakes (Table 17) only declines slightly from maximum usage in Level 2. Level 1 also contains the highest relative percentage of single-edged utilized flakes (with the exception of Level 8 which only contains a single utilized piece); almost $82 \%$ of the utilized flakes in this level are either unilateral or distal (Table 7). This reverses an apparent trend toward the use of multiple edges that is visible in Levels 6 through 2 . The high percentage of unilateral usage (Table 7) could be related to the high percent of laterally retouched pieces that McGuff (1978: 161) considered distinctive of the second portion of the Late Prehistoric period (equivalent to the Toyah phase) in the Palmetto Bend Reservoir. 


\section{DIAGNOSTIC ARTIFACT SEOUENCE}

Suggested

Chronology

- 1250 AD

$1000 \mathrm{AD}$

O AD

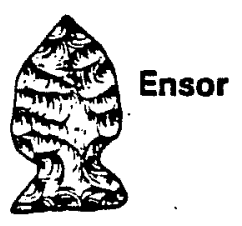

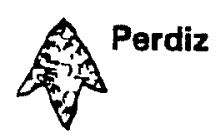

$\Longrightarrow$ Bone Tempered

Triangular Arrow Point
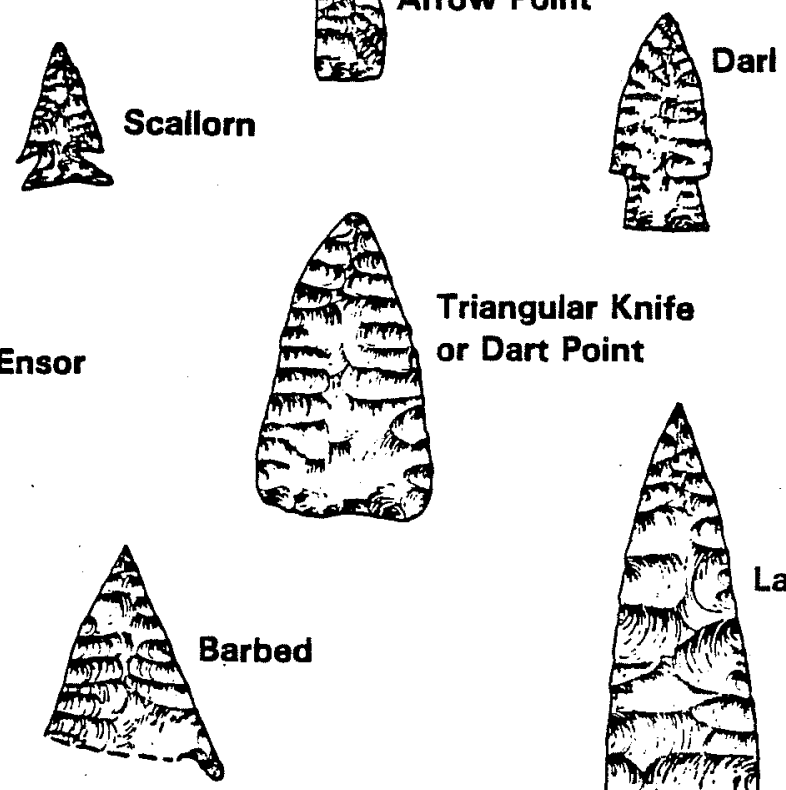

Triangular Knife or Dart Point

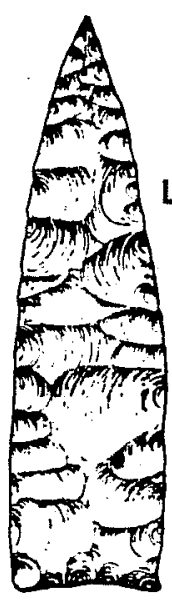

$48 \mathrm{~cm}$
$58 \mathrm{~cm}$

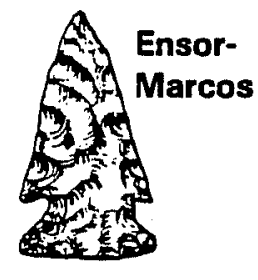

$38 \mathrm{~cm}$
Below

Surface

$18 \mathrm{~cm}$
이 Shell $28 \mathrm{~cm}$
Ornament

\section{BC}

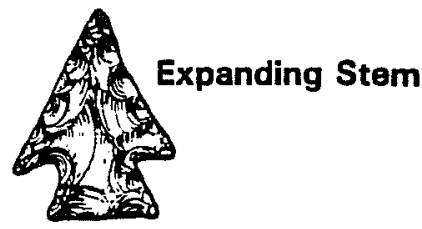

$68 \mathrm{~cm}$
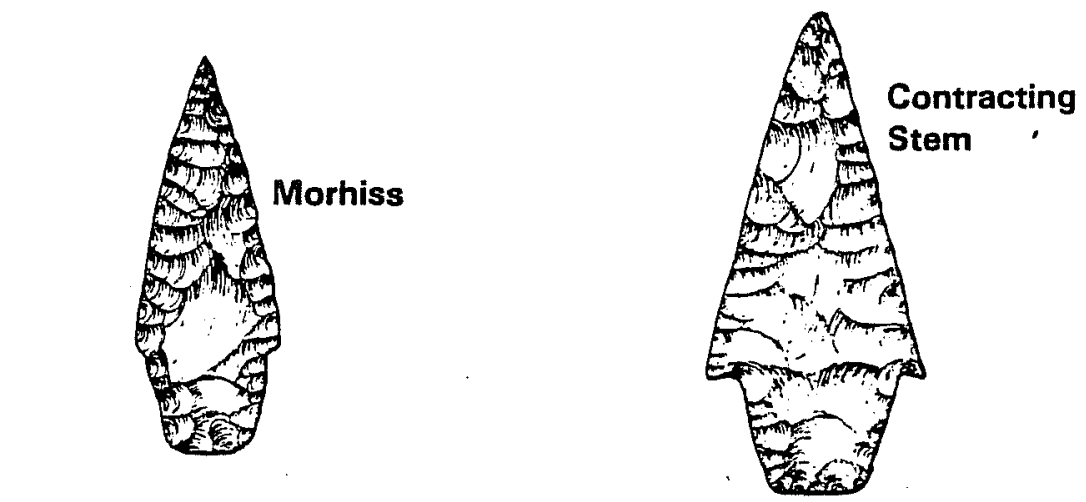

$78 \mathrm{~cm}$

$1000 \mathrm{BC}$

Contracting

Figure 18. Diagnostic Artifact Sequence. 
TABLE 16. FLAKE VERSUS BLADE UTILIZATION PERCENTAGES

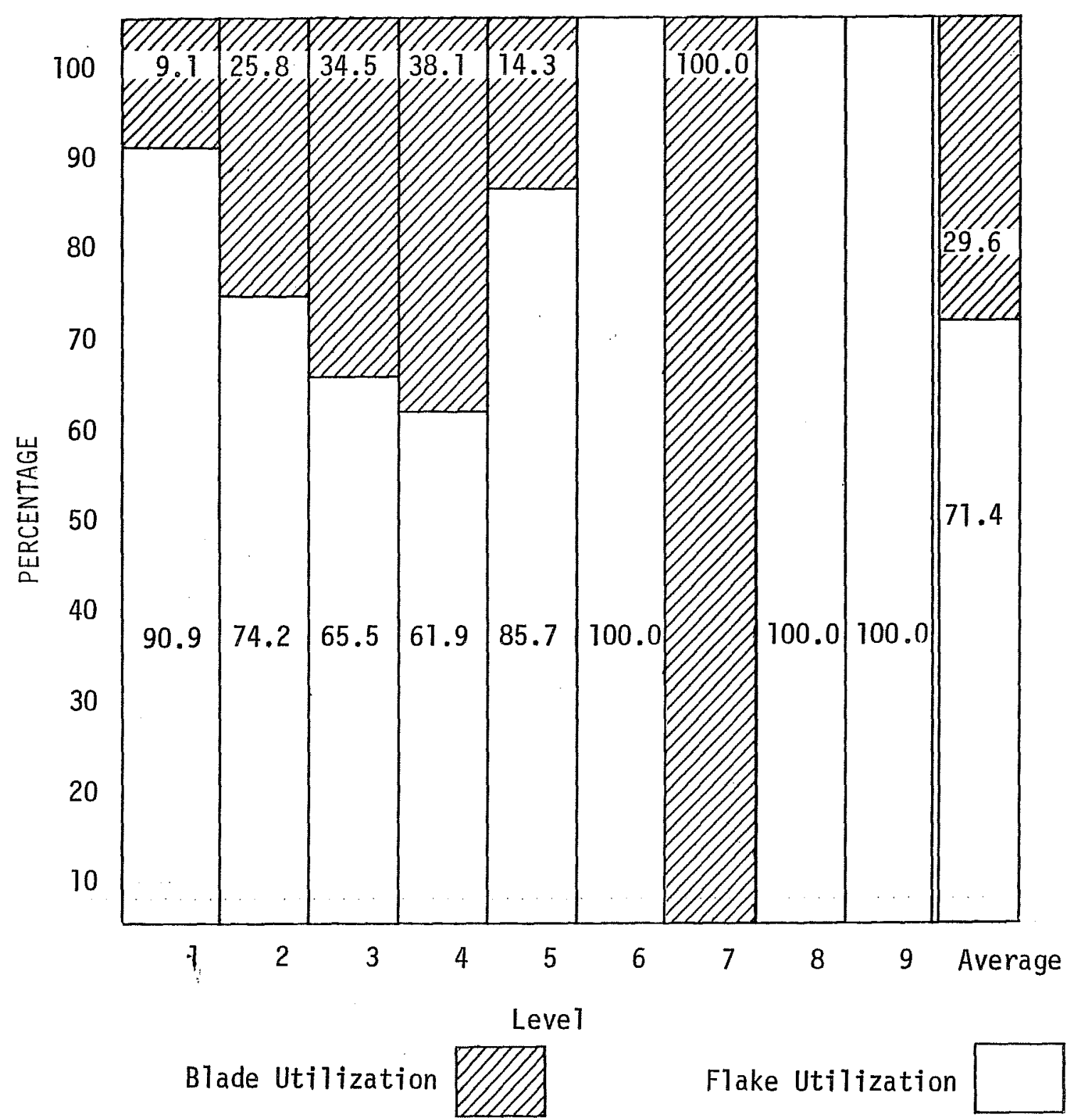


TABLE 17. SINGLE VERSUS MULTIPLE EDGE FLAKE (AND BLADE) UTILIZATION

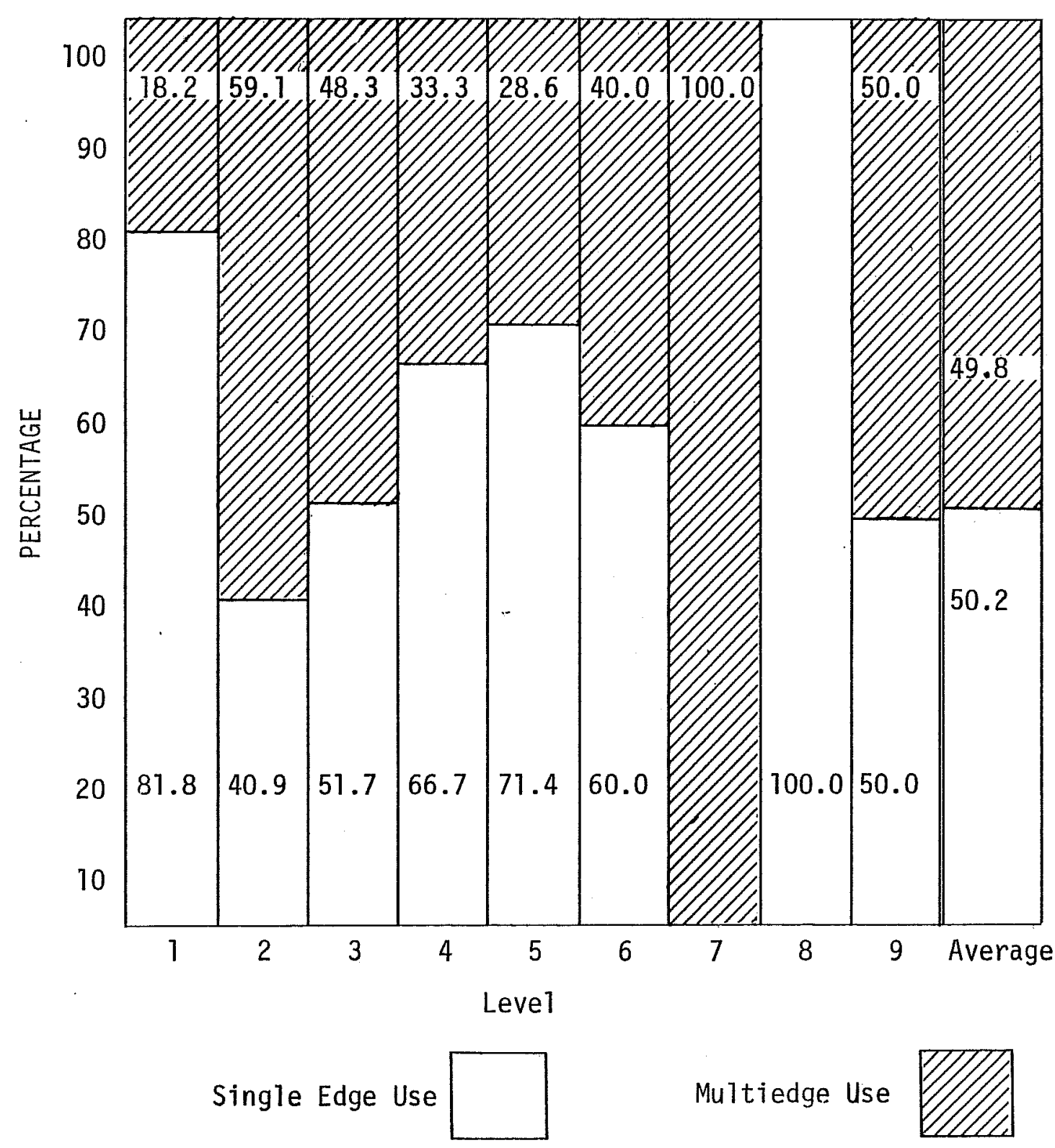


McGuff (1978) also points out that a ". . . high percent of thin, plano-convex bifaces with no wear present . . ." are found in this late period. This correlates well with the relatively large number of unfinished thin bifaces from Level 1 (cf. Table 18). A closer examination of this distribution shows that this trend in unfinished thin bifaces is a result of the Stage IV bifaces present.

These eight bifaces (none of which show any wear and several of which are slightly plano-convex) are almost $20 \%$ of the total Stage IV sample from the site, the highest percentage of any major lithic artifact category present in Level 1. This also represents the largest number of any undivided group of artifacts present in Level 1. The presence of these "blanks" in a level, which is almost totally lacking in large, finished, thin bifaces, suggests that they may actually have served as expedient tools in performing a function with low visible wear and no need for regular, razor-sharp edges.

Whether these bifaces are replacements for some other tool type of declining popularity or whether they represent a new cultural function cannot be inferred from the data available. However, the possibility of expedient tools whose function takes precedence over morphological regularity or aesthetic appearance is supported by technological analysis of the arrow points associated with the Toyah phase at the Berger Bluff site. Of the seven arrow points and preforms associated with the late occupation, only one (the possible bulbar specimen) is completely bifacially chipped. The other six specimens are primarily or wholly unifacial and are markedly utilitarian when compared to the finely chipped pieces from the Austin phase occupation immediately below this. In comparison, only one Scallorn preform, apparently broken during manufacture, shows this unifacial pattern.

The distinction between preform and finished artifact tends to blur in analysis of expedient tools. A group of Perdiz and cliffton from one or more sites can be sorted into a technological continuum from barely shaped flakes to bifacially flaked Perdiz (cf. Beasley 1978). But the point at which an artifact becomes finished is subjective; almost any unbroken specimen could have provided the piercing function needed in an arrowhead. It may be that in this case viewing these points as a technological continuum is obscuring the existence of a wide range of individual variation dependent either on specific cultural variables or possibly varying with site function.

The predominance of Stage IV bifaces and utilitarian unifacial arrow points is suggestive of change in technological emphasis if not in the actual method of production between the Austin and Toyah phases. This and the general morphological changes of the tools are the best indicators of the replacement of local peoples by a Plains type culture as suggested by McGuff (1978:173). changes in subsistence strategies are the obvious alternate explanation for technological change, although change in subsistence may itself be a function of cultural replacement. The evidence for such replacement is further complicated at the Berger Bluff site by the potential for functional differences between the components.

The Toyah occupation at the Berger Bluff site is interpreted as a short-term hunting camp, either a single event or a sporadic occupation sometime between 
TABLE 18. RELATIVE PERCENTAGES FOR ALL LITHIC AND NONLITHIC ARTIFACTS
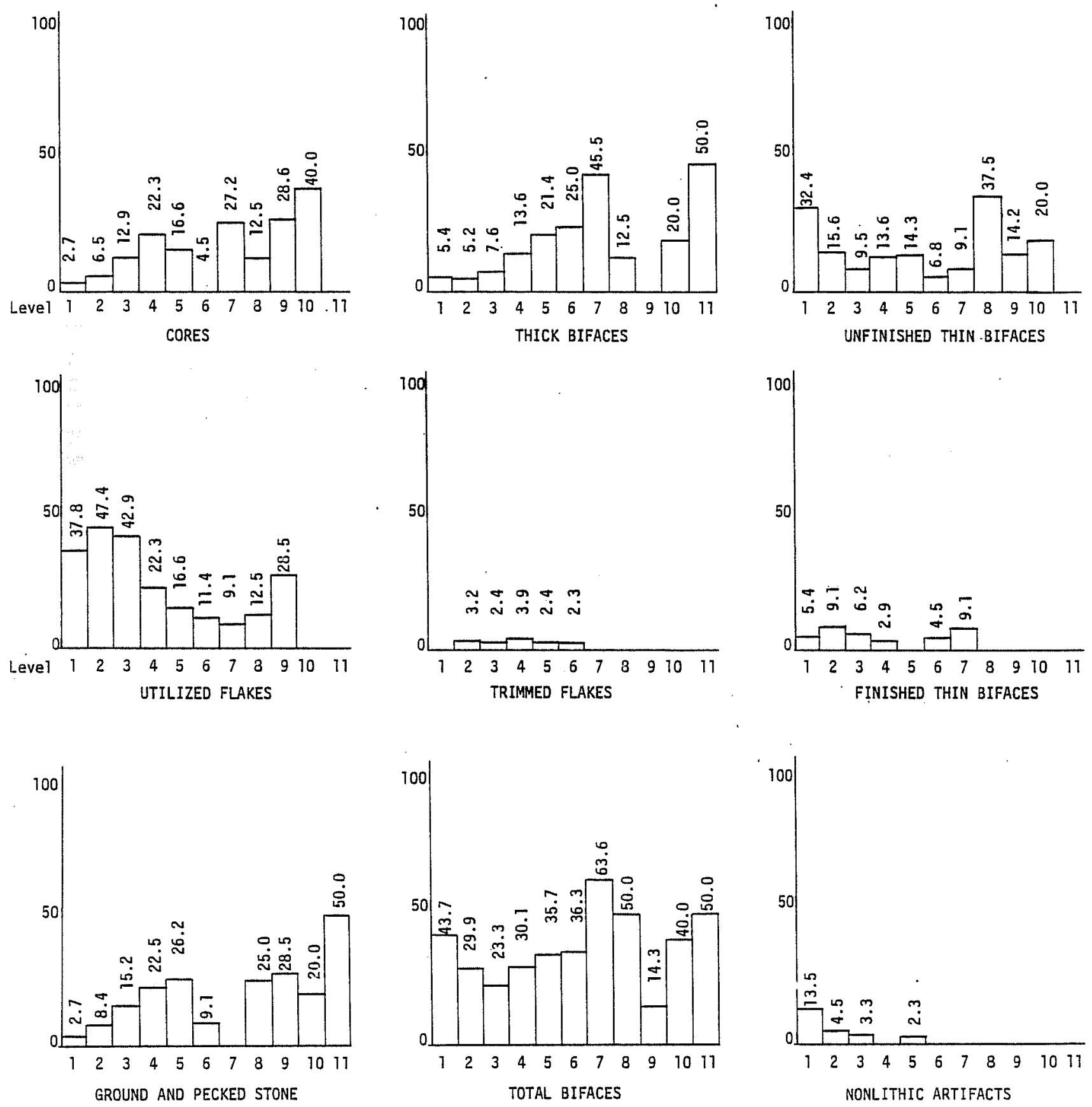

Includes all lithic and nonlithic artifacts with the exception of flakes and chips. 
A.D. 1200 and 1600. Evidence for the short duration of occupation is based not only on the paucity of artifacts, but also on the lack of features or a definable occupation floor, since campsite modifications such as these have been suggested to increase with the length of stay (Schiffer 1978:244). Using the same logic, length of stay correlates directly with the variety of maintenance activities performed (Schiffer 1978). An increase in variety of maintenance activities suggests a concurrent increase in artifact types utilized. Therefore, the relatively small number of artifact categories present in the Toyah assemblage may be taken as an additional indicator of a short-term occupation.

A final indicator of a short-term occupation is the utilitarian nature of the artifacts present. It is suggested that, in general, the shorter the occupation, the more utilitarian and less aesthetic the artifacts tend to become. In this case, the utilitarian nature of the artifacts might be more correlated with an overall technological shift to simpler production techniques; if this is true, it might be an indication of the relative mobility of the culture itself.

The presence of ceramics at the site does not conflict with a short-term occupation. It is probable that only a single small vessel is represented by the sherds.

\section{Austin Phase Occupation}

The subsistence remains in the upper level are not a clear indicator of site function, but the relative paucity when compared to lower levels may offer support to the short-term occupation hypothesis. Evidence from Toyah phase sites elsewhere would suggest that they are bison-hunting people, and the bovid long bones present in the upper levels are probably aboriginal. However, the presence of a historic Sus scrofa (pig) tooth in the upper levels leaves open the possibility of some later mixing. In addition to the bovid remains, whitetail deer, riverine species, and various rodents are represented in the subsistence remains of this level.

Directly below the Toyah phase assemblage is a relatively we11-defined occupation floor associated with artifacts, which seem to reflect a classic central Texas Austin phase occupation (Jelks 1962). The primary diagnostic indicators of this occupation are six Scallorn or Scallorn-like arrow points occurring in Levels 2 through 4. Also apparently associated are Darl and Darl-1ike points from Level 2 as well as possibly two serrated flakes found in Level 3 (Jelks 1962:86).

The thickness of this zone and its occurrence in several levels makes it difficult to identify trends from the general level counts. In most units, this zone first occurred near the bottom of Level 2. Thickness of the deposit was quite variable, but in places it was up to $20 \mathrm{~cm}$ thick and occasionally intruded into the top of Level 4. The occurrence of one Scallorn point base (serrated flake) in an arbitrary level below the level of occurrence of the Ensor-related materials is not thought to be evidence of mixing; there is no evidence from the recorded elevations that any Austin phase material was mixed with or stratigraphically beneath Late Archaic materials. The discrepancy is related to the ground surface slope through the excavation units. 
Recorded elevations for artifacts mapped in place and associated with Occupation Floor I vary between 26 and $32 \mathrm{~cm}$ below the surface. Diagnostic artifacts from this floor include a complete Dare specimen (Fig. 16,a) and an asymmetric Scallorn-like arrow point (Fig. 16,b). Additionally, a large unbroken Morhiss dart point was found in apparently undisturbed context at a depth of $30 \mathrm{~cm}$. More than likely it was collected for reuse, but never actually used, or simply picked up as a curio from an earlier site.

Also included in the 0ccupation Floor I artifacts are several bifaces, biface fragments, and a small chert core. The core is a decorticate platform multidirectional specimen. The bifaces include two Stage II, two Stage IV, and three Stage $V$ specimens. One of the latter is a square-based preform (Group 1 , Form 2), and another is round based (Group 1, Form 4). Each of the specimens is relatively unique, and no major trends can be identified. It is interesting to note, however, that four of the six Scallorn-related and two of the three Darl points exhibit strong thermal alteration.

No hearths were encountered in association with the Austin phase occupation floor, but a lens of mussel shell and concentrated debitage was identified as a discrete midden area (Feature 1). The concentration of mussel shel1 is thickest in the general Austin phase zone, but within the midden area umbo counts run to several thousand per level. Pelycepod species identified from the midden show no gross differences in mussel exploitation during this period, but no quantitative separation has been made.

Bone fragments occur throughout the midden area, but do not seem more highly concentrated than other portions of the zone excavated. The primary species exploited appears to be white-tailed deer, although riverine species in the form of turtle and gar are also numerous.

The Austin phase zone is the most concentrated cultural stratum present in the area excavated. The high density of artifacts, as well as the relative diversity of types present, argues for a longer period of occupation than the overlying Toyah zone. Certainly the accumulation of debris in the midden was no overnight affair. Yet there is no evidence for a permanent or long-term occupation. No features other than the midden were associated with this zone, and its 1 imited extent belies a lengthy stay. Its discrete character also may indicate a single occupation period rather than a number of overnight stays. The evidence seems to point to a short or medium duration seasonal campsite of locally transhumant Austin phase peoples. An accurate time of occupation estimate would be nearly impossible, but for comparative purposes it is suggested that the Austin campsite might have lasted a maximum of several months as opposed to a several week maximum for the Toyah camp.

\section{Late Archaic II Occupation}

For lack of a clear association with other named phases, the next lowest cultural zone is simply identified as the second of two Late Archaic occupations at the site. Like the Toyah zone, no clear occupation floor was delineated. An elevation of $38 \mathrm{~cm}$ for an Ensor-Marcos projectile point (Stage III, Group 2, Subgroup 1, Form 2) is interpreted as being representative of this zone. Two small Ensor points found nearby are thought to be associated with this zone. 
Other artifacts mapped in place within this zone include a large triangular Stage VI biface fragment with a deeply concave base and slightly projecting ears and a subround-based Stage $V$ fragment. A Group 1 Core-Biface (Stage I) was also found at this elevation. A large triangular square-based biface found at $34 \mathrm{~cm}$ below the surface may also be associated with this zone.

As this relatively sparse zone is sandwiched tightly between two denser zones, no level counts can be associated with these materials nor can any other artifact associations be made. It is interesting to note the variations in stoneworking quality present in these materials. While none of the bifaces approach the excellent workmanship present in the overlying Austin phase zone, capable craftsmanship is demonstrated by the large concave proximal fragment; the Ensor-Marcos, although less well made, is still relatively symmetrical with even flaking. The two Ensor points, on the other hand, are crudely made and only barely symmetrical. One or both of these points may have been rechipped or reused. This general trend toward declining stonework craftsmanship may be a result of changing cultural values, or it may be related to site function as was suggested for the utilitarian Toyah materials.

The diversity exhibited by this small sample suggests that they may not all be related to the same occupation. Perhaps several short-term occupations by various groups were located next to the periphery of the main excavation unit. The lack of features at this level would seem to support this. Other than the cross-dating of the Ensor and Marcos types to the Late or Transitional Archaic in central Texas, very little can be said of this poorly documented occupation.

Late Archaic I Occupation

Beneath the Ensor period materials and separated from them by a thin sterile zone was the most distinct occupation floor at the site, Occupation Floor II. Lacking the density of faunal material present in Occupation Floor I, Occupation Floor II was characterized primarily by lithic debris. On the whole, this debris was as dense and more evenly distributed than the Occupation Floor I debris. In addition, a tendency toward larger materials was noted during the excavation.

Occupation Floor I I was easily observed in all the excavated units. At least two features are thought to be associated with this floor, and sixteen artifacts were mapped in place on it. Observations in the field which suggested that it was actually two very closely layered floors are supported by the bimodal distribution of depths. Occupation Floor IIA artifacts were recorded between $46-50 \mathrm{~cm}$ below the surface; Occupation Floor IIB artifacts fell between 54-56 cm in depth. No artifacts were recorded in between, al though a small amount of debitage actually spanned this gap.

No clear diagnostics were recovered from this floor, although a well-made dart point fragment (Fig. 15,f) with a pronounced barb was found on this floor and is suggestive of Archaic notched points such as Castroville or Marshall.

On the basis of its stratigraphic position below the Ensor zone, an early Late Archaic date is postulated.

The only other Stage VI artifact recovered from this zone (both this and the barbed fragment are from Occupation Floor IIA) is a long narrow concave-based 
or lanceolate biface (Fig. 15,h). Its concave base and especially its long parallel-sided form were echoed more than a half dozen times in Stages II-V bifaces recovered from this zone (cf. Figs. 13,d,e; 14,a,c). This distinct shape is considered diagnostic of this floor at the Berger Bluff site and may eventually prove useful in relating this occupation to similar components elsewhere.

Artifacts mapped with Occupation Floor IIA include the two Stage VI bifaces described above and four other bifaces or fragments. These latter include two fragments found $2.27 \mathrm{~m}$ apart which fit together to form an almost complete square-based Stage $V$ biface (Fig. 14,C). Computed depths from the surface for these two pieces are 48 and $47 \mathrm{~cm}$ (absolute elevations, on the other hand, were $13 \mathrm{~cm}$ apart). A Stage III and Stage IV biface were also recorded. In addition to the bifaces, a single facet, unidirectional decorticate platform core and a bone awl were found with the Occupation Floor IIA materials.

Occupation Floor IIB artifacts consist of four bifaces, one core fragment, one single facet multidirectional decorticate platform core, and two trimmed flakes. One of the trimmed flakes is serrated (Fig. 12,a), and the other is bilaterally chipped. Bifaces from Occupation Floor IIB include three Stage V specimens: one concave-based, one round-based, and an ungrouped fragment. The fourth biface is a Stage II thick biface.

Although both Austin phase and Late Archaic II materials may intrude slightly into the upper few centimeters of Level 4 in many of the units excavated, 0ccupation Floor II is almost wholly contained with in that level and contributes the vast majority of the artifacts. Therefore, it is felt that comparison of the artifact inventory for Level 4 is generally representative of this occupation. A scan of the intra-level artifact percentages from Table 18 shows several interesting facts:

1. During the Late Archaic I period, cores show the highest intra-level percentage for any of the levels with reasonable sample sizes ( 6 and above).

2. Unfinished thin bifaces account for a slightly larger portion of the total artifact sample in the Late Archaic I occupation than in the subsequent Late Archaic II occupation.

3. Finished thin bifaces are proportionately less numerous than in any subsequent occupation.

4. Thick bifaces form a larger percentage of all artifacts than in subsequent occupations and a smaller percentage than in most preceding occupations.

5. Flake utilization is less than the upper levels, while trimmed flakes (with an admittedly small sample size) increase to their highest relative percentage.

6. Nonlithic artifacts drop to zero, although a bone awl plotted in Level 3 is thought to be associated with this floor.

The increase in core production is the clearest trend and should be indicative of an increase in flake utilization or flake tool production. Neither is visible. Utilized flake percentages drop off, and the relatively large and 
thick bifaces from this zone do not support an increase in flake tool production. Part of this increase may be due to misidentification of early stage bifacial cores; at least two split cobbles from this level were identified as cores, but may be associated with biface production as in the core-biface split cobble blanks. On the other hand, the trends in total biface production and core production are apparently independent of one another (cf. Table 18). At any rate there is an increase in unfinished and rejected bifaces and debitage cores with a corresponding decrease in finished products.

Another trend visible in the artifacts from this level is the utilization of a wider range of chert qualities than in any other level. A higher number of medium- and coarse-grained cherts are included in the artifact sample. It is almost as if the inhabitants were purposefully selecting poorer grades of chert. This selection in no way indicates lack of knowledge of chert qualities and stoneworking techniques; the chipping on Occupation Floor II is some of the best present at the site.

There is some variation in stoneworking quality, however, which may be more pronounced because of the large number of rejects present. Several of the unfinished specimens from this level show a tendency to twist, and on most of the rejected versions of the lanceolate point described above the reason for rejection is obvious. On these specimens a knot is present at approximately the midpoint length and just to one side of the midpoint width. A coincidence, perhaps, but also possibly an inherent. flaw in the technological approach to these long, thin specimens.

One other technological factor stands out. Almost all of the split cobble cores and blanks found at the site occur at this level, and one is definitely associated with Occupation Floor II. Although one specimen is also present in a lower level, it appears that this form may have achieved maximum importance as a technique in lithic tool production during the Occupation Floor II period.

In addition to the artifactual material found at this level, two features are thought to be associated with this occupation. The first of these, Feature 3 , is a small pitlike depression filled with dark-stained earth (Fig. 9,b). No burned rocks or charcoal were found, and no artifacts were directly associated. It appears that this feature was dug from a surface associated with Occupation Floor IIB. During the 1977 excavation, a small cluster of rocks was found at a depth of about $60 \mathrm{~cm}$ (Fox, Black, and James 1979:37). Its location in the southeast quadrant of that test unit would place it close to the densest

occurrence of materials on Occupation Floor II (Fig. 10,b;1977 hearth was above right half of picture). The recorded elevation would indicate that this feature is also contemporaneous with Occupation Floor IIB.

The Occupation Floor II is interpreted as the longest temporal occupation present in the sampled area at the site. Artifact totals and diversity compare favorably with those of Occupation Floor I. The major difference in debris density is found in the faunal inventory: 0ccupation Floor II has less musse? and less bone. While part of this may be due to preservation (bone preservation generally decreases with depth at the site), it may also be due to a shift in resource utilization.

Another potential indicator of the length of occupation might be seen in the high percentage of production debris relative to finished products. Occupation 
of any site as a long-term encampment from which hunting and gathering forays are made will result in an eventual net loss in finished artifacts that are carried from the site and lost or broken in use. Debitage, on the other hand, remains at the site.

Another factor, which may indirectly relate to the length of occupation, is the variation in chert quality present. While this variation may relate to specific cultural values or perhaps specialized tool functions, it may also be due to exhausting the finer grade chert materials. As suggested above, this latter resource depletion might be complicated by environmental trends toward aggradation which might bury many cobble sources; on the other hand, it could be directly related to length of stay at the site.

For these reasons 0ccupation Floor II is seen as a seasonal base camp utilized for some period of time longer than the Austin phase occupation. The presence of two distinct floors can be interpreted in several ways, but seems most likely to be two different occupations of the same group (?) separated by a multiyear hiatus or perhaps only one extremely high seasonal flood.

\section{Intermediary Zone}

Beneath the concentration of materials found on Occupation Floor II, artifact densities show a sharp decline. Three distinct clusters of cultural material occur between 0ccupation Floor II and the underlying Morhiss zone. These are found at approximately 60,70 , and $80 \mathrm{~cm}$ depth below the surface and are each represented by five or six plotted artifacts and several small clusters of sandstone. It is thought that these clusters represent separate short-term occupation floors.

Only one finished projectile point came from this area: a small, thick, but finely chipped expanding stem piece (Fig. 16,i). Unfortunately, it was not recovered in situ and cannot be clearly associated with a floor. Analysis of level elevations shows that it could only be associated with one of the two lower floors. Of these, it is more probably the middle floor since the lowest one only crosses one corner of the base of the level. In any case, the value of the artifact as a comparative chronological indicator is lessened by the fact that it cannot be associated with a type.

These floors occur in Levels 5 and 6 and probably account for the majority of artifacts inventoried for those levels, although a portion of the Morhiss floor occurs in Level 6. There are marked differences between the artifact inventories in Levels 5 and 6 , but the reasons for these differences are not clear. The most important trends are (from Table 19):

1. Total biface production is the same in the two levels, but shows a slight increase from the two levels above.

2. Within the biface category there is a shift in emphasis. The trend of high percentages of blanks and low percentages of finished products reaches a maximum in Level 5, where there are no finished thin bifaces at all. 
TABLE 19. ARTIFACT INVENTORIES BY LEVEL

\begin{tabular}{|c|c|c|c|c|c|c|c|c|c|c|c|}
\hline Leve 1 & Cores & $\begin{array}{c}\text { Utilized } \\
\text { Flakes }\end{array}$ & $\begin{array}{l}\text { Trimmed } \\
\text { Flakes } \\
\end{array}$ & $\begin{array}{l}\text { Chi } \\
\text { Thick } \\
\text { Biface }\end{array}$ & $\begin{array}{r}\text { ped } \frac{L}{b} \\
\text { B if } \\
\text { Unfinished } \\
\text { Thin }\end{array}$ & \begin{tabular}{|l|} 
ithic \\
one \\
aces \\
$\begin{array}{c}\text { Finished } \\
\text { Thin }\end{array}$ \\
\end{tabular} & $\begin{array}{l}\text { Total } \\
\text { Biface }\end{array}$ & $\begin{array}{c}\text { Chipped Stone } \\
\text { Total }\end{array}$ & $\begin{array}{l}\text { Ground and } \\
\text { Pecked Stone }\end{array}$ & $\begin{array}{l}\text { Total } \\
\text { Lithics }\end{array}$ & Nonlithic Artifacts \\
\hline 1 & 1 & 14 & & 2 & 13 & 2 & 17 & 32 & 1 & 33 & 5 \\
\hline 2 & 10 & 73 & 5 & 8 & 24 & 14 & 46 & 134 & 13 & 147 & 7 \\
\hline 3 & 27 & 90 & 5 & 16 & 20 & 15 & 51 & 173 & 32 & 205 & 7 \\
\hline 4 & 23 & 22 & 5 & 14 & 16 & 3 & 33 & 83 & 23 & 106 & \\
\hline 5 & 7 & 7 & 1 & 9 & 6 & & 15 & 30 & 11 & 41 & 1 \\
\hline 6 & 2 & 5 & 1 & 11 & 3 & 2 & 16 & 24 & 4 & 28 & \\
\hline 7 & 3 & 1 & & 5 & 1 & 1 & 7 & 11 & & 11 & \\
\hline 8 & 1 & 1 & & 1 & 3 & & 4 & 6 & 2 & 8 & \\
\hline 9 & 2 & 2 & & & 1 & & 1 & 5 & 2 & 7 & \\
\hline 10 & 2 & & & 1 & 1 & & 2 & 4 & 1 & 5 & \\
\hline 11 & & & & 1 & & & 1 & 1 & 1 & 2 & \\
\hline$\nabla$ & 5 & 2 & 4 & 7 & 3 & 6 & 16 & 27 & 2 & 29 & 3 \\
\hline $\begin{array}{l}\text { Group } \\
\text { Totals }\end{array}$ & 83 & 217 & 21 & 75 & 91 & 43 & 209 & 530 & 92 & 622 & 23 \\
\hline
\end{tabular}

$\nabla$ Unprovenienced specimens. 
3. The above trend is reversed somewhat in Level 6 , where unfinished thin bifaces decrease to their lowest percentage, while finished bifaces are present once more.

4. Core percentages drop to a low peak in Level 6 , but are only slightly less than average in Level 5.

5. The importance of utilized flakes continues to decline with increasing depth.

6. Ground and pecked storie reaches a peak in Level 5, but declines sharply below this.

One feature (Feature 2) from the 1977 excavation unit occurred at $75 \mathrm{~cm}$ and may be associated with one of these floors, although the elevation seems to place it between the lower two. This small cluster of sandstone contained no charcoal or stained earth, and its function cannot be ascertained (Fox, Black, and James 1979:37).

Little can be said of the materials occurring in this zone, except that they appear to represent several distinct campsite occupations. An overal1 decline in artifact densities may indicate shorter periods of occupation, and the presence of only a single feature in the zone supports this. Increased sedimentation rates, however, may be possible for this appearance between campsites. Discrepancy of the artifact inventories between the excavation levels suggests that these three possible floors represent different site functions or perhaps occupation by different peoples.

\section{Morhiss Occupation}

This occupation zone is marked by a burned rock feature (Feature 4, Fig. 10,a) and two Morhiss projectile points. One of the latter was found $87 \mathrm{~cm}$ below the surface and is taken to be representative of an occupation floor at this level. Also mapped at this level are two Stage II bifaces and one Stage I cobble blank core-biface.

The feature from this level (which was found in the wall and not excavated completely) consisted of a small stack of burned rocks. No charcoal was found, but two artifacts, one each of the Stage II bifaces and the core-bifaces, were thought to be directly associated.

The low number of artifacts found in Level 7 , which is thought to be primarily associated with the Morhiss zone, makes the validity of generalizations from the data questionable. Several trends from upper levels are continued, however. Utilized flakes continue to decline, and thick bifaces continue to increase with increasing depth (Table 18). Overa11, bifaces reach their highest percentage, while ground and pecked stone drops to zero.

Almost the only conclusion that can be drawn from the data is that a relatively short-term Morhiss phase campsite was located here. If the paucity of artifacts from Level 7 is any indication, then the camp was occupied for a much shorter time than any of the above occupations. However, since some of the 
Morhiss materials occur with Level 6, it seems likely that the campsite is approximately equivalent in occupational length to the Toyah and Ensor occupations. In contrast to those occupations, chipping quality is relatively good in this zone. On the other hand, the best worked Morhiss point from the site comes from Level 2 with the Austin phase materials.

\section{Middle Archaic Occupation}

It is difficult to say how much of the cultural material from below the Morhiss zone relates to distinct occupations, but at least two clusters of material can be identified. Four artifacts were mapped in place near $110 \mathrm{~cm}$ below the surface, and Feature 2 was found at approximately $125 \mathrm{~cm}$ in depth.

No diagnostic artifacts were recovered from this area, and the sample of materials from the excavation levels is too small for valid generalizations. Feature 2 is unique because it does not appear to have been a hearth at a11, but more likely a small chipping station. Different materials present suggest that it was more than just a single chipping event and may be associated with a short-term camp.

\section{Paleo-Indian Occupation}

At the base of the bluff, excavation Unit 2 uncovered a hearth which was radiocarbon dated to $11,550 \pm 800$ years B.P. or approximately 9600 B.C. No cultural materials were excavated from this area, although they are visible in stratum II for a distance of more than $40 \mathrm{~m}$ along the bank (Fig. 11). The hearth is located more than six meters below the surface of the bluff (or more than three meters below the lowest point in the main excavation unit). Also visible in the bluff face is a somewhat higher stratum of cultural material, which was also beneath the maximum main unit depth.

The cultural zone in which the hearth is located appears to be in a completely different microenvironmental niche (six or more meters closer to the water) than the upper zones at the site. Yet preliminary observations suggest that some things remained constant during that period. Flake debitage of various sizes visible in the profile indicates a variety of 1 ithic tool manufacturing activities. Subsistence resource procurement also shows similarities: mussels, small mammals, and riverine resources (Kenneth $M$. Brown, personal communication) were exploited during the early period as they were much later.

\section{Conclusions}

Data from the Berger Bluff site show potential for elaboration of coastal plain prehistory. While no one site should be uncritically used as a typical indicator of the cultural sequence within an area, it should be possible to hypothesize relationships that can be tested from further excavation data. The following hypotheses, then, offer potential refinements to the understanding of the coastal plain cuitural sequence. 
1. During the Late Prehistoric period, the coastal plain was within the range for hunters and gatherers from central Texas. There is no evidence in the cultural materials present in the upper zones of the site which would distinguish the occupants from the Austin and Toyah phase peoples of central Texas. Perhaps the emphasis on coastal resource utilization that developed during the Transitional Archaic (cf. McGuff 1978) may indeed imply the utilization of this area by a purely inland group. The Berger Bluff site shows no evidence of any coastal contact during the Late Prehistoric period in contrast to the Berclair site (Hester and Parker 1970) where coastal materials were associated with Toyah phase materials. The presence of coastal materials is not limited to the Berclair site; possible coastal pottery and modified marine she 11 were found at the Hinojosa site in Jim Wells County (Hester 1977:26, 27). Yet the majority of material from the Berclair and Hinojosa sites is typical of central Texas Late Prehistoric groups. It is suggested here that al though contact may have been extensive at certain times and places, it was still primarily central Texas groups who would trade with coastal peoples rather than exploiting coastal resources.

2. The Late Archaic of the coastal plain in the San Antonio-Guadalupe River drainage area can be subdivided into at least two distinct phases. The later of these phases corresponds to the Ensor occupation zone at the site, and it may represent the inland coastal equivalent of the central Texas Twin Sisters phase (Weir 1976). The presence of an Ensor point is the only common trait linking the two, suggesting temporal and possible cultural correspondences.

The earlier phase is hypothesized on the basis of Occupation Floor II. Although no unquestionable diagnostic indicator is present, the well-made barbed point is strongly suggestive of barbed points belonging to the San Marcos phase in centrat Texas (e.g., Castroville, Montell, Marshall; see Weir 1976:55). Again, no evidence of central Texas influence is implied, but differences in the artifacts from these two zones at the Berger Bluff site suggest a parallel two phase division.

The unidentified projectile point occurring between 0ccupation Floor IIB and the Morhiss zones is tentatively grouped with the earlier of these two Late Archaic phases. It may, however, fall closer to Middle Archaic materials.

3. At some time during or at the end of the Late Archaic period the indigenous Morhiss complex peoples are replaced by central Texas cultures. Although it is uncertain whether or not the local Morhiss complex undergoes evolution into some Late Archaic equivalent, by the start of the Late Prehistoric period groups from central Texas are inhabiting the San Antonio-Guadalupe River basin. This finding echoes that from 41 GD 21 and 41 GD $21 \mathrm{~A}$ where central Texas-1ike Late Prehistoric materials overlie Morhiss materials (D. Fox 1979).

Similarities to central Texas projectile points in the Late Archaic materials are matched by some variation as in the long lanceolate points from Occupation Floor II. The overall evidence would seem to suggest that Morhiss may be replaced by very early Late Archaic, but this is very tenuous, and there is no evidence as to whether the replacement might have been accompanied by a period of coexistence or whether it might have been abrupt. 


\section{RECOMMENDATIONS}

The Berger Bluff site is a rich and important coastal site, which has already provided valuable data on aboriginal technology and subsistence in the inland coastal area. Further analysis of the vast amount of archaeological materials collected from the site may yield even more significant information in the future.

Although the site has been subject to episodes of erosion in the past, a great deal of cultural material is still present. However, because of the nature of the sediments, the wave action from the reservoir is likely to cause erosion of a considerable portion of the richest part along the bluff's edge. While such erosion is unavoidable, rather extensive samples of the site deposits have been recovered during the 1977 and 1979 excavations; and a large portion of the site will remain undamaged by the reservoir. This portion should be protected against future construction.

Unfortunately, the most serious danger to the site may be in improved access for pothunters. It is difficult to predict the intensity of looting that might occur, but there is probably no means of effectively protecting the site. In fact, any protective measures may have the reverse effect of attracting attention to the site and intensifying. destruction.

Further research at the site would almost certainly help to clarify specific questions regarding the validity of some of the more ephemeral occupation zones and give a clearer picture of the function of the better defined zones. Even without further excavation, the data already collected should be of some utility in setting up research designs for other sites in the area. Research to date suggests that the cultural sequence in the area is similar, but not identical to the coastal and central Texas culture area. Hopefully, the hypotheses proposed here will provide some impetus for serious research, which may culminate not only in the identification of specific local phases, but in the understanding of aboriginal adaptation to the inland coastal plain area.

Future GBRA plans at the site include minimal grading and the placement of a concrete-lined drainage canal at the foot of the eroded slope. While further grading may do some damage, the overall effect of the cement lining will be to retard erosion and protect the site by capping it. Portions of the slope above the concrete lining are scheduled to be planted with grass to prevent erosion.

It is felt that the GBRA plans will benefit the future of this important archaeological resource. As an additional protection, we recommend that the site be nominated to the National Register of Historic Places. 


\section{REFERENCES CITED}

Beasley, T. S.

1978 A Late Prehistoric Site in Webb County, Texas. La Tierra 5(2):4-9. Birmingham, W. W. and T. R. Hester

1976 Late Pleistocene Archaeological Remains from the Johnston-Heller Site, Texas Coastal Plain. In Papers on Paleo-Indian Archaeology in Texas: I:15-33. Center for Archaeological Research, The university of Texas at San Antonio, Special Report 3.

Blair, W. F.

1950 The Biotic Provinces of Texas. Texas Journal of Science 2(1):93-117. Brown, K. M.

n.d. Manuscript in preparation on the "lower bench" area at 41 GD 30A. Bureau of Economic Geology

1975 Geologic Atlas of Texas. Beeville-Bay City Sheet; Scale: 1:250,000. Calhoun, C. A.

1965 Archeology of the Coastal Bend. Paper presented at the Houston . Archeological Society Symposium on Coastal Archeology.

Campbe11, T. N.

1940 Notes on Artifacts. In Pleistocene Artifacts and Associated Fossils from Bee County, Texas, by E. H. Sel 1ards:1640-1643. Geological Society of the Americas, Bulletin, 51 .

1947 The Johnson Site: Type Site of the Aransas Focus of the Texas Coast. Bulletin of the Texas Archeological and Paleontological Society 18:40-75.

1952 The Kent-Crane Site: A She11 Midden on the Texas Coast. Bulletin of the Texas Archeological and Paleontological Society 23:39-77.

1958 Archeological Remains from the Live Oak Point Site, Aransas County, Texas. Texas Journal of Science 10(4):423-442.

1960 Archeology of the Central and Southern Sections of the Texas Coast. Bulletin of the Texas Archeological Society 29:145-175.

1976 Archaeological Investigations at the Morhiss Site, Victoria County, Texas, 1932-1940. In An Archaeological Survey of Coleto Creek, Victoria and Goliad Counties, Texas, by A. A. Fox and T. R. Hester:8185. Center for Archaeological Research. The University of Texas at San Antonio, Archaeological Survey Report 18. 
Cheatum, E. P. and R. W. Fullington

1971a The Aquatic and Land Mollusca of Texas. Part One: The Recent and Pleistocene Members of the Gastropod Family Polygyridae in Texas. Dallas Museum of Natural History, Bulletin 1.

1971b The Aquatic and Land Mollusca of Texas. Supplement: Keys to the Families of the Recent Land and Fresh-Water Snails of Texas. Dallas Museum of Natural History, Bulletin 1.

Collins, M. B.

1975 Lithic Technology as a Means of Processual Inference. In Lithic Technology: Making and Using Stone Tools, edited by E. Swanson: 15-34. Aldine, Chĩcago.

Corbin, J. E.

1974 Model for Cultural Succession for the Coastal Bend Area of Texas. Bulletin of the Texas Archeological Society 45:29-54.

1976 The Archaic of the Texas Coast. In The Texas Archaic: A Symposium, edited by T. R. Hester:91-97. Center for Archaeological Research, The University of Texas at San Antonio, Special Report 2.

Duffield, L. F.

1970 Vertisols and Their Implications for Archaeological Research. American Anthropologist 72:1055-1062.

Environmental Consultants, Inc.

1975 Coleto Creek Reservoir Environmental Assessment. Prepared for the Guadalupe-Blanco River Authority.

Evans, G. L.

1962 Notes on Terraces of the Rio Grande, Falcon-Zapata Area, Texas. Bulletin of the Texas Archeological Society 32:33-45.

1979 Field Notes on the Stratigraphy of the Berger Bluff Terrace. Notes on file, Center for Archaeological Research, The University of Texas at San Antonio.

Fox, A. A.

1979 Preliminary Report of Archaeological Testing at the Tonkawa Bluff, Victoria City Park, Victoria, Texas. Center for Archaeological Research. The University of Texas at San Antonio, Archaeological Survey Report 70. 
Fox, A. A., F. A. Bass, Jr., and T. R. Hester

1976 The Archaeology and History of Alamo Plaza. Center for Archaeological Research. The University of Texas at San Antonio, Archaeological Survey Report 16.

Fox, A. A., S. L. Black, and S. R. James

1979 Intensive Survey and Testing of Archaeological Sites on Coleto Creek, Victoria and Gol iad Counties, Texas. Center for Archaeological Research. The University of Texas at San Antonio, Archaeological Survey Report 67.

Fox, A. A. and T. R. Hester

1976 An Archaeological Survey of Coleto Creek, Victoria and Goliad Counties, Texas. Center for Archaeological Research, The University of Texas at San Antonio, Archaeological Survey Report 18.

Fox, A. A. and K. Livingston

1979 Historical, Architectural, and Archaeological Investigations at the Steiner-Schob Complex, Victoria County, Texas. Center for Archaeological Research. The University of Texas at San Antonio, Archaeological Survey Report 52.

Fox, A. A., E. H. Schmiedlin, and J. L. Mitchell

1978 Preliminary Report on the J-2 Ranch Site (41 VT 6), Victoria County, Texas. La Tierra 5(3):2-14.

Fox, D. E.

1979 Archaeological Investigations of Two Prehistoric Sites on the Coleto Creek Drainage, Goliad County, Texas. Center for Archaeological Research. The University of Texas at San Antonio, Archaeological Survey Repart 69.

Fox, D. E., R. J. Mallouf, N. O'Malley, and W. M. Sorrow

1974 Archaeological Resources of the Proposed Cuero I Reservoir, De Witt and Gonzales Counties, Texas. Texas Historical Commission and Texas Water Development Board, Archeological Survey Report 12.

Fullington, R. W. and W. L. Pratt, Jr.

1974 The Aquatic and Land Mollusca of Texas. Part Three: The Helicinidae, Carychijdae, Achatinidae, Bradybaenidae, Bulimulidae, Cionellidae, Haplotrematidae, Helicidae, Oreshelicidae, Spiraxidae, Streptaxidae, Strobilopsidae, Thysanophoridae, Vallonidae (Gastropoda) in Texas. Dallas Museum of Natural History. Bulletin 1. 
Gerstle, A., T. C. Kelly, and C. Assad

1978 The Fort Sam Houston Project: An Archaeological and Historical Assessment. Center for Archaeological Research, The University of Texas at San Antonio, Archaeological Survey Report 40.

Gilmore, $K$.

1973 The Keeran Site: The Probable Site of La Salle's Fort St. Louis in Texas. Texas Historical Commission, Office of the State Archeologist, Report 24.

1974a Mission Rosario; Archeological Investigations 1973 (Part I). Texas Parks and Wildlife Department, Historic Sites and Restoration Branch, Archeological Report 14.

1974b Mission Rosario; Archeological Investigations 1974 (Part 2). Texas Parks and Wildlife Department, Historic Sites and Restoration Branch, Archeological Report 14.

Gunn, J. and R. A. Mahula, eds.

1977 Hop Hill: Culture and Climatic Change in Central Texas. Center for Archaeological Research, The University of Texas at San Antonio, Special Repart 5.

Guntharp, E.

1978 A Study of Gastropods at the St. Mary's Hall Site. Ms. on file, Center for Archaeological Research, The University of Texas at San Antonio.

Ha11, G. D., S. L. Black, and C. Graves

1982 Archaeological Investigations at Choke Canyon Reservoir, South Texas: The Phase I Findings. Center for Archaeological Research, The University of Texas at San Antonio, Choke Canyon Series 5.

Hester, T. R.

1971 Archeological Investigations at the La Jita Site, Uvalde County, Texas. Bulletin of the Texas Archeological Society 42:51-148.

1975 Chipped Stone Industries on the Rio Grande Plain, Texas: Some Preliminary Observations. Texas Journal of Science 26(1-2):213-222.

1976 Late Pleistocene Aboriginal Adaptations in Texas. In Papers on Paleo-Indian Archaeology in Texas: $I: 1-14$. Center for Archaeological Research, The University of Texas at San Antonio, Special Report 3.

1977 Archaeological Research at the Hinojosa Site (41 JW 8), Jim Wells County, Southern Texas. Center for Archaeological Research, The university of Texas at San Antonio, Archaeological Survey Report 42. 
Hester, T. R., ed.

1976 The Texas Archaic: A Symposium. Center for Archaeological Research, The University of Texas at San Antonio, Special Report 2.

Hester, T. R. and T. C. Hill, Jr.

1971 An Initial Study of a Prehistoric Ceramic Tradition in Southern Texas. Plains Anthropologist 16(43):195-203.

1975 Eating Land Snails in Prehistoric Southern Texas: Ethnohistoric and Experimental Data. The Nautilus $80(2)$.

Hester, T. R. and R. C. Parker

1970 The Berclair Site: A Late Prehistoric Component in Goliad County,

Southern Texas. Bulletin of the Texas Archeological Society 41:1-23.

Hester, T. R. and H. J. Shafer

1975 An Initial Study of Blade Technology on the Central and Southern Texas Coast. Plains Anthropologist 20(69):175-185.

Jelks, E. B.

1962 The Kyle Site: A Stratified Central Texas Aspect Site in Hill County, Texas. Department of Anthropology. The University of Texas, Archaeology Series 5.

McGuff, P. R.

1978 Prehistoric Archeological Investigations at Palmetto Bend Reservoir: Phase 1, Jackson, County, Texas. Texas Archealogical Survey, The university of Texas at Austin, Research Report 58, Palmetto Bend Series 4.

Mallouf, R. J., D. E. Fox, and A. K. Briggs

1973 An Assessment of the Cultural Resources of Palmetto Bend Reservoir, Jackson County, Texas. Texas Historical Commission and Texas water Development Board, Archeological Survey Report 11.

Montgomery, J. L.

1978 The Mariposa Site: A Late Prehistoric Site on the Rio Grande Plain of Texas. Studies in the Archaeology of Chaparrosa Ranch. Center for Archaeological Research, The. University of Texas at San Antonio, Special Report 6(2).

Mounger, M. A.

1959 Mission Espiritu Santo of Coastal Texas: An Example of Historic Site Archeology. Unpublished M.A. thesis, University of Texas, Austin. 
Newcomb, W. W., Jr.

1961 The Indians of Texas: From Prehistoric to Modern Times. University of Texas Press, Austin.

Patterson, P. E.

1977 A Lithic Reduction Sequence: A Test Case in the North Fork Reservoir Area, Williamson County, Texas. Bulletin of the Texas Archeological Society 48:53-82.

Rodnick, D.'

1973 History of the Goliad Missions and Their Indians. In The Keeran Site: The Probable Site of La Salle's. Fort St. Louis in Texas, edited by $K$. Gilmore:7-18. Texas Historical Commission, Office of the State Archeologist, Report 24.

Schiffer, M. B.

1978 Methodological Issues in Ethnoarchaeology. In Explorations in Ethnoarchaeology, edited by R. A. Gould:229-248. University of New Mexico Press, ATbuquerque.

Schmiedlin, E. H.

1979 A Preliminary Report on the Burris Site (41 VT 66), Victoria County, Texas (with an addendum by T. R. Hester). La Tierra 6(1):25-27.

Sellards, E. H.

1940 Pleistocene Artifacts and Associated Fossils from Bee County, Texas. Bulletin of the Gealogical Society of America 51:1627-1658.

Shafer, H. J. and V. M. Bryant, Jr.

1977 Archeological and Botanical Studies at Hinds Cave, Val Verde County, Texas. Texas A\&M University, Anthropology Laboratory Report 1. College Station.

Sharrock, F. W.

1966 Prehistoric Occupation Patterns in Southwest Wyoming and Cultural Relationships with the Great Basin and Plains Culture Areas. Department of Anthropology, University of Utah, Anthropology Papers 77.

Skelton, D. W.

1977 Archeological Investigations at the Fayette Power Project, Fayette County, Texas. Texas Archeological Survey. The University of Texas at Austin, Research Report 60. 
Skinner, A. S.

1971 Prehistoric Settlement of the De Cordova Bend Reservoir, Central Texas. Bulletin of the Texas Archeological Society 42:149-270.

Sollberger, J. B. and T. R. Hester

1972 The Strohacker Site: A Review of Pre-Archaic Manifestations in Texas. Plains Anthropologist 17(58), Pt. 1:326-344.

Story, D. A.

1968 Archeological Investigations at Two Central Texas Gulf Coast Sites. State Building Commission Archeological Program, Report 13.

Suhm, D. A.

1960 A Review of Central Texas Archeology. Bulletin of the Texas Archeological Society 29:63-108.

Suhm, D. A. and E. B. Jelks

1962 Handbook of Texas Archeology: Type Descriptions. Texas Archeological Society, Special Publication 1 and Texas Memorial Museum, Bulletin 4.

Wakefield, W. H.

1968 Archeological Surveys of Palmetto Bend and Choke Canyon Reservoirs, Texas. Texas Archeological Salvage Project, The University of

Texas at Austin, Survey Repart 5.

Weir, F. A.

1976 The Central Texas Archaic. Unpublished Ph.D. dissertation, Washington State University, Pullman. 


\section{APPENDIX I. \\ THE BURRIS SITE (41 VT 66)}

After a portion of this potentially valuable site was bulldozed during construction of the Coleto Creek Dam, the Texas Historical Commission recommended that the site be nominated to the National Register of Historic Places in order to insure its protection. During the testing of 41 GD 30A, the author and William Birmingham spent part of a day at the site gathering data for that purpose. The following short report documents that effort and summarizes some of the prior information available on the site.

\section{Environmental Setting}

The site location, just below the Coleto Creek Dam and more than $9 \mathrm{~km}$ downstream from the Berger Bluff site (41 GD 30) is shown in Figure 19. The general regional environment described in the second section of this report a 750 applies to the Burris site. Physiographically it is almost identical to the Berger Bluff site set on a high knoll on the west bank of Coleto Creek just downstream from a small intermittent drainage (Fig. 20). The Burris site, however, has not been subject to the extensive lateral cutting that the other has and is not in as severe danger from natural erosion.

The Geologic Atlas of Texas (Bureau of Economic Geology 1975) locates the site in sediments of the Lissie Formation, a Quaternary fluvial deposit which is the local equivalent of the Montgomery and Bently Formations. However, the sandy nature of the sediment and the depth of cultural material in the exposed profile suggest that the site itself is located on a small remnant of a Holocene terrace of Coleto Creek.

Although the soil mapped in the general area of the site belongs to the DacostaEdna association, the site itself is on a small strip of either Falfurrias or Padina soils according to the Department of Agriculture soil scientist who mapped the area (Alan Peer, personal communication). Falfurrias soils, which are deep sands, appear to match the actual soils at the site very closely.

Vegetation in the general area of the site is similar to that of the Berger Bluff site. In the immediate area, anaqua, hackberry, pecan, sycamore, and live oak were the most common large trees. The pattern of vegetation follows that of the knoll with a slightly better developed understory growth of vines and low shrubs than at the other site. Fauna at the Burris site should be much the same as that observed at the Berger Bluff site and the reservoir area as a whole (see the detailed list in Fox, Black, and James 1979:5-7).

Previous Archaeological Investigations

This site was initially discovered when a power line right-of-way was cleared through the D. L. Burris property just downstream from the Coleto Creek Dam. 
This page has been

redacted because it

contains restricted

information. 


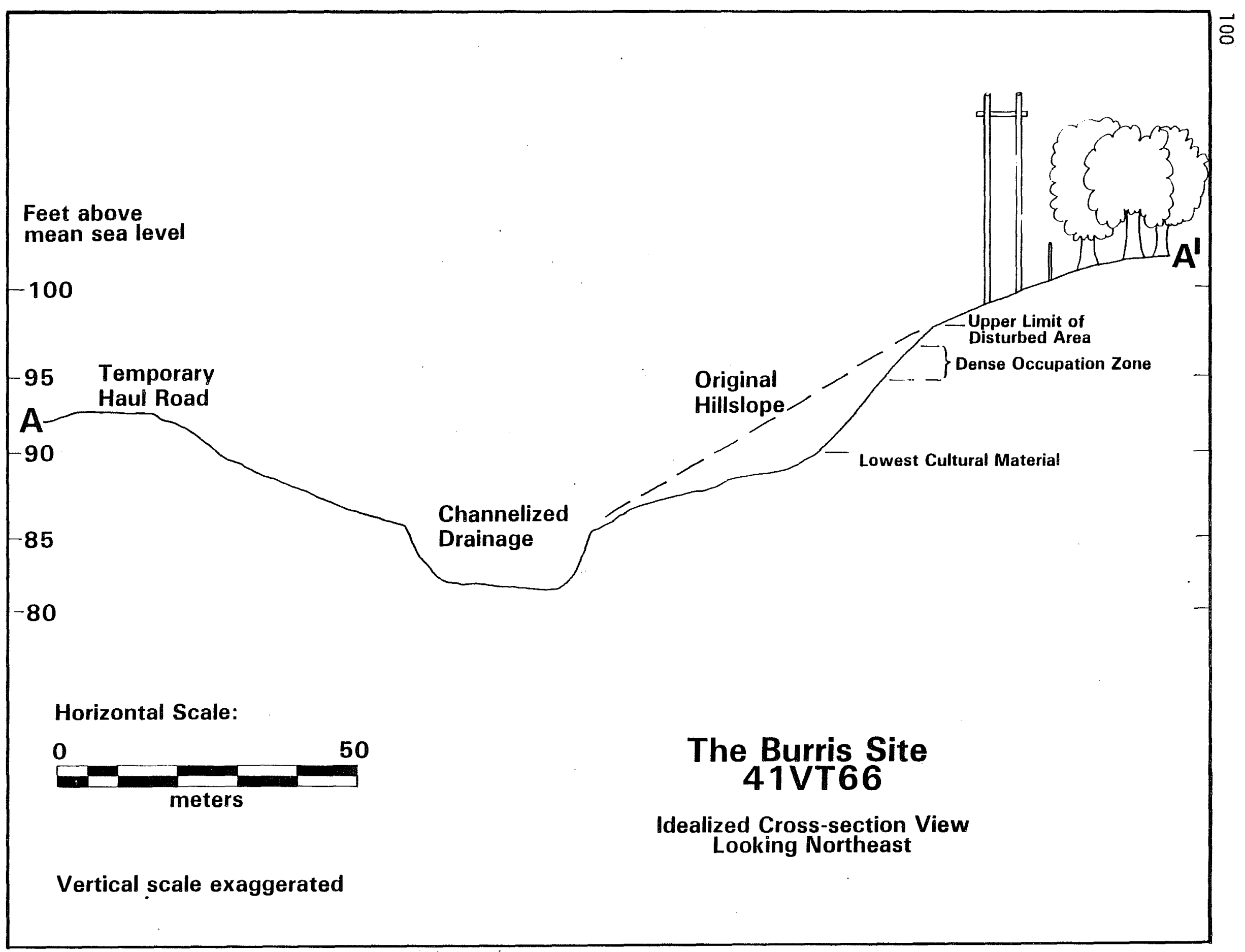

Figure 20. Idealized Cross Section of the Burris Site. 
At that time a local avocational archaeologist visited the site and conducted preliminary subsurface testing which indicated cultural material to a depth of at least two meters. At a later visit to the site, it was discovered that a portion of the site had been inadvertently disturbed during ground leveling for the channelization of a small drainage in front of the dam. A large quantity of cultural material was exposed by this cut, and a collection was made at that time.

The site was recorded and the collection documented in the initial published report of the site (Schmiedl in 1979). A later visit to the site and an additional collection was made by T. R. Hester, A. A. Fox, and D. E. Fox of the Center for Archaeological Research, Alton Briggs of the Texas Historical Commission, and David Welsch of the GBRA.

Prior to the initial recording of this site, a site known as 41 VT 41 was recorded during the initial Coleto Creek survey (Fox and Hester 1976). This site was reported to cover an area $100 \mathrm{~m}$ in diameter and to extend down to a depth of $2.5 \mathrm{~m}$ in an exposed section. of cutbank. Due to the dense undergrowth the areal extent of the site was difficult to estimate accurately, but it was felt that it could in no way extend north to the dam area. Therefore, no further work was recommended on the basis that it would not be damaged by construction. Subsequent visits to the site have shown that there may be little areal separation between 41 VT 66 and 41 VT 41 , but only controlled subsurface testing on both sites will demonstrate this relationship.

\section{Site Description}

This site is a buried deposit containing prehistoric artifacts, debitage, and we11-preserved faunal material. It is located at the end of a broad finger ridge which may be an early Holocene terrace remnant (Fig. 19). The site is located approximately 10. m above the creek and extends from 25-100 m away from the creek. It is made up of several components, of which 41 VT 66 is only the most northwestward extension. From this site cultural material extends south and west more than $100 \mathrm{~m}$.

The cutbank exposure on the GBRA property shows an extremely dense deposit of cultural material occurring in a stratum a little more than a meter thick

(Fig. 20) and covered by a meter or more of relatively less dense deposit. It appears that the top stratum is almost sterile in the cutbank, but a sma11 amount of material is present. It appears that the Late Prehistoric material from the site may have come from the upper zone, and that the thick stratum beneath may be primarily Archaic. 


\section{Materials Collected}

The material collected was from the surface of the site. Only obvious artifacts and a sample of various types of cultural debris were collected. A11 of this material was from the disturbed hillside, and no specific provenience was recorded. The following is a brief list of the collection, using the classification system described in the main body of this report:

Lithics

$\begin{array}{ll}\text { Secondary flakes } & 7 \\ \text { Tertiary flakes } & 5 \\ \text { Decorticate chips } & 4 \\ \text { Stage II bifaces } & 3 \\ \begin{array}{l}\text { Stage II I bifaces } \\ \text { (thick bifaces) }\end{array} & 4 \\ \begin{array}{l}\text { Stage IV bifaces } \\ \text { (intermediate, thin } \\ \text { bifaces) }\end{array} & 2 \text { (Fig. 17,f) } \\ \begin{array}{l}\text { Stage V bifaces } \\ \text { (thin biface preforms) }\end{array} & 3 \text { (Fig. 17,h) } \\ \begin{array}{l}\text { Stage VI biface } \\ \text { (Ensar-Marcos } \\ \text { projectile point) } \\ \text { Hammerstone }\end{array} & 1 \text { (Fig. 17,g) } \\ \end{array}$

Faunal Remains

Bison 2

Deer 12

Unidentified Carnivore 1

Softshell turtle 3

Unidentified bird 3

Marine Clam

Dinocardium robustin 4

Macrocallista nimbosa 3

Freshwater Mussel

Amblema plicata 1

Unidentified musse $1 \quad T$ 


\section{REFERENCES CITED}

Bureau of Economic Geology

1975 Geologic Atlas of Texas. Beeville Bay City Sheet; Scale: $1: 250,000$.

Fox, A. A., S. L. Black, and S. R. James

1979 Intensive Survey and Testing of Archaeological Sites on Coleto Creek, Victoria and Goliad Counties, Texas. Center for Archaeological Research. The University of Texas at San Antonio, Archaeological Survey Report 67.

Fox, A. A. and T. R. Hester

1976 An Archaeological Survey of Coleto Creek, Victoria and Goliad Counties, Texas. Center for Archaeological Research. The University of Texas at San Antonio, Archaeological Survey Report 18.

Schmiedlin, E. H.

1979 A Preliminary Report on the Burris Site (41 VT 66), Victoria County, Texas (with an addendum by $T$. R. Hester). La Tierra $6(1): 25-27$. 


\author{
APPENDIX II. \\ FAUNAL ANALYSIS: 41 GD 30A \\ Lois Marion Flynn
}

The funds allotted for faunal analysis of $41 \mathrm{GD} 30 \mathrm{~A}$ were very limited.

Therefore, analys is of the material was undertaken as part of a laboratory analysis course at The University of Texas at San Antonio. The recovered material was to be identified and described. To fully assess the role of the vertebrate fauna, in the prehistoric hunting and gathering society represented at $41 \mathrm{GD} 30 \mathrm{~A}$, requires more expertise in zooarchaeology than an initial laboratory analysis course can provide. It is hoped, that based on this descriptive report, further interpretation of the material can be done by those qualified to do so.

Methodology

A preliminary sorting of the faunal material was done by Lois Flynn. Because of time limitations, all carapace, plastron, and unidentifiable material was weighed, but not counted. Species were identified (by Karen W. Scott and Lois Flynn) using the vertebrate collection at The University of Texas at San Antonio. Additional identifications were made by Richard Hulbert, Jr., a graduate student at The University of Texas at Austin. Hulbert used the collection from the Vertebrate Paleontology Laboratory, Texas Memorial Museum, The University of Texas at Austin.

Species identifications were recorded for each level of each excavation unit, and additional observations such as age, butchering marks, burning, or other modifications were noted. Diagnostic elements were used to calculate the minimal number of each species from the site.

The faunal material is presently stored at the Center for Archaeological Research, The University of Texas at San Antonio.

\title{
Statistical Data
}

The total weight of all the faunal material recovered was $5806.7 \mathrm{~g}$; $2861.9 \mathrm{~g}(49.3 \%)$ was identifiable material; $2944.8 \mathrm{~g}(50.7 \%)$ was unidentifiable.

The total weight of all the burned faunal material was $575.6 \mathrm{~g}(9.9 \%)$, unidentified unburned material accounted for $2369.2 \mathrm{~g}(40.8 \%)$, and identifiable elements were $2861.9 \mathrm{~g}(49.3 \%)$.

The distribution, by weight, of the faunal material was concentrated in Levels 1-4, with Levels 2 and 3 accounting for $65 \%$ of the total weight (Table 20).

Five classes of fauna (fish, amphibians, reptiles, birds, and mammals) were identified. The species identified and the maximum number of each species are listed in Table 21. The provenience of identified species is represented by Table 22. 
TABLE 20. DISTRIBUTION OF FAUNAL MATERIAL BY WEIGHT

\begin{tabular}{ccc}
\hline Leve1 & Weight (in grams) & $\begin{array}{c}\text { Percentage } \\
\text { of Total Weight }\end{array}$ \\
\hline 1 & 998.3 & 17.2 \\
2 & 2225.1 & 38.3 \\
3 & 1557.9 & 26.8 \\
4 & 797.3 & 13.7 \\
5 & 83.5 & 1.4 \\
10 & 2.2 & 0.03 \\
surface 6 & 15.6 & 0.3 \\
unProvenienced & 126.8 & 2.2 \\
\hline TOTAL & 5806.7 & 100.0 \\
\hline
\end{tabular}

A total of 1293 elements were identified (Table 23). Taxonomicalily, for scientific and common names, Blair et al. (1968) was followed. Turtle species represented by carapace and plastron fragments are not included in this number, as that material was weighed, not counted.

Fish, mostly represented by gar scales, are found in Levels 1-5 of the excavations. Gar scales were most plentiful in Levels $7-4$, and two medial vertebra fragments tentatively identified as bass were present in Level 4.

Turtle elements are found in Levels 1-4. Turtle species are represented mostly by carapace and plastron fragments and account for almost all of the identifiable material that showed evidence of having been burned. Snapping turtle and river cooter identifications were based on bone elements, while the red-eared turtle (pond slider) identification was by carapace comparison. The red-eared turtle identification is tentative, since most of the fragments were sma11.

Snake elements were found in Levels 1-4, with most representation in Levels 2 and 3. No cranial elements were present. Hulbert identified the vertebra elements based on the procedures of Holman (1979) and Auffenberg (1963). A total of eight genera is represented with seven species verified.

Although bird remains were found in Levels 1-4, the concentration is in Levels 1 and 2. Hawks, owls, bobwhite quail, and turkey elements were present. In addition, green-winged teal, thrush, and robin were tentatively identified. 
TABLE 21. FAUNAL INVENTORY: 41 GD 30A

\begin{tabular}{|c|c|c|}
\hline Common Name & Scientific Name & Minimum No. \\
\hline $\begin{array}{l}\text { Bass } \\
\text { Gar } \\
\text { Longnose gar }\end{array}$ & $\begin{array}{l}\text { Micropterus } \mathrm{sp} \text {. } \\
\text { Lepisosteus } \mathrm{sp} \text {. } \\
\text { Lepisosteus osseus }\end{array}$ & $\begin{array}{l}1 \\
1 \\
1\end{array}$ \\
\hline $\begin{array}{l}\text { Red-eared turtle } \\
\text { River cooter } \\
\text { Snapping turtle } \\
\text { Spiny softshell turtle }\end{array}$ & $\begin{array}{l}\text { Chrysemys scripta } \\
\text { Chrysemys concinna } \\
\text { Chelydra serpentina } \\
\text { Trionyx spiniferus }\end{array}$ & $\begin{array}{l}1 \\
1 \\
1 \\
1\end{array}$ \\
\hline $\begin{array}{l}\text { Copperhead } \\
\text { Corn snake } \\
\text { Cottonmouth } \\
\text { Pine snake } \\
\text { Racer/Coachwhip snake } \\
\text { Rat snake } \\
\text { Rat snake } \\
\text { Water snake } \\
\text { Western diamondback rattlesnake } \\
\text { Western hognose snake }\end{array}$ & $\begin{array}{l}\text { Agkistrodon contortrix } \\
\text { Elaphe guttata } \\
\text { Agkistrodon piscivorus leucostoma } \\
\text { Pituophis melanoleucus } \\
\text { Coluber/Masticophis sp. } \\
\text { Elaphe sp. } \\
\text { Elaphe obsoleta } \\
\text { Natrix sp. } \\
\text { Crotalus atrox } \\
\text { Heterodon nasicus }\end{array}$ & $\begin{array}{l}1 \\
1 \\
1 \\
1 \\
1 \\
1 \\
1 \\
1 \\
1 \\
1\end{array}$ \\
\hline $\begin{array}{l}\text { Bobwhite quail } \\
\text { Great horned owl } \\
\text { Green-winged teal } \\
\text { Hawk } \\
\text { Louisiana/Little blue heron } \\
\text { Robin } \\
\text { Thrush } \\
\text { Wild turkey }\end{array}$ & $\begin{array}{l}\text { Colinus virginianus } \\
\text { Bubo virginianus } \\
\text { Anas crecca } \\
\text { Buteo swansoni } \\
\text { Egretta tricalor/Egretta caerulea } \\
\text { Turdus migratorius } \\
\text { Turdidae-genus/species unknown } \\
\text { Meleagris gallopavo }\end{array}$ & $\begin{array}{l}1 \\
1 \\
1 \\
1 \\
1 \\
1 \\
1 \\
1 \\
1\end{array}$ \\
\hline $\begin{array}{l}\text { Black-tailed jackrabbit } \\
\text { Bobcat } \\
\text { Bovides } \\
\text { Common cotton rat } \\
\text { Coyote } \\
\text { Dog } \\
\text { Domestic sheep/goat } \\
\text { Eastern cottontail } \\
\text { Eastern mole } \\
\text { European pig } \\
\text { Fox squirrel } \\
\text { Fulvous harvest mouse+ } \\
\text { Javelina } \\
\text { Kangaroo rat } \\
\text { Opossum } \\
\text { Pack rat } \\
\text { Pine vole* } \\
\text { Plains pocket gopher } \\
\text { Pocket mouse+ } \\
\text { Raccoon } \\
\text { Striped skunk } \\
\text { White-tailed deer }\end{array}$ & $\begin{array}{l}\text { Lepus californicus } \\
\text { Lynx rufus } \\
\text { Bovidae cf. Bos/cf. Bison* } \\
\text { Sigmodon hispidus } \\
\text { Canis latrans } \\
\text { Canis sp. } \\
\text { Ovis aries/Capra hirca } \\
\text { Sylvilagus floridanus } \\
\text { Scalopus aquaticus } \\
\text { Sus scrofa } \\
\text { Sciurus niger } \\
\text { Reithrodontomys sp. } \\
\text { Pecari angulatus } \\
\text { Dipodomys sp. } \\
\text { Didelphis virginiana } \\
\text { Neotoma sp. } \\
\text { Pitymys pinetorum } \\
\text { Geomys bursarius } \\
\text { Perognathus sp. } \\
\text { Procyon lotor } \\
\text { Mephitis mephitis } \\
\text { Odocoileus virginianus }\end{array}$ & $\begin{array}{r}1 \\
1 \\
1 \\
6 \\
1 \\
1 \\
1 \\
4 \\
12 \\
1 \\
1 \\
1 \\
1 \\
1 \\
2 \\
2 \\
1 \\
10 \\
1 \\
2 \\
1 \\
3\end{array}$ \\
\hline
\end{tabular}

+ Tentative identification.

* Not present in area today. 
These latter birds are migratory. The green-winged teal winters throughout Texas from September to April; robins from November to May. Species of thrushes migrate through Texas from April to May and from September to October.

Opossum remains are represented by six elements; four were in Leve1 2. A minimum of two individuals are represented by a Rt. $M_{2}$ element.

A minimum of 12 moles is based on a count of right humeri. Because moles are burrowing animals, it is difficult to determine whether the recovered elements are naturally intrusive or a result of human activities.

Six raccoon elements were recovered. Three were in Unit N998 E98, Leve1 4: two in Level 1, and one in Level 2. Based on a Rt. $M_{1}$ count, two individuals are represented. A third individual may be represented by a $M_{1}$ that was not verified as to right or left placement.

Skunk and coyote were represented by left mandible fragments in Level 4 .

Bobcat elements (teeth in Levels 2 and 3 ) and a left humerus distal fragment in Level 4 were identified.

Squirrel was represented by an incisor and a right mandible in Level 3 and a left mandible in Level 4.

Geographic rather than osteological reasons determined the identification of plains pocket gopher (Geomys bursarius), pine vole (Pitymus cf. Pinetorum), eastern cottontail (Sylvilagus cf. fleridanus), and white-tailed deer (Odocoileus virginianus).

Plains pocket gophers were identified in Levels 1-3, with a concentration of elements in Levels 1 and 2. A minimum of 10 individuals was based on the count of the right humeri.

Two mice species, pocket mouse and harvest mouse, were tentatively identified in Level 2. Three rat species were identified. Kangaroo rat was evident in Level 2. A minimum number of six common cotton rats, in Levels 1-3, was based on a count of right mandibles. Pack rat was identified in Levels 1-4. A minimum of two pack rat species is based on left femur proximal fragments. The burrowing habits of gophers, mice, and rat species make it difficult to determine if the recovered remains are in cultural contexts or are intrusive.

R. Hulbert identified pine vole (Pitymus cf. pinetorum) in Unit N97 E99, Level 2 (an edentulous left mandible fragment from a mature specimen), and in Unit N98 E97, Level 3 (an anterior half of a sku17 without teeth). It is the only species represented on this site that is clearly outside its modern range, northeastern and central Texas. Hulbert states:

"The Pine Vole is currently known from relict populations on the Edwards Plateau. In the Late Pleistocene and Early Holocene (10,000-7000 years B.P.), P. pinetorum had a much more widely spread distribution than today, reflecting a more mesic plant climate. If the horizon (N97 E99 Level 2 and N98 E97 Level 3) containing the $P$. cf. pinetorum specimens can be roughly dated 
Fish (Osteichthyes) Bass (Micropterus sp.)

Gar species (Lepisosteus sp.) Longnose gar (Lepisosteus asseus) Unidentified

Turtles (Testudines) Red-eared turtle (Chrysemys scripta) River cooter (Chrysemys concinna) Snapping turtle (Chelydra serpentina) Softshell turtle species (Trionyx sp.)

Spiny softshell turtle

(Trionyx spiniferus)

Unidentified

Snakes (Serpentes)

Copperhead (Agkistrodon contortrix) Corn snake (Elaphe guttata)

Cottonmouth (Agkistrodon piscivorus leucostoma)

Moccas in (Agkistrodon sp.)

Pine snake (Pituophis melanoleucus)

Pit vipers (Crotalinae)

Racer/Coachwhip snake (Coluber) Masticophis sp.)

Rat snake (Elaphe cf. obsoleta) Rat/Pine snake (Elaphe/Pituophis) Rattlesnake (Crotalus sp.)

Water snake (Natrix sp.)

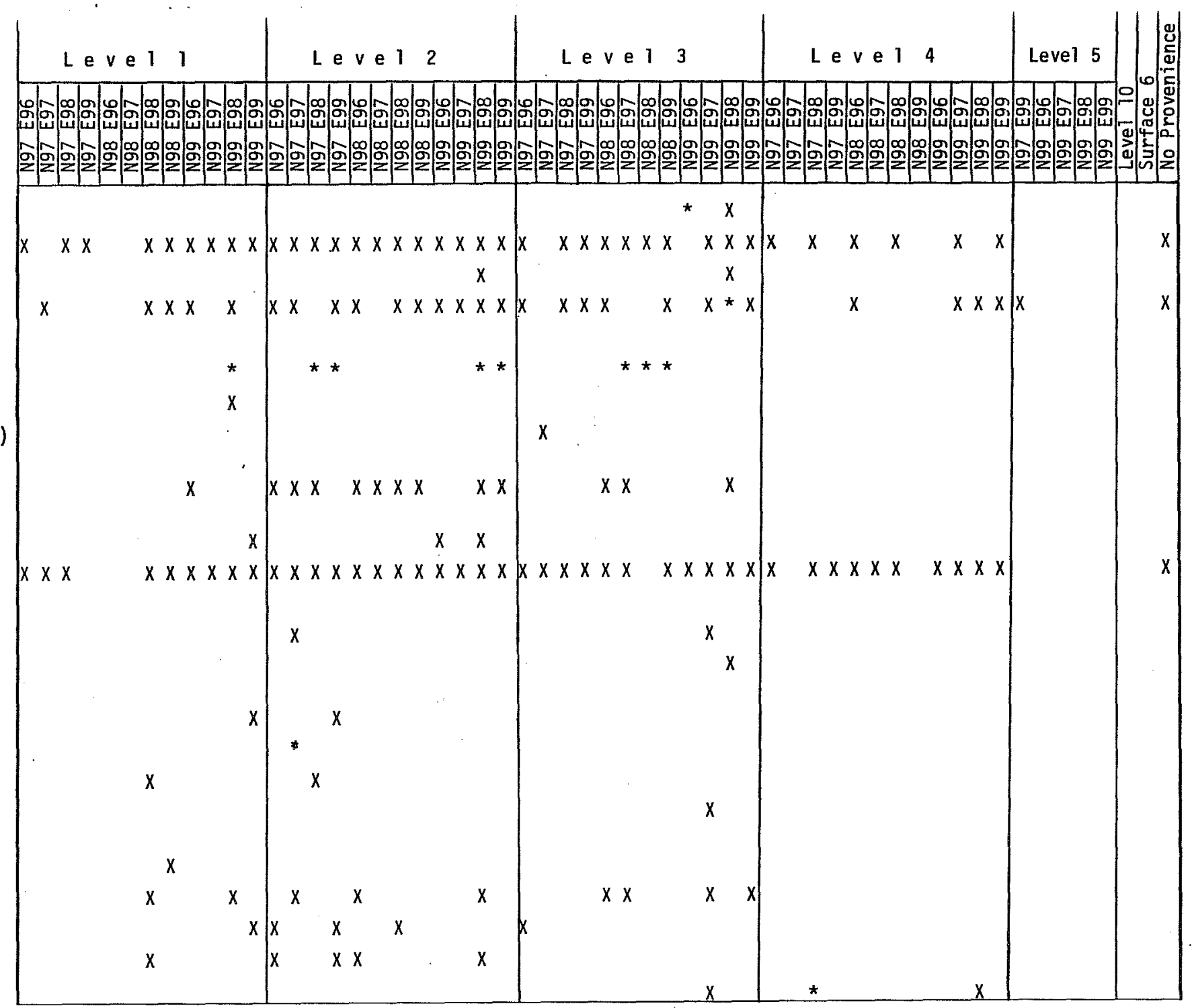


Table 22. (continued)

Western diamondback rattlesnake (Crotalus atrox)

Western hognose snake (Heterodon nasicus)

Unidentified

\section{Birds (Aves)}

Bobwhite quail (Colinus virginianus) Great horned owl (Bubo virginianus) Green-winged teal (Anas crecca) Hawk (Buteo sp.)

Heron (Egretta sp.)

Owl (Bubo sp.)

Robin (cf. Turdidae mighatorius)

Thrush (Tundidae cf.)

Wild turkey (Meleagris gallopavo) Unidentified

Mammalia (Mammalia)

Black-tailed jackrabbit (Lepus califarnicus)

Bobcat (Lynx rufus)

Common cotton rat (Sigmodon hispidus)

Cow/Bison (Bos sp./Bison sp.) Coyote (Canis latrans)

Dog (Canis sp.)

Domestic sheep/goat (Ouis sp./ capra sp.)

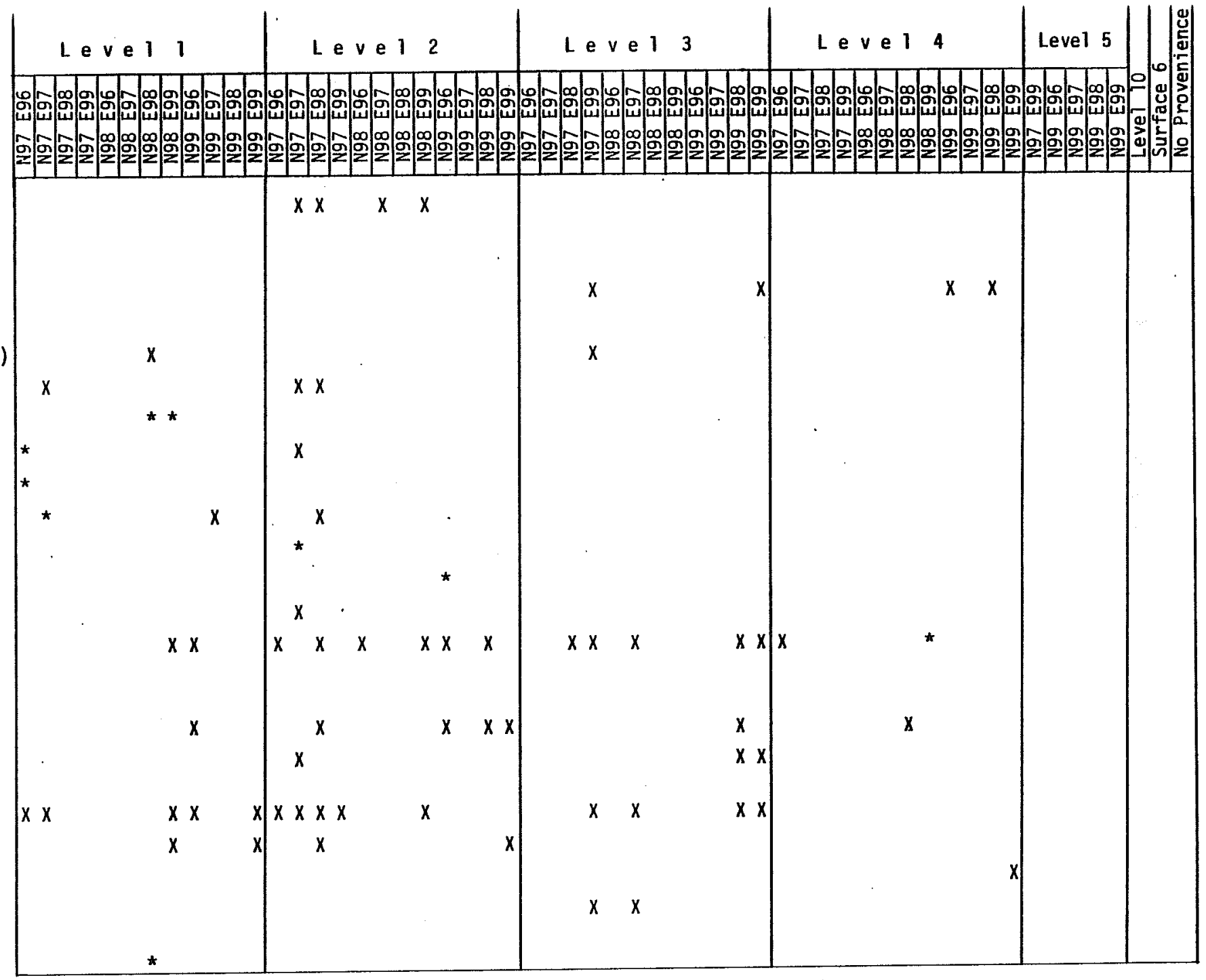




\section{Eastern cottontail}

(Sylvilagus cf. floridanus)

Eastern mole (Scalopus aquaticus) European pig (Sus scrofa)

Fox squirrel (Sciurus niger)

Fulvous harvest mouse (Reithrodontomys sp.)

Gopher (Geomyidae sp.)

Javelina (Pecari angulatus)

Kangaroo rat (Dipodomys sp.)

Opossum (Didelphis virginiana)

Pack rat (Neotoma sp.)

Pine vole (Pitymys cf. pinetonum)

Plains pocket gopher

(Geomys bursarius)

Pocket mouse (Perognathus sp.)

Rabbit (Leporidae)

Raccoon (Procyon lotor)

Rodent (Rodentia)

Squirrel (Sciurus sp.)

Striped skunk (Mephitis mephitis)

White-tailed deer (Odocoileus virginianus)

Unidentified

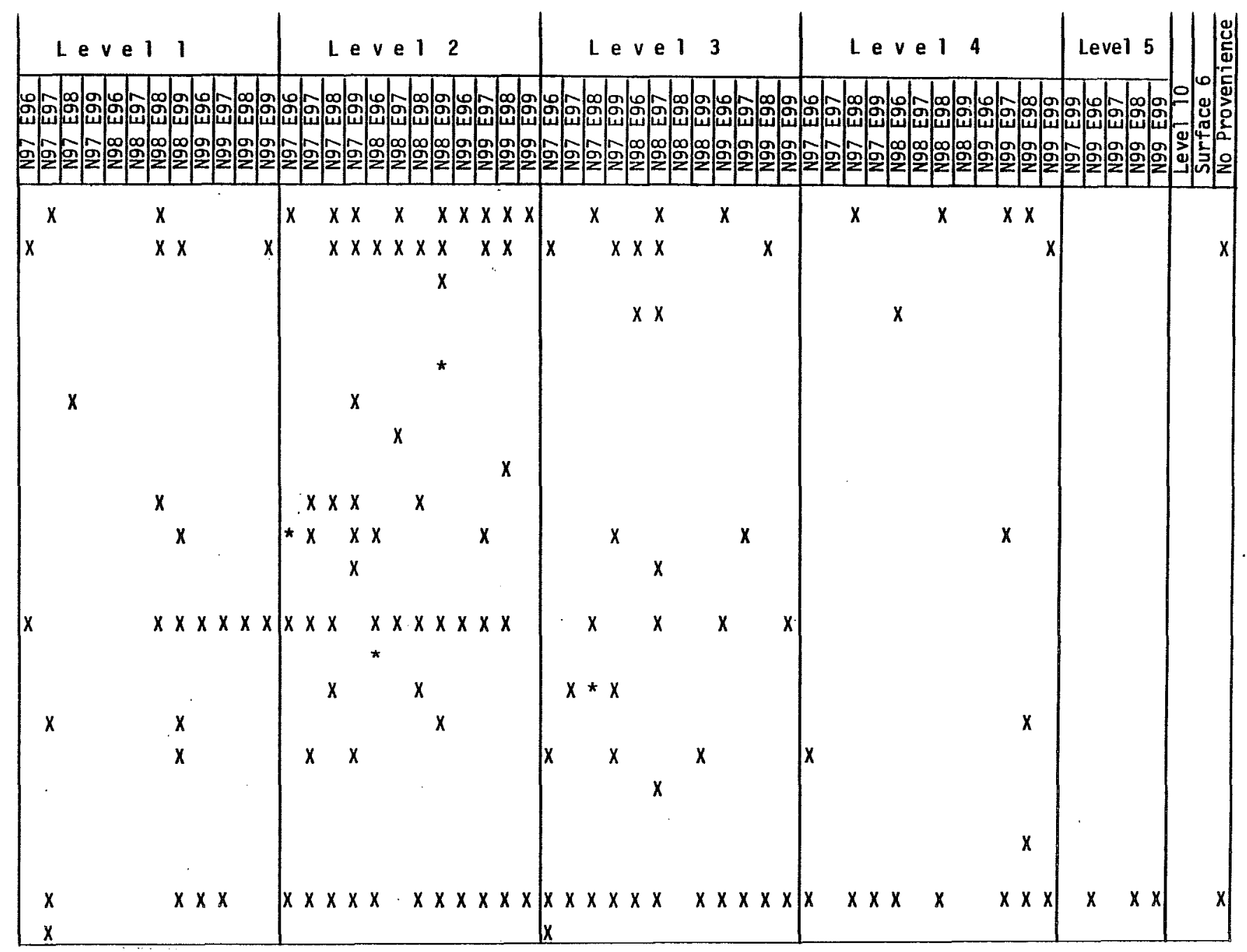


using associated cultural material, this occurrence would be of interest to paleontologists."

A minimum of four Eastern cottontails is based on the count of right calcanei. Remains were found in Levels 1-4, with a concentration of elements in Level 2.

A concentration of black-tailed jackrabbit is evident in Level 2, although elements are found in Levels 1,3 , and 4.

Javelina identification was based on a tooth fragment from Level 2. Also in this level was a heavily worn second molar fragment of a European pig. If material culture found in this horizon (N98 E99, Level 2) supports evidence for protohistoric occupation of the site, it would be of interest to historic archaeologists, as it may represent feral pig. Spanish ships wrecked off the coast of Texas frequently listed hogs on their cargo inventories. However, the tooth of the pig is most likely an intrusive item representing a local pig farming operation (Anne A. Fox, personal communication). The javelina tooth probably also represents mixing of the upper two levels.

White-tailed deer were found in Leve1s 1-5. A total of 141 deer elements was identified: 60 were tooth elements, 42 metapodial elements, 34 long bone fragments, and the remaining scapula, vertebra, and skull fragments. Most of the long bone fragments showed longitudinal (parallel with the bone shaft) breaks. Several from Levels 3 and 4 exhibited spiral breaks. No evidence of cutting, chopping, or chewing was noticed. Spiral breaks are characteristic of green bone; but slightly weathered bone, which breaks more easily than green bone, can also exhibit spiral breaks (Myers, Voorhies, and Corner 1980). A minimum of three deer is represented: two adult animals based on the Lt. $P_{2}$ count and one juvenile based on a right tibia proximal fragment.

Large long bone fragments recovered in Levels 1 and 2 could not be distinguished as cow or bison. Except for the one bovid element in Level 2 discussed earlier, there was no evidence of butchering, burning, or gnawing.

In Level 1, a tooth fragment, which appeared smaller than deer, was tentatively identified as sheep/goat. 


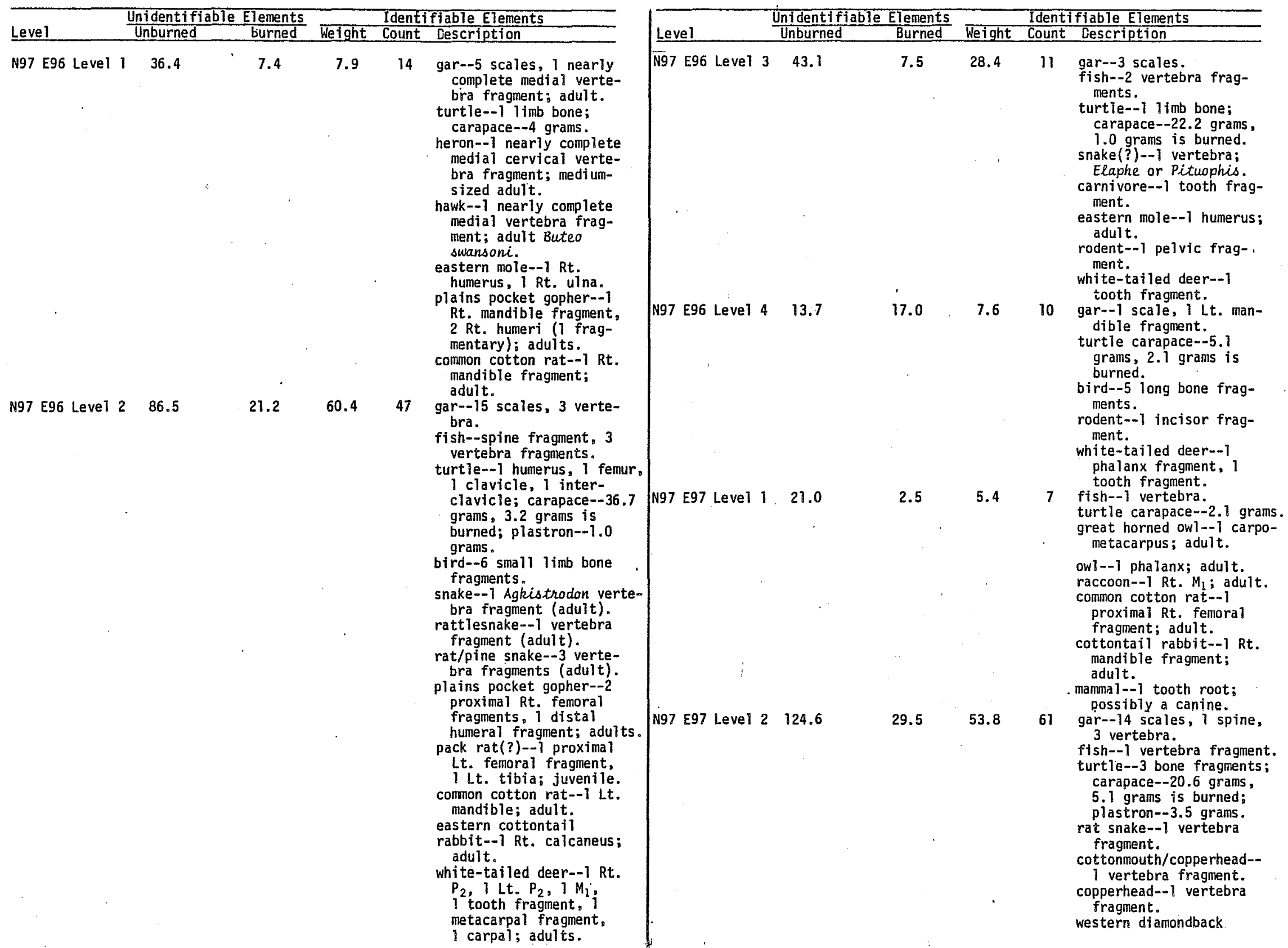


Tab7e 23. (continued)

\begin{tabular}{lll}
\hline Level Unidentifiable Elements & Identifiable Elements \\
\cline { 3 - 3 } & Unburned & burned \\
\hline
\end{tabular}

rattle-snake--3 vertebra; adult.

hawk--1 coracoid; adult.

great horned owi--1 talon;

wild turkey--1 distal Lt. tarsometatarsus fragment; adult. opossum--1 Rt. $M_{2}, 1$ Lt. $\mathrm{M}_{2} ;$ adult.

bobcat--1 Lt. $M_{1}$; adult. eastern mole--1 humerus. plains pocket gopher--1 Rt. incisor, 2 Rt. mandible fragments, $1 \mathrm{P}_{4}$. 1 Rt. pelvic fragment,

1 Lt. pelvic fragment, 1 Rt. tibia fragment; all are adult, except fragment, I medial ion bone fragment.

common cotton rat-- 1 Lt.

$M_{2}, M_{3} \cdot$
pack rat-1 proximal Lt. femoral fragment of Neotoma sp.; juvenile. immature.

white-tailed deer--1 tooth fragment, 1 carpal, lst Rt. phalanx, l phalanx fragment; adult.

napping turt

turtle (?)--1 phalanx;

carapace- 6.0 grams.

rabbit--1 maxilla frag-$$
\text { ment. }
$$

white-tailed deer--1 Lt.

$P_{2}, 2$ tooth fragments,

4 long bone fragments.

1 carpal; adult.

N97 E98 Level $2 \quad 255.4$

N97 E97 Level $2 \quad 124.6$

29.5

53.8

0

N97 E97 Level $4 \quad 25.4$

6.5

N97 E98 Level
4.6 gar--1 scale.
turtle carapace--1.2 robin--1 humerus; adult. rodent--1 distal femoral

2.9 grams is burned.

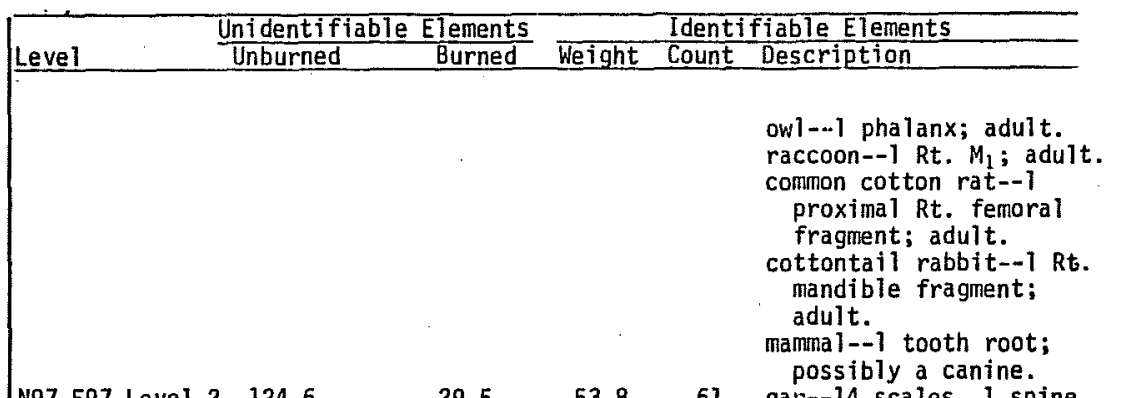

gar-- 14 scales, 1 spine. 3 vertebra.

fish--1 vertebra fragment. turtle -3 bone fragments carapace--20.6 grams, 5.1 grams is burned; plastron- -3.5 grams.

rat snake--1 vertebra fragment.

cottonmouth/copperhead-1 vertebra fragment.

copperhead--1 vertebra fragment.

western diamondback

rattle-snake--3 vertebra

hawk--1 coracoid; adult. great horned owl--1 talon; adult.

wild turkey--1 distal Lt. tarsometatars robin--1 humerus; adult. opossum--1 Rt. $M_{2}, 1$ Lt. $\mathrm{M}_{2}$; adult.

bobcat--1 Lt. $M_{1}$; adult. eastern mole--1 humerus.

plains pocket gopherRt. incisor, 2 Rt. mandible fragments, $P_{4}$, lit. pelvic fragment, 1 Rt. al1 are adult, except tibia fragment (juvenile). gar--52 scales, 2 vertebra.

urtle carapace--49.7 grams, 2.6 grams is burned; plastron-5. grams.

grams.
gopher--1 Lt. humerus me Jial fragment; juvensnake--2 cervical vertebra, adult. rattlesnake--1 vertebra dult.

great horned ow --1 vertebra; adult. 
Table 23. (continued)

\begin{tabular}{lll}
\hline Level & Unidentifiable Elements & Identifiable Elements \\
& Burned & Weight Count Description \\
\hline
\end{tabular}

rodent--1 distal femora fragment, 1 medial long bone fragment.

common cotton rat--1 Lt. maxilla fragment, $M_{1}$, $M_{2}, M_{3}$.

pack rat--1 proximal $\mathrm{Lt}$ femoral fragment of imnature.

white-tailed deer--1 tooth fragment, 1 carpal, ist Rt. phalanx, I phalanx fragment; adult.

N97 E97. Level $3 \quad 29.5$

42.0

11 snapping turtle--i vertebra; adult.

turtle (?) - - phatanx carapace--6.0 grams. 2.9 grams is burned. rabbit--1 maxilla fragment.

white-tailed deer--1 Lt. $P_{2}, 2$ tooth fragments, 4 long bone fragments,

N97 E97 Level $4 \quad 25.4$

6.5

0

1 carpal; adult.

N97 E98 Level $1 \quad 6.9$

4.6

2.3

2

gar--1 scale.

turtle carapace--1.2

grams.

gopher--1 Lt. humerus medial fragment; juvenile.

N97 E98 Level $2 \quad 255.4$ ile. Neotoma sp.; juvenile.

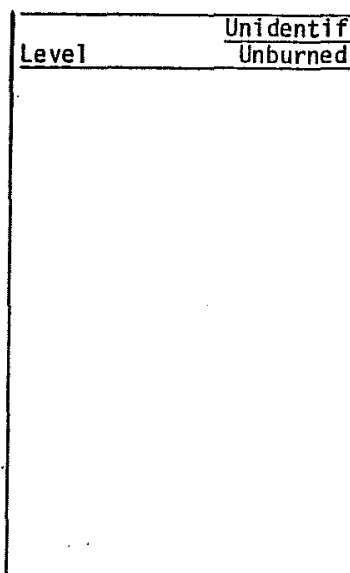

N97 E98 Leve1 $3 \quad 73.0$

46.2

bra. scales, 2 verte

turtle carapace--49.7

grams, 2.6 grams is burned; plastron--5.2

grams.

pine snake--2 cervical

vertebra; adult.

western diamoniback

rattlesnake--1 vertebra;

adult.

great horned owl--1 vertebra; adult.

ow1--1 Rt. phalanx, 1 Lt. phalanx; adult.

bird--4 small limb fragments.

possum--l Lt. maxilla fragment $w / M_{4}, 1$ vertebras little wear.

eastern mole--1
humerus, 1 Rt. uina; humerus
adult.
N97 E99 Leve1 I 0.8 Burned

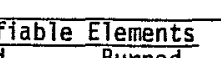

Identifiable Element

plains pocket gopher--1

femur; adult.

common cotton rat--1 Rt.

mandible; adult

eastern cottontaii--1 axis;

adult.

black-tailed jackrabbit--

1 Lt. scapula fragment

1 metapodial fragment;

adult. fragment, $i$ Lt. mandible fragment; adults.

white-tailed deer--1 Rt.

$\mathrm{P}_{3}, 1 \mathrm{Rt}$. petrosal;

adult.

cow/bison--1 long bone

14 gar--1 scale, 1 vertebra

fragment.

fish--3 vertebra frag-

ments.

turtle carapace--20 grams.

large bird--1 proximal

radius fragment.

plains pocket gopher--2

humeral fragments.

rabbit(?)--1 vertebra

Juvenile.

white-tailed deer--2

tooth fragments, ist

Lt. phalanx, 2nd Rt.

phalanx, 1 proxima

tibia fragment.

N97 E98 Leve1 $4 \quad 31.8 \quad 15.1 \quad 41.7 \quad 13$ gar--1 scale, 1 vertebra fragment.

turtle carapace- -14.5

grams, 3.4 grams is burned.

water snake--2 vertebra fragments; adult.

eastern cottontail

rabbit--1 vertebra, $1 \mathrm{kt}$. calcaneus, 1 incisor

fragment; adult.

white-tailed deer--1

molar, 3 tooth frag-

ments, 1 proximal Rt.

tibia fragment; all

adult, except for tibia

fragment (juvenile).

0.64 gar--4 scales 
Tab7e 23. (continued)

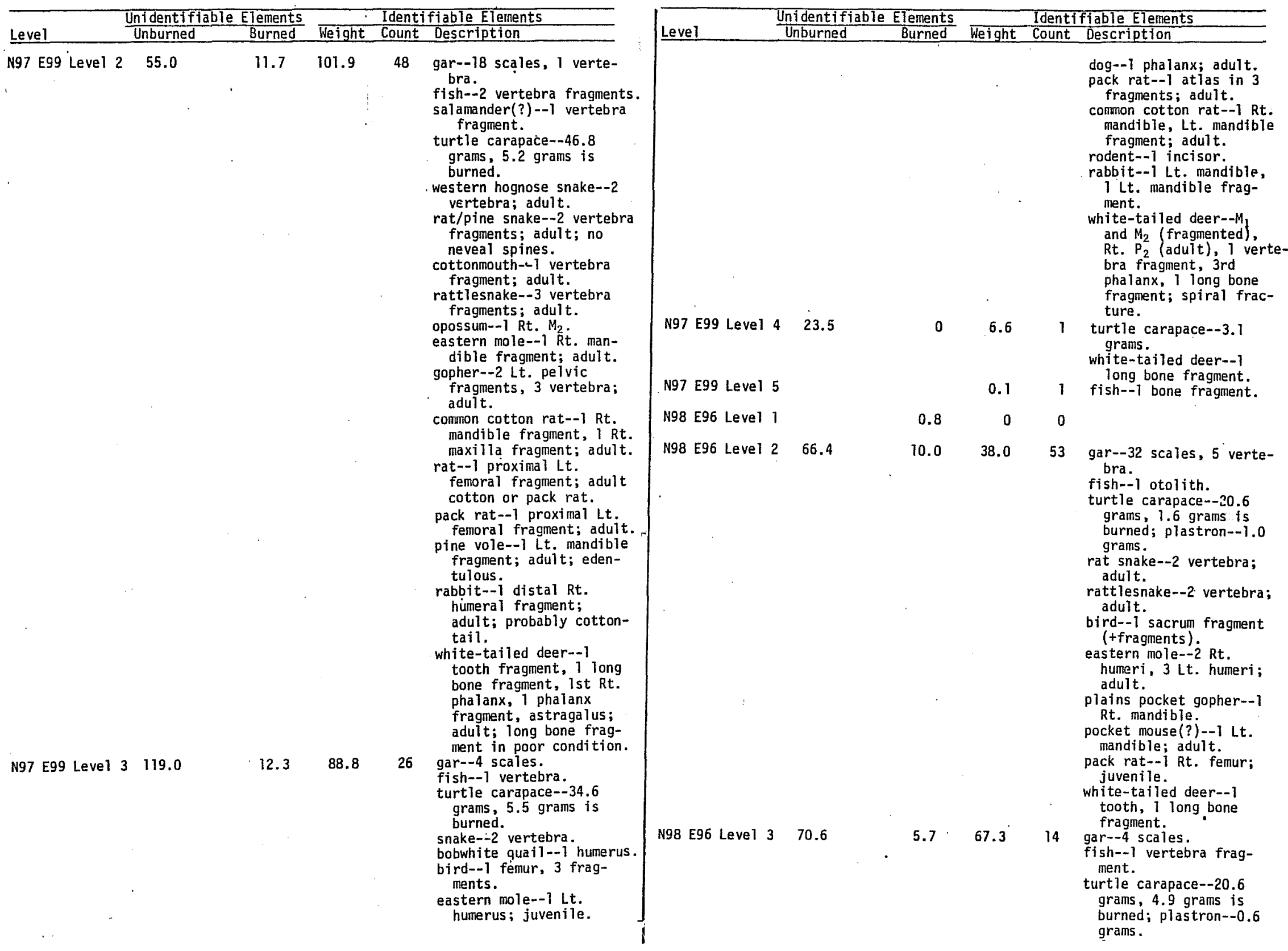


Table 23. (continued)

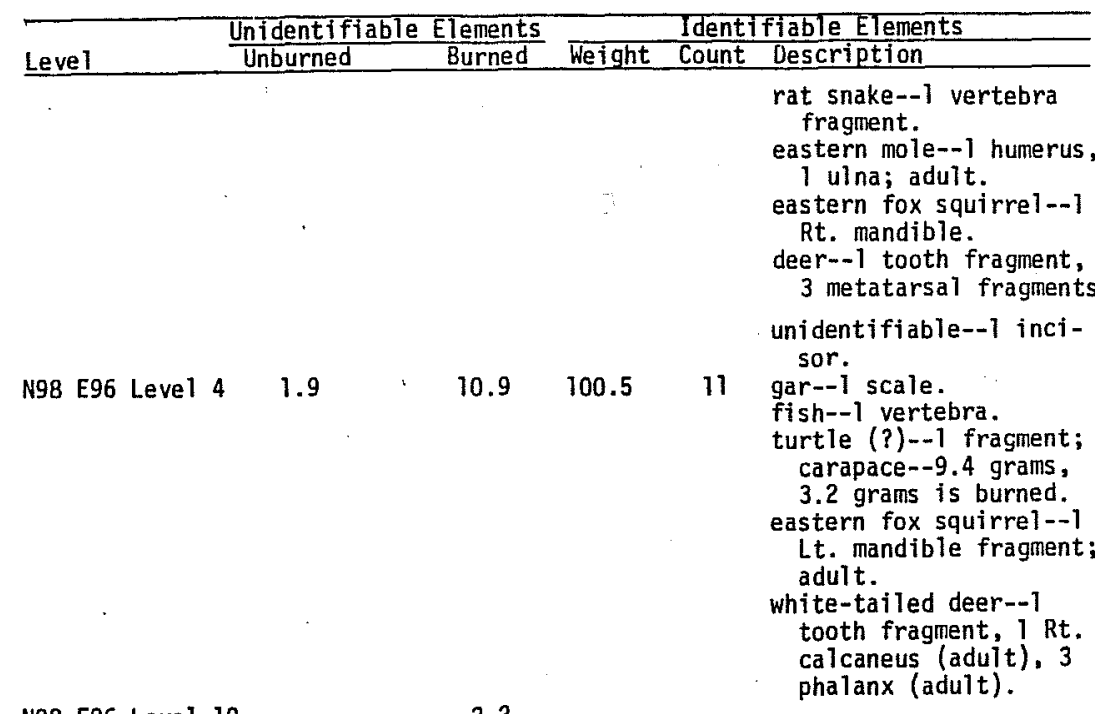

N98 E96 Level 10

67 gar--50 scales, 2 vertebra.

turtle carapace--16.2 grams, 3.0 grams is burned; plastron--1.5 grams.

snake--3 vertebra (Colubrid species). western diamondback rattlesnake--adult humerus; adult. humerus; adult. plains pocket gopher--Rt. $I_{1}, L t . I_{1}, 3$ Lt. humeral fragments, 1 Lt. femus, 1 Rt. femur,
1 Lt. tibia; all adult, except Rt. femur. cottontail--1 distal Rt.

N98 E97 Level 3 Lot 1 27.1

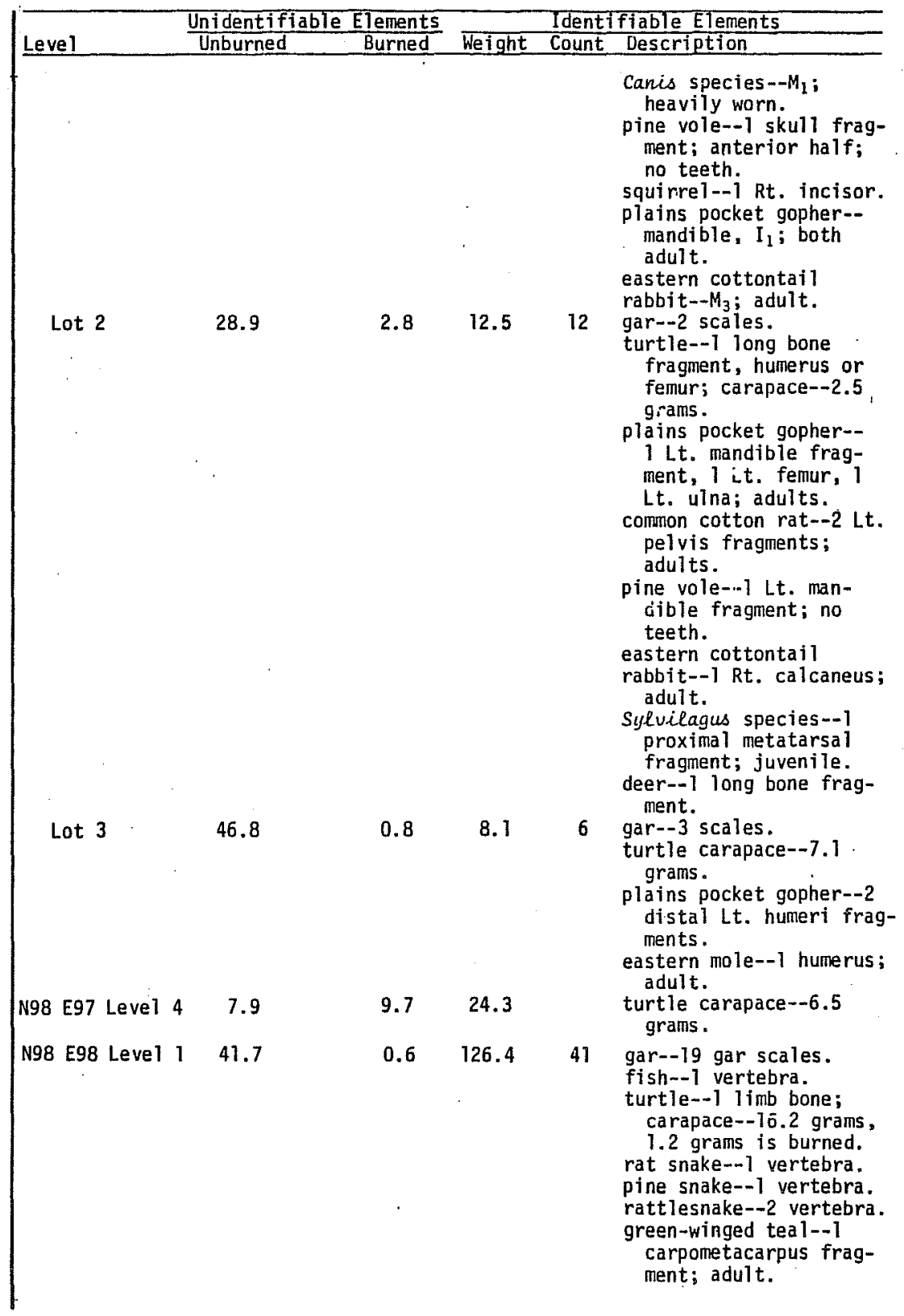

gar--25 scales, bone fragment. urtle--2 long bone fragments; carapace-- 18. grams, 0.8 grams is
burned; plastron-- 8.4 burned;
grams.

rat snake--1 vertebra; heavily worn. 
Table 23. (continued)

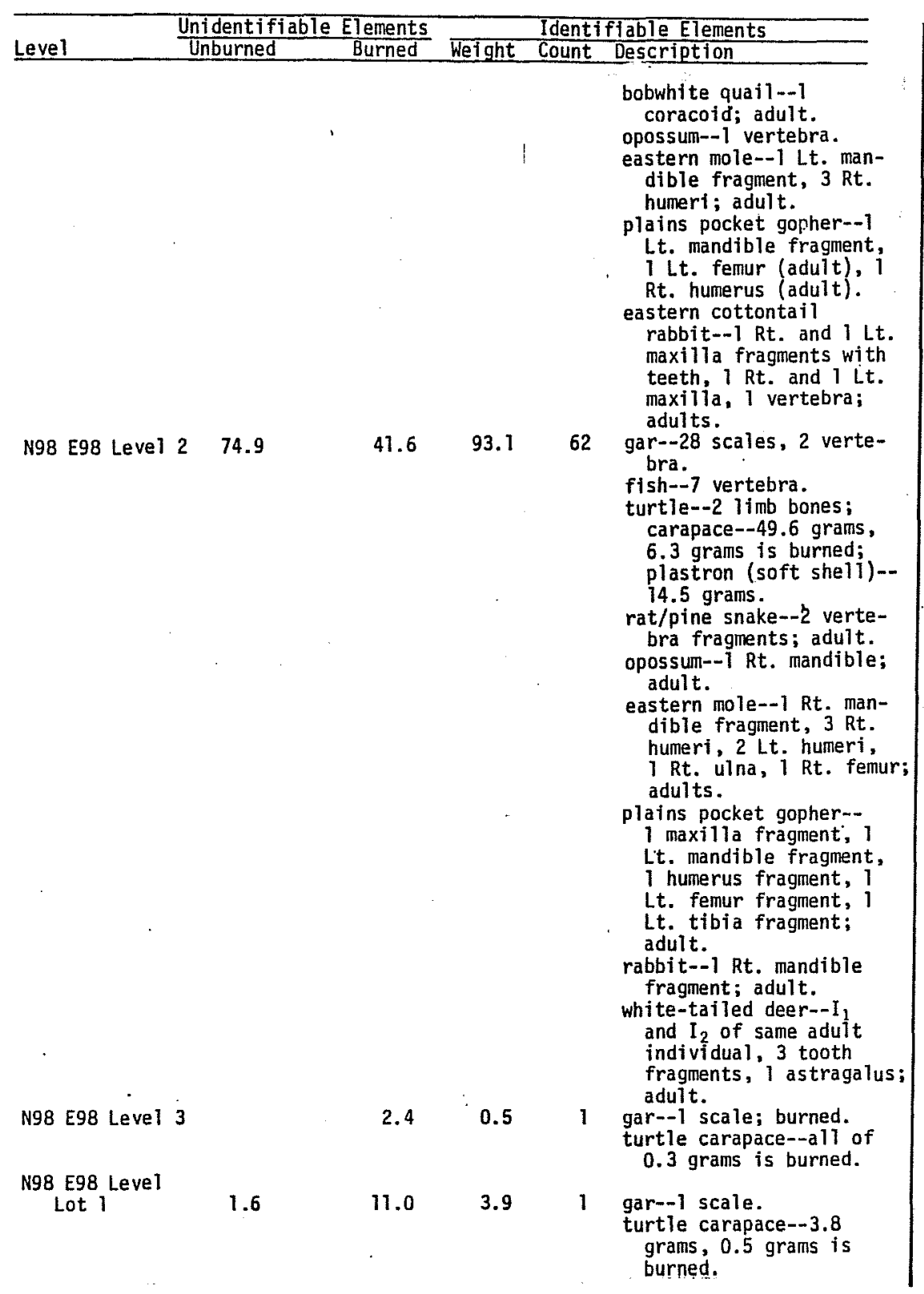

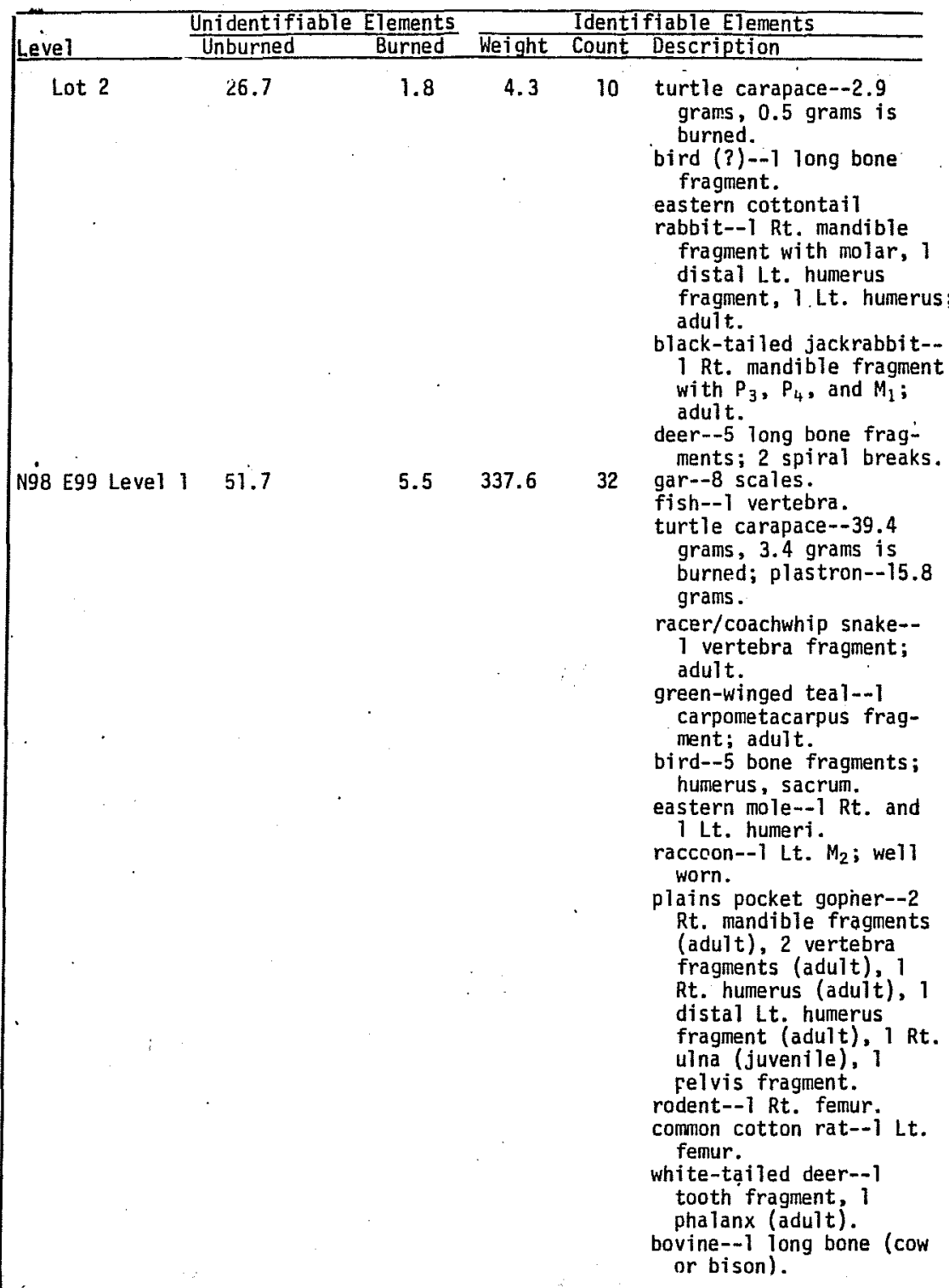




Level Unidentifiable Elements

N98 E99 Level $2 \quad 13.0$

19.1

83.2

38

\section{gar--9 scales, 1 verte- bra fragment.}

fragments,

1urtle carapace--35.7

rams, 6.0 grams is

Gurned; plastron- 7

burned; $i$ bone fragment. western di amondback

rattlesnake--2 vertebra

1 fragmented);

bird-- 3 bones.

eastern mole--1 Rt. Ulna; adult.

raccoon--1 Rt. $M_{1}$; adult.

plains pocket gopher--1

Lt. scapula fragment.

1 Lt. humerus, 1 Rt.
femur, 1 Lt. femur

femur, 1 Lt. femur

fragment; adul t

femur.

common cotton rat-- l Lt.

humerus.
cottontail rabbit-- Rt. mandible, 1 proximal Rt. uina fragment.

black-tailed jackrabbit1 maxilla fragment.

european pig-- $M_{2}$ fragment; heavily worn.

white-tailed deer--1 Lt.

incisor, 3 tooth frag-

ments, 1 long bone

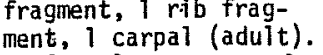

N98 E99 Level $3 \quad 81.8$

$4.1 \quad 31.0$

15

-3 scales.

fish--7 vertebra frag-

ments.

turtle carapace--24.4 grams, 5.9 grams is burned.

rodent--2 long bone frag-

ments. 1st phalanx fragment,

$\begin{array}{lllll}\text { N99 E96 Leve1 1 62.3 } & 13.5 & 33.6 & 51 & \begin{array}{c}\text { 2nd phalanx fragment. } \\ \text { gar--31 scales, } 1 \text { verte } \\ \text { bra fragment. }\end{array}\end{array}$

(surface-99.65 cm)

13.5
bra fragment.
fish--1 vertebra frag-

ment.
turtle--1 clavicle-

interclavicle frag-

ment; carapace--19.

grams, 3.0 grams is

burned.

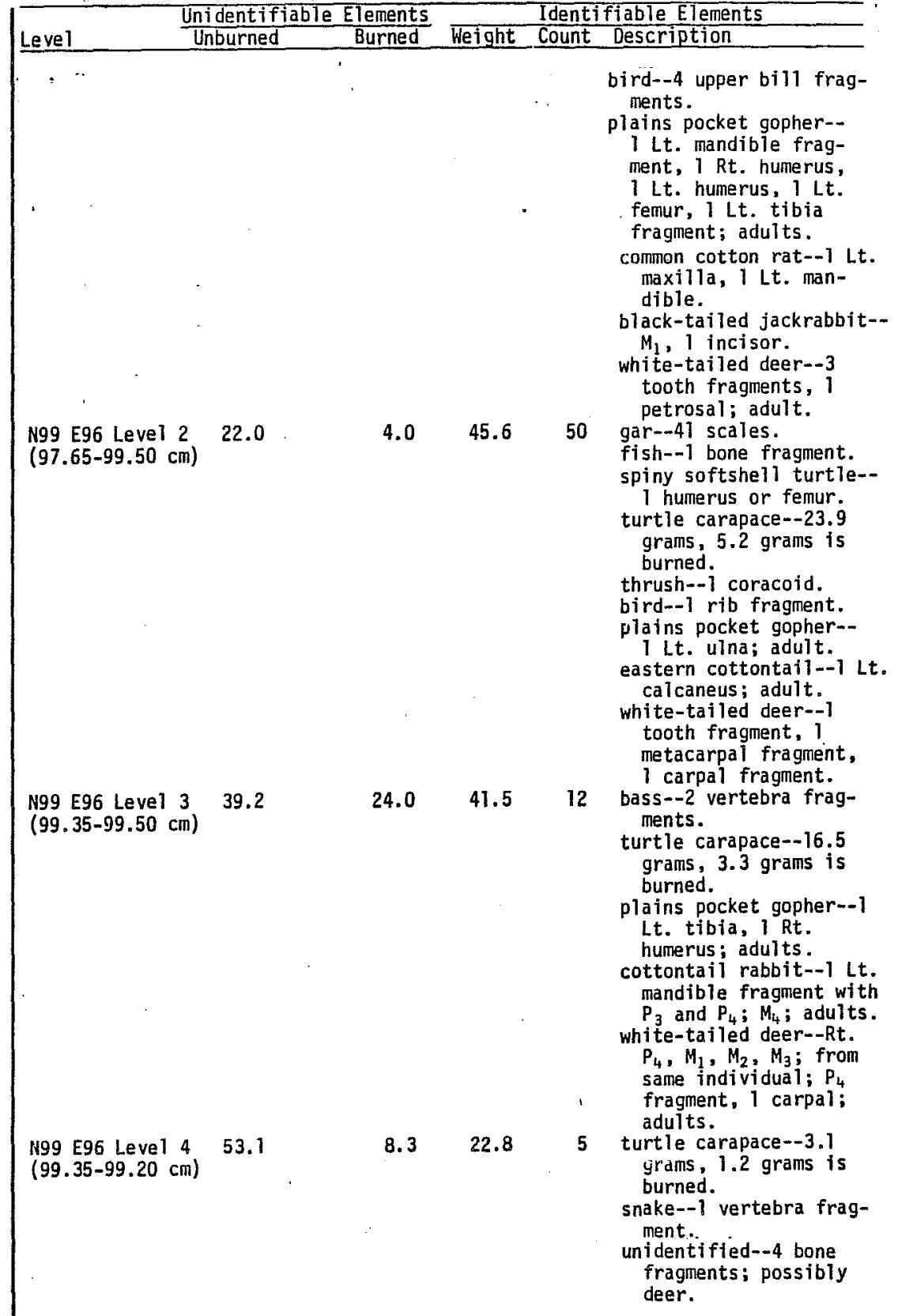


TABLE 23. (continued)

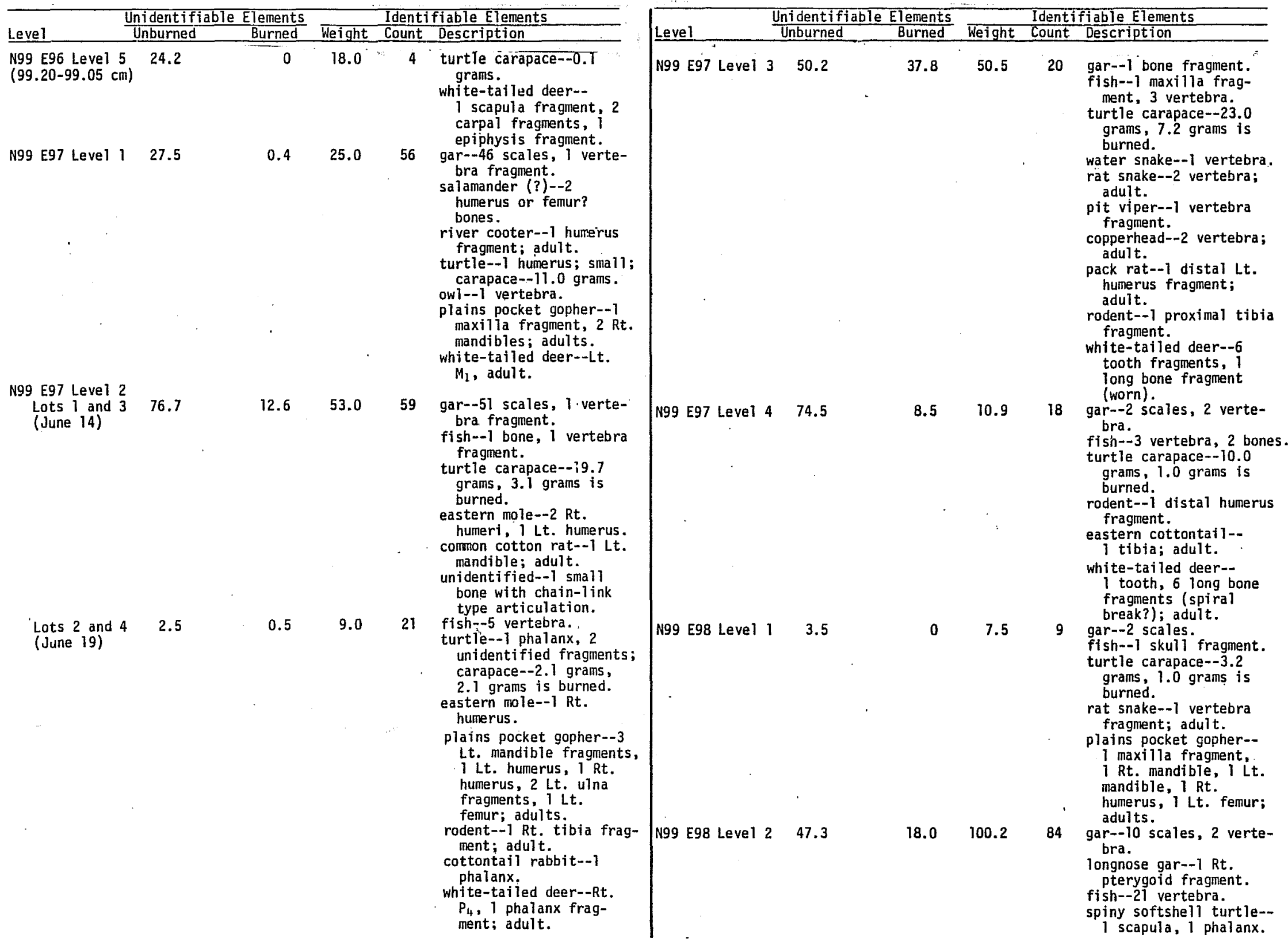


Table 23. (continued)

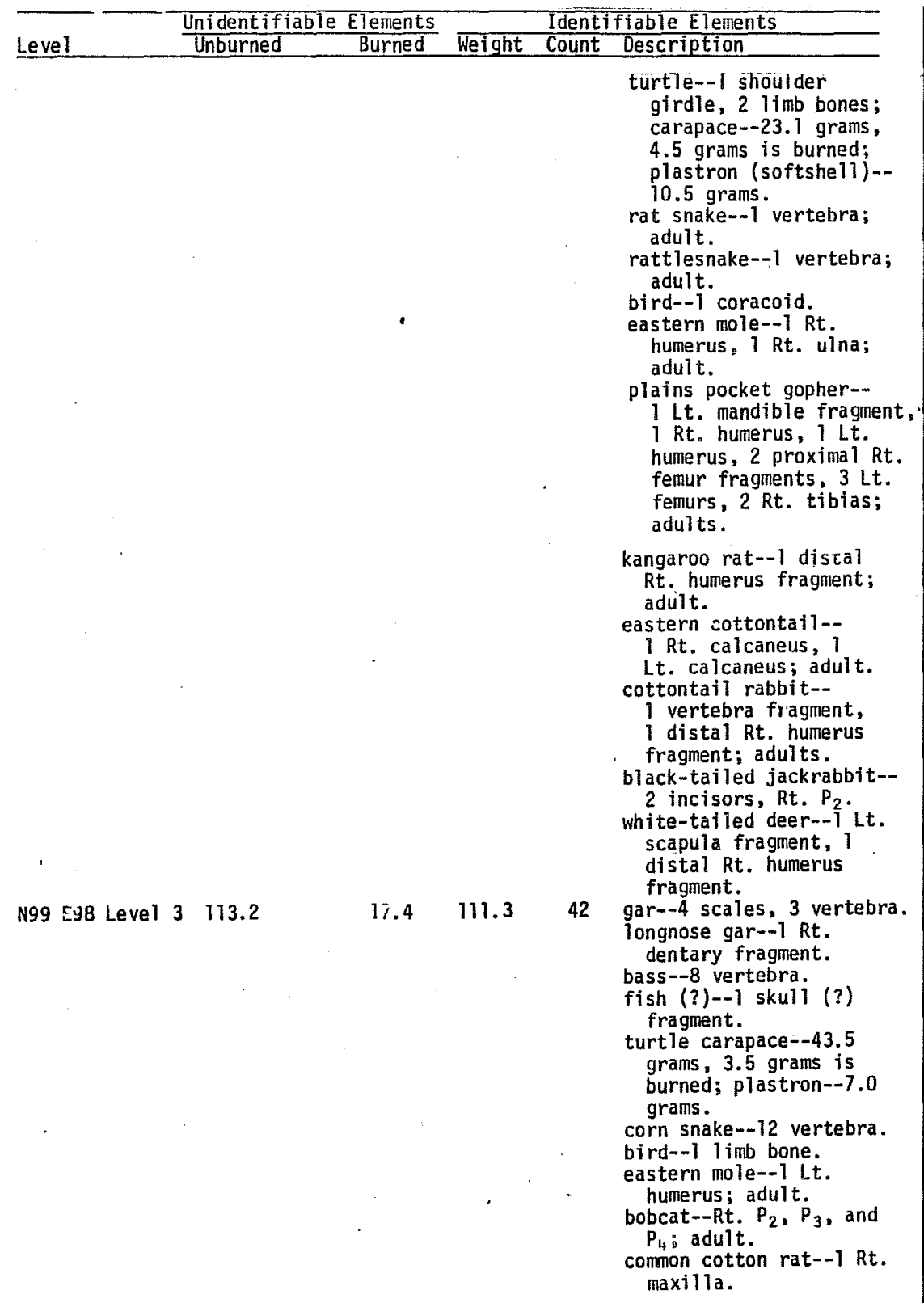

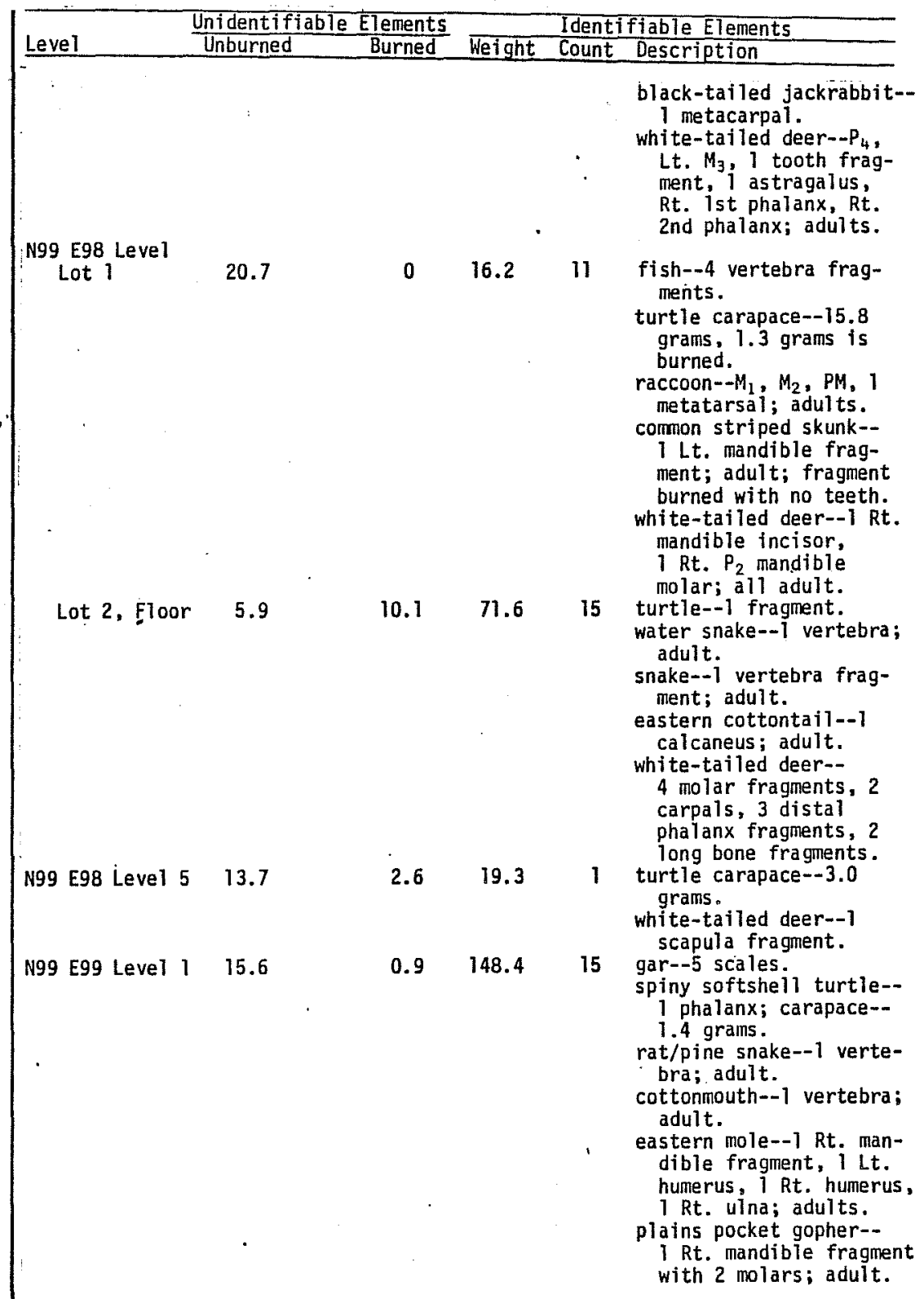


Table 23. (continued)

\begin{tabular}{|c|c|c|c|}
\hline & Unidentifiable Elements & Ident & fiable Elements \\
\hline Level & Unburned Burned & Weight Count & Description \\
\hline
\end{tabular}

N99 E99 Level $2 \quad 30.5$

$14.4 \quad 330.1$

20

bone fragment.

fish--1 vertebra frag-

ment, 3 bone fragments. turtle carapace--38.3 grams, 1.5 grams is
burned; plastron--22.8 grams.

cottontail--

1 Lt. calcaneus.

black-tailed jackrabbit--

1 Rt. mandible.

white-tailed deer--

tooth fragment,

cow/bison--1 long bone

N99 E99 Leve1 $3 \quad 72.0$

$21.7 \quad 36.6$

25

fragment.

gar--9 scales. ments.

turtle--1 bone; carapace-

19.9 grams, 1.9 grams

is burned.

rat snake--2 vertebra

fragments; adult.

snake--1 unidentified

vertebra.

bird--1 bone fragment.

bobcat--1 distal Lt.

humerus fragment.

plains pocket gopher--

1 Rt. mandible frag-

ment, 1 proximal Rt.

femur; adults.

common cotton rat-- $1 \mathrm{Rt}$.

mandible; adult.

white-tailed deer--

tooth fragment, 1 long

bone fragment, I meta-

carpal fragment.

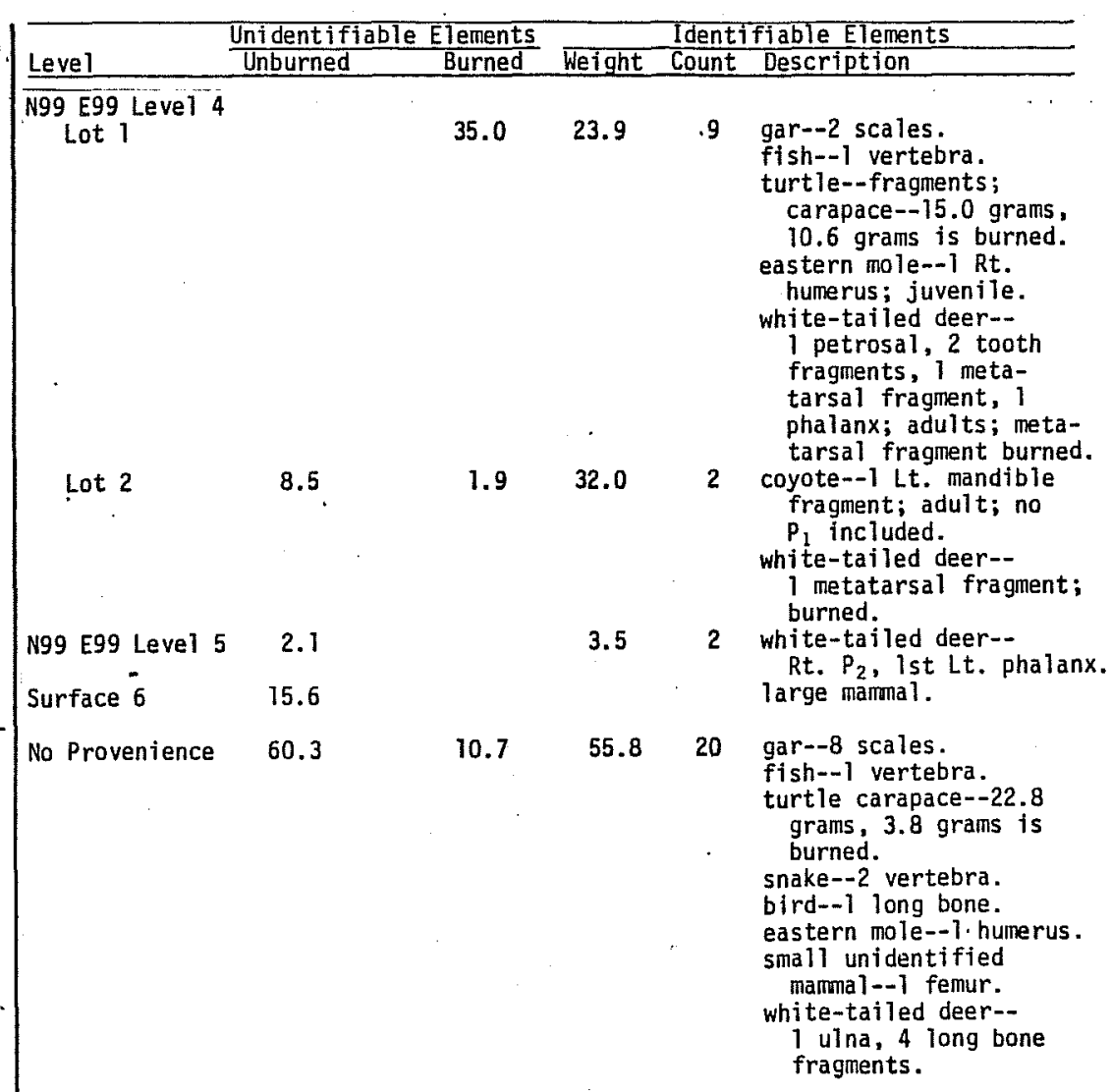




\section{REFERENCES CITED}

Auffenberg, W.

1963 The Fossil Snakes of Florida. Tulane Studies in Zoology 10(3):131216.

Blair, W. F., A. P. Blair, P. Bradkorb, F. R. Cagle, and G. A. Moore

1968 Vertebrates of the United States (2nd edition). McGraw-Hi11, New York.

Holman, J. A.

1959 The Mammals of North America. Vo1. 1. Ronald Press, New York. Myers, T. P., M. R. Voorhies, and R. G. Corner

1980 Spiral Fractures and Bone Pseudotools at Paleotological Sites. American Antiquity 45(3):483-490. 



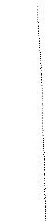

